\title{
Investigation of the Behavior of VOCs in GroundWater Across Fine- and Coarse-Grained Geological Contacts using a Medium-Scale Physical Model
}

\author{
F. Hoffman, \\ M.L. Chiarappa
}

Laboratory Directed Research and Development

Project 95-ERP-124

Final Report

March 1998

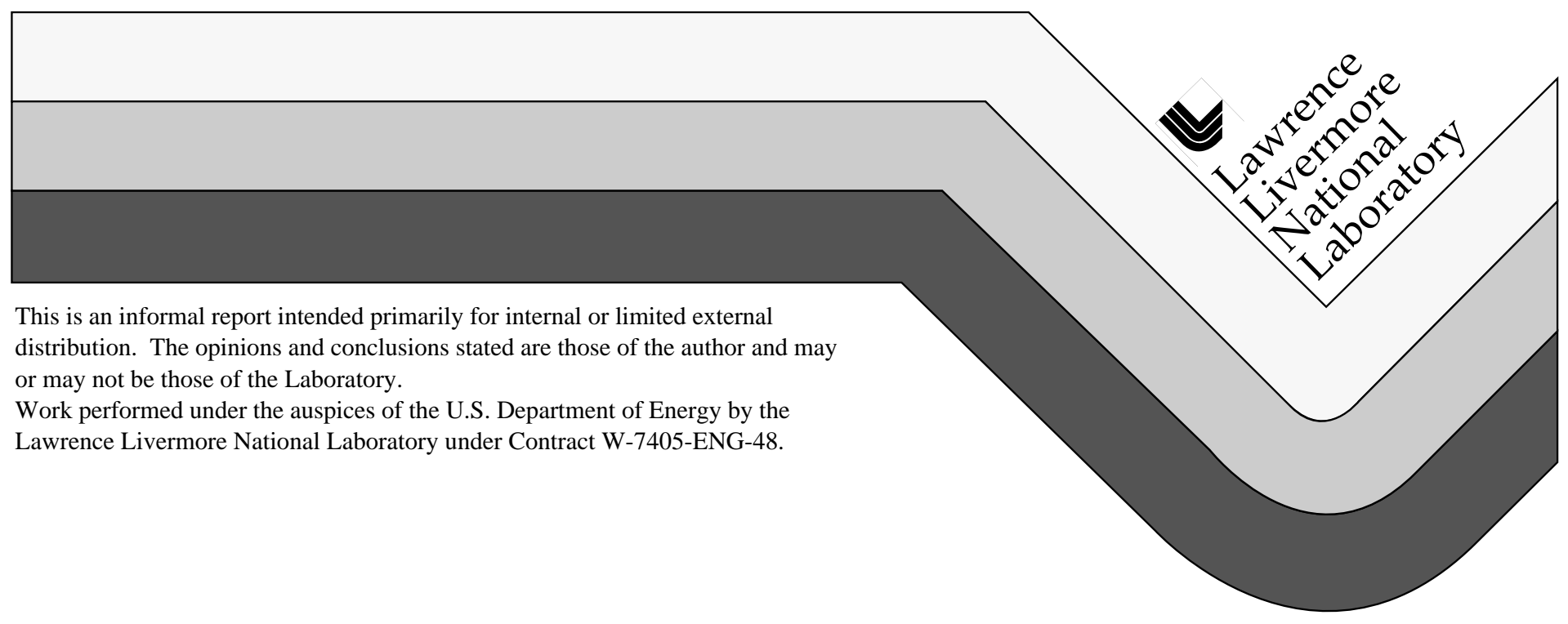




\section{DISCLAIMER}

This document was prepared as an account of work sponsored by an agency of the United States Government. Neither the United States Government nor the University of California nor any of their employees, makes any warranty, express or implied, or assumes any legal liability or responsibility for the accuracy, completeness, or usefulness of any information, apparatus, product, or process disclosed, or represents that its use would not infringe privately owned rights. Reference herein to any specific commercial product, process, or service by trade name, trademark, manufacturer, or otherwise, does not necessarily constitute or imply its endorsement, recommendation, or favoring by the United States Government or the University of California. The views and opinions of authors expressed herein do not necessarily state or reflect those of the United States Government or the University of California, and shall not be used for advertising or product endorsement purposes.

This report has been reproduced directly from the best available copy.

Available to DOE and DOE contractors from the Office of Scientific and Technical Information P.O. Box 62, Oak Ridge, TN 37831

Prices available from (423) 576-8401

Available to the public from the National Technical Information Service

U.S. Department of Commerce 5285 Port Royal Rd. Springfield, VA 22161 
Investigation of the Behavior of VOCs in Ground Water Across Fine- and CoarseGrained Geological Contacts using a Medium-Scale Physical Model

\section{Table of Contents}

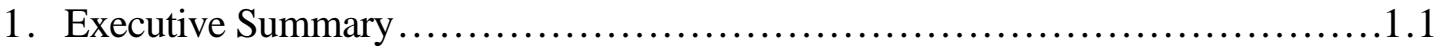

2. Column Experiments to Study Retardation of Volatile Organic Compounds in Low Organic Carbon Sediments..........................................2.1

3. Dynamic Headspace Method for Analyzing VOCs in Low-Volume Aqueous

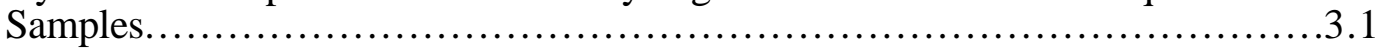

4. Diffusive Transport Of Dissolved Volatile Organic Compounds In Sediments

5. Description Of Numerical Model Of VOC Transport Across Geologic Contacts 



\section{Investigation of the Behavior of VOCs in Ground Water Across Fine- and Coarse-Grained Geological Contacts using a Medium-Scale Physical Model}

\section{5-ERP-124}

\section{F. Hoffman, M. L. Chiarappa}

\subsection{Executive Summary}

One of the serious impediments to the remediation of ground water contaminated with volatile organic compounds (VOCs) is that the VOCs are retarded with respect to the movement of the ground water. Although the processes that result in VOC retardation are poorly understood, we have developed a conceptual model that includes several retarding mechanisms. These include adsorption to inorganic surfaces, absorption to organic carbon, and diffusion into areas of immobile waters. This project was designed to evaluate the relative contributions of these mechanisms; by improving our understanding, we hope to inspire new remediation technologies or approaches.

Our project consisted of a series of column experiments designed to measure the retardation, in different geological media, of four common ground water VOCs (chloroform, carbon tetrachloride, trichloroethylene, and tetrachloroethylene) which have differing physical and chemical characteristics. It also included a series of diffusion experiments designed to measure the diffusion of VOCs in aquifer materials. To establish parameters that constrain the model, we compared the data from these experiments to the output of a computational model.

For the column experiments, we modified a chromatographic glass column with Teflon and with stainless-steel end fittings and packed it with a fine-grained, well-sorted sand that contained no detectable organic carbon. We ran the experiments by (1) simultaneously injecting the four VOCs, and then (2) injecting clean water into the column.

The accomplishments of this project include the development and refinement of the sampling and analytical techniques required to deal with the constraints of the low flow velocity. The velocity of the water through the columns simulated the velocities of ground water at LLNL, and the size of the column necessitated the collection of a $1.0-\mathrm{mL}$ sample over $15 \mathrm{~min}$. To minimize volatilization of the VOCs during the sample-collection period, we added a syringe pump operating in withdrawal mode so that the sample was collected in a sealed, zero-pressure system. The resulting 1.0-mL sample was transferred to a soil volatile organic analysis (SVOA) vial and purged with helium on an auto-sampler before being injected into a gas chromatograph (GC). The initial experiments were run using chloride as a conservative tracer. However, the discovery that chloroform is not retarded through the column, allowed us to use it, instead of chloride, as a conservative tracer in both the column and diffusion experiments.

For the diffusion experiments, we designed and constructed the experimental apparatus and perfected the technique of packing the experimental vials with sands of differing grain size. We also devised a method of sampling the vials at the conclusion of the experiment by crushing the packed, saturated, and contaminated vial into a SVOA vial prior to GC analysis.

The diffusion experiment introduced a novel analytical technique for estimating VOC retardation by using the conservative chloroform to determine the tortuosity coefficient of the sand. The tortuosity coefficient is a measure of the length of the tortuous path a solute travels versus the actual distance traveled along the column. The larger diffusion-reduction factors of the other VOCs provided retardation coefficients, under diffusive flux conditions. All experimental results for the tortuosity coefficients have fallen within the expected range for a 
homogeneous sand. In addition, the calculated retardation factors have been consistent with those determined under advective-flux conditions.

Our computational model was prepared using the numerical code PDEase, which provides a variable grid that allows us to calculate contaminant transport across geological boundaries at a greater level of detail than that provided by other codes. It appears that our model is reproducing reasonable values for advective, dispersive, and diffusive transport. Sensitivity analyses and parameter-estimation activities provided appropriate parameters for (1) better determination of source-area contributors to LLNL's VOC ground water plumes, and (2) use in predicting the time required to achieve cleanup to meet regulatory standards.

\section{Conclusion}

- We developed a sampling and chemical analytical technique, that allows the accurate and precise analysis of volatile organic compounds in samples as small as $1.0 \mathrm{~mL}$ at $\mu \mathrm{g} / \mathrm{L}$ concentrations.

- Our column experiments on retardation of TCE \& PCE in low organic carbon sediments allowed us to accurately constrain the retardation parameter in our conceptual and computational models.

- We developed a new technique for measuring the effective diffusion coefficient of VOCs in ground water in low organic carbon sediments and in estimating retardation coefficients of VOCs under diffusive flux. We were able to use this technique to constrain the retardation, diffusion, and tortuosity parameters for use in our computational models.

- Adaptive-grid Finite Element Analysis is capable of accurately resolving the transport of VOCs in ground water across fine and coarse grained geological contacts.

- The preliminary results of our model of VOC transport at the TFA source area demonstrate the rapid remediation of High Hydraulic Conductivity (HK) zones and the slow process of diffusion of contaminants out of Low Hydraulic Conductivity (LK) zones and into neighboring $\mathrm{HK}$ zones.

\section{Acknowledgments}

This project was conceived by Fred Hoffman and developed in collaboration with Bill Durham and Marina Chiarappa. Al Duba, Carl Boro, and Bill Ralph participated in the design and construction of the experimental apparatus. Roger Martinelli and Ken Carroll were instrumental in the design and conduct of sample collection and analysis. Said Doss and Bob Gelinas guided the use of the adaptive grid modeling and Zafer Demir guided the parameter sensitivity study. The project benefited from frequent discussions with Jacob Bear, Walt McNab, Brian Viani and Dorothy Bishop. Much of the work was conducted by a series of skilled and enthusiastic students: Kim Bair, now at the University of Florida, Brian Manz, now at Colorado State University, Kari Fox now at the Colorado School of Mines, Jennifer O'Boyle, who recently graduated from Humboldt State University, and Eric Brown at the University of California, Berkeley. Graphic support was provided by Kim Heyward and administrative support was provided by Linda Cohan. 


\title{
Column Experiments to Study Retardation of Volatile Organic Compounds in Low Organic Carbon Sediments
}

\author{
F. Hoffman, M.L. Chiarappa, B. Manz, K. Fox, J. O’Boyle
}

\subsection{Introduction}

Column experiments were conducted to determine the retardation of selected Volatile Organic Compounds (VOCs) in ground water in low organic carbon sediments. The retardation factors and other parameters derived in these experiments were meant to provide constraints on our computational model and on our interpretation of data from other experiments, described elsewhere in this final report, to examine parameters such as diffusion, tortuosity coefficients, and mechanical dispersion, that affect contaminant transport. The goal of the project was to further our understanding of the mechanisms that control the transport of contaminants from fine-grained sediments in contaminant source areas into coarse-grained zones where they are advected away to form contaminant plumes.

\subsection{Experiment Design and Operation}

\subsubsection{Column design}

The sand was packed in a glass chromatographic column approximately $15 \mathrm{~cm}$ long and $5 \mathrm{~cm}$ in diameter. The end fittings are made of Teflon and are separated from the sand with stainless steel screens. The plumbing from the pumps to the column is Teflon and stainless steel tubing and fittings (Figure 1).

\subsubsection{Column Packing}

The sand used in the column was Oklahoma No. 1 sand, a fine-grained, high purity quartz sand with no detectable organic matter. Standard U.S. sieves were used to evaluate grain size. A portion of the Oklahoma No. 1 sand was cleaned to remove a layer of clay-sized minerals that coats the grains. The clay accounts for $0.2-0.3 \%$ of the original mass of the sand and is composed of illite, kaolinite, and clay-sized quartz. Two columns were used in the experiment: one containing the cleaned sand and the other containing the original sand.

To create as homogenous a packing as possible, the column was half filled with water and vibrated as the sand was slowly poured into the column. One of the ends of the column has a fitting that allows the bedding to be screwed in to the top of the sand pack. This fitting was applied hand tight following the pour. After each column packing, one or two air bubbles could be seen against the side of the glass column but these bubbles dissolved away after several days of pumping deionized water through the column.

Porosity (0.32) and bulk density $\left(1.7 \mathrm{~g} / \mathrm{cm}^{3}\right)$ of the packed column were determined gravimetrically and hydraulic conductivity $\left(4 \times 10^{-3} \mathrm{~cm} / \mathrm{s}\right)$ was measured using a constant head hydraulic conductivity test.

\subsubsection{Column Operation}

Influent water was delivered to the column from a syringe pump with four $100 \mathrm{~mL}$ syringes loaded with the same water. From the syringes, the water was directed to a stainless steel mixing tube and then to the column. Sampling ports were located after the mixing tube and before the column, and at 


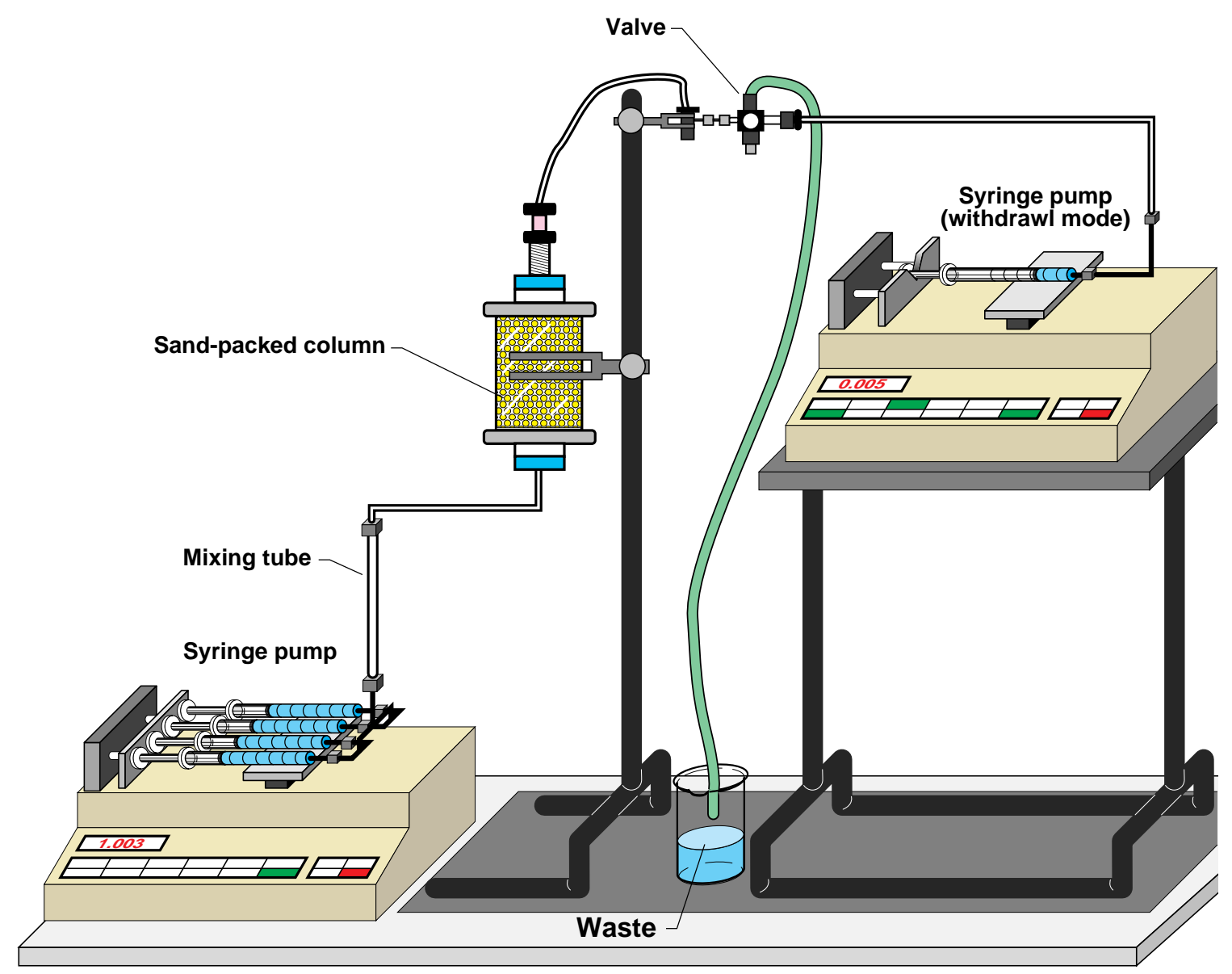

Figure 1. Schematic representation of the column experimental setup. The influent syringe pump, at the lower left, provided a regulated flow of $4.0 \mathrm{~mL} / \mathrm{hr}$, and the sampling syringe pump at the upper right collected a $1.0 \mathrm{~mL}$ sample in a sealed zero pressure system.

the effluent end of the column. Samples of the effluent were taken with a syringe pump in withdrawal mode, which maintained a sealed system from influent through effluent (Fig. 1). The influent pump was operated at a flow of $4.0 \mathrm{~mL} / \mathrm{hr}$, resulting in a flow velocity through the column of $17 \mathrm{~cm} / \mathrm{day}$. This velocity is comparable to the velocities of contaminated ground water beneath the LLNL Livermore site.Column Chemistry

The first experiments were run with $300 \mu \mathrm{g} / \mathrm{l}$ of chloroform $\left(\mathrm{CHCl}_{3}\right.$, carbon tetrachloride $\left(\mathrm{CCl}_{4}\right)$, trichloroethylene (TCE), and tetrachloroethylene (PCE) respectively, and $100 \mathrm{mg}$ of sodium chloride $(\mathrm{NaCl})$. The chloride ion was assumed to be conservative and therefore its' breakthrough curve was representative of the velocity of the water. Following the breakthrough experiments, we loaded the influent syringes with deionized water and repeated the experiments to simulate cleanup. Upon breakthrough of the clean water, the effluent appeared cloudy, and continued this way through the conclusion of the experiments.

We interpret the cloudiness as the result of the liberation of clay-sized particles coating the quartz grains of the sand. We postulate that the sodium ions, from the $\mathrm{NaCl}$ introduced as a tracer, disrupted the clays, and the introduction of a new fluid of differing ionic strength, caused the clays to disengage from the quartz grains and be advected away with the water.

Fortunately, the initial breakthrough curves for chloride and chloroform were coincident, indicating that the chloroform is not retarded through the sand and could therefore be used as a conservative tracer. All future experiments were run without the sodium chloride. 
In an effort to determine whether or not the clay coating on the quartz grains had an effect on the retardation, we removed clay from some of the sand before packing a new column. The removal process included multiple rinses with sodium chloride followed by rinses with deionized water. Additional rinses incorporated an ultrasonic bath and clean water rinses until no colloidal material was visible.

The colloidal material was collected and gravimetrically determined to be approximately $0.25 \%$ by weight of the original sand. X-ray diffraction analysis of the colloidal particles indicated that it was composed of illite, kaolinite and quartz particles. We also calculated the specific surface of the clay sized materials removed from the sand and estimated that the surface area of the removed clays represents approximately $25 \%$ of the surface area of the material packed in the column. The method used to estimate the specific surface is given in Hillel (1982). Other references used in studying the specific surface are listed in the Literature Cited section below. All further retardation experiments were conducted simultaneously on columns containing the original sand and sand from which the colloidal material had been removed respectively.

A $300 \mathrm{ppb}$ solution was prepared by adding $1.5 \mathrm{~mL}$ of a $100 \mathrm{ppm}$ stock solution of $\mathrm{CHCl}_{3}, \mathrm{CCl}_{4}$, TCE, and PCE in methanol to a $500 \mathrm{~mL}$ volumetric flask containing organic-free water. The solution was allowed to stir for $45 \mathrm{~min}$. prior to loading the four $100 \mathrm{~mL}$ Hamilton gas-tight syringes. Care was taken to minimize any bubbles during filling of the syringes. One milliliter samples were taken from each syringe before putting the plunger in place. This concentration was considered the influent concentration of the column $\left(\mathrm{C}_{\mathrm{o}}\right)$. The flow rate used was $1.0 \mathrm{~mL} / \mathrm{hr}$ to resemble ground water flow. The four 100-mL syringes were loaded onto a Harvard Apparatus 22 syringe pump and the stainless steel lines were flushed for $10 \mathrm{~min}$. at a rate of $0.5 \mathrm{~mL} / \mathrm{min}$. and then $1.0 \mathrm{~mL} / \mathrm{hr}$ for four hours or until flow was switched to the column. Hourly samples were taken 12 hours after flow was started to the columns and continued for 14 hours.

Following break-through, contaminant clean-up rates were calculated for $\mathrm{CHCl}_{3}, \mathrm{CCl}_{4}, \mathrm{TCE}$, and PCE by flowing organic-free water through the column. Four clean 100-mL Hamilton syringes were filled with organic-free water and the lines were flushed for $3 \mathrm{hr}$ at $1.0 \mathrm{~mL} / \mathrm{hr}$. Influent samples were analyzed to ensure the lines were properly flushed before starting flow to the column. Five consecutive effluent samples were taken after flow was turned on to the column and a mean of these samples was considered the $\mathrm{C}_{\mathrm{o}}$ for the clean-up phase. Hourly effluent samples were taken 12 hours after flow was started to the column and continued for 14 more hours like the break-through experiment. Sampling the effluent was reduced to three samples per day for 2 more days and then daily sampling until the concentrations were non-detectable. This process typically took 2 weeks.

\subsubsection{Column Sampling Method}

Sampling low-volume aqueous VOC samples from the columns was accomplished by collecting a $1.0 \mathrm{~mL}$ sample into a Dynatech vial (SVOA) (Dynatech Precision, Inc.). The SVOAs were originally designed for extracting VOCs from soil on a PTA $30 \mathrm{~W} / \mathrm{S}$ autosampler using an in-vial purge-and-trap system. The vials have a glass frit that supports the sample and each end of the vial has a screw cap and Teflon-lined silicone septum for sparging the VOCs directly from the vial. Initially, the columns were sampled by pre-weighing a SVOA and placing it on a bird-like perch with a septum covering the top of the vial. Sample collection was timed for $15 \mathrm{~min}$., followed by the addition of $200 \mathrm{ng}$ of chlorobenzene as the surrogate. In later experiments, a syringe withdrawal method was used to minimize volatilization of VOCs during sampling and to improve the precision of the analysis. A syringe pump operating in withdrawal mode, was added so that the sample was collected in a sealed zero pressure system. The resulting $1.0 \mathrm{~mL}$ sample was then transferred to a SVOA for analysis and spiked with surrogate. 


\subsection{Results}

\subsubsection{Column Experiment}

Breakthrough and cleanup curves were prepared to show the progression of dissolved VOCs into and out of the sand columns. Normalized VOC concentrations were plotted with respect to time. Variations in the breakthrough and cleanup curves for $\mathrm{CHCl}_{3}, \mathrm{CCl}_{4}, \mathrm{TCE}$, and PCE indicate differences in transport rates as a result of individual VOC behavior. The ratio of the rate of transport relative to the velocity of water is defined as the retardation factor.

In order to determine retardation factors, a computer model called CXTFIT2 (Toride et al., 1995) was used to evaluate the observed concentrations. This model attempts to fit a curve to the observed data and estimate transport parameters, including retardation, by solving the advection-dispersion equation (ADE). The model can be run in two different modes, equilibrium and non-equilibrium. The non-equilibrium mode attempts to account for partitioning of compounds between mobile and immobile water and adsorption of VOCs by instantaneous and first order kinetic reactions. The initial concentration, column length, total time of the experiment, and flow velocity are included as the input parameters.

The breakthrough and cleanup curves represented by our experimental data indicate non-ideal behavior, i.e. asymmetrical curves with long tails, common to VOC contaminated ground water at field sites and in laboratory experiments (Allen-King et. al, 1996). The CXTFIT2 non-equilibrium mode tends to provide the best fit to the observed data as a result of the increased number of variables available for adjustment, The difference between the equilibrium and non-equilibrium modes of CXTFIT2 are shown in Fig. 2 .

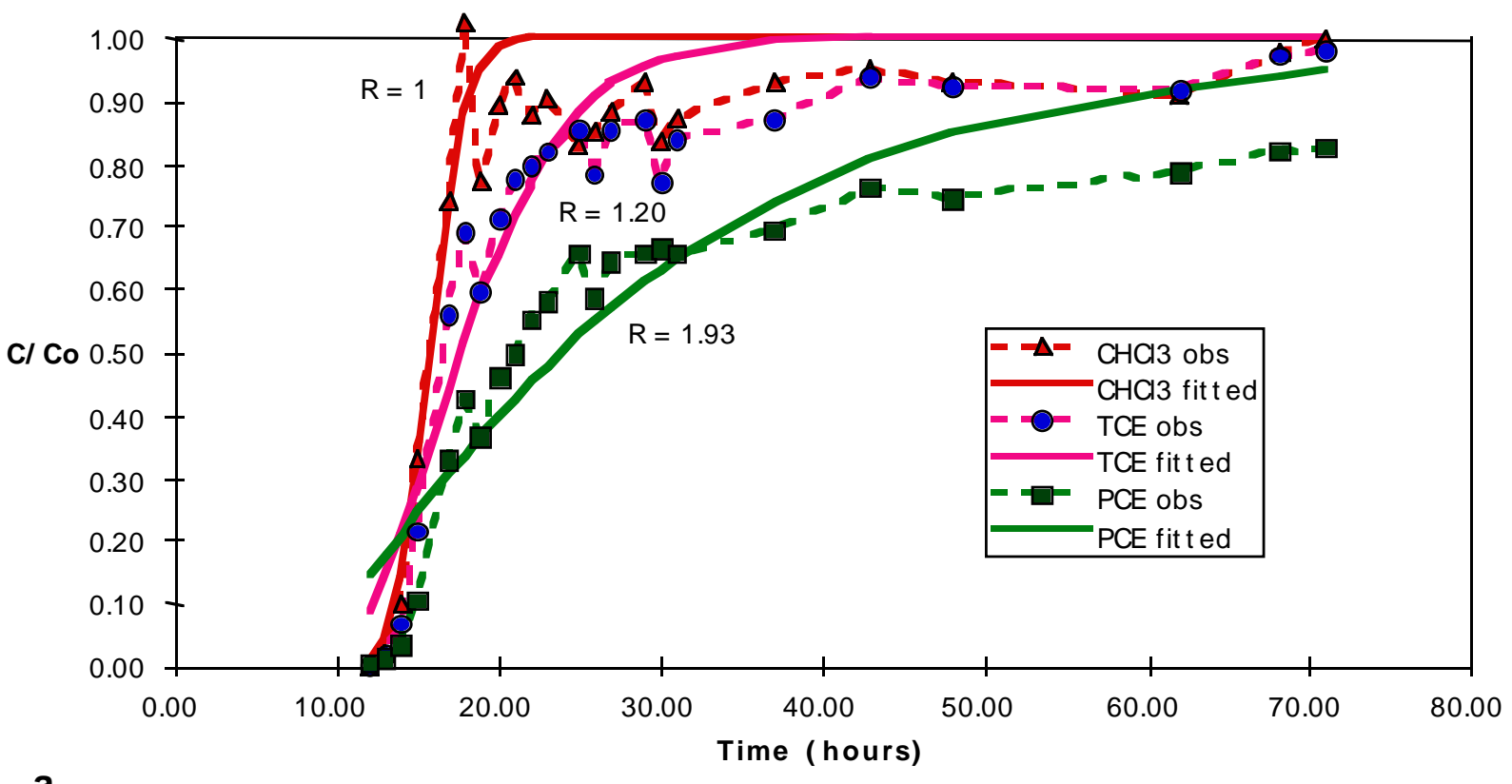

a

Figure 2. (a) Breakthrough curve with CXTFIT2 fit in equilibrium mode 


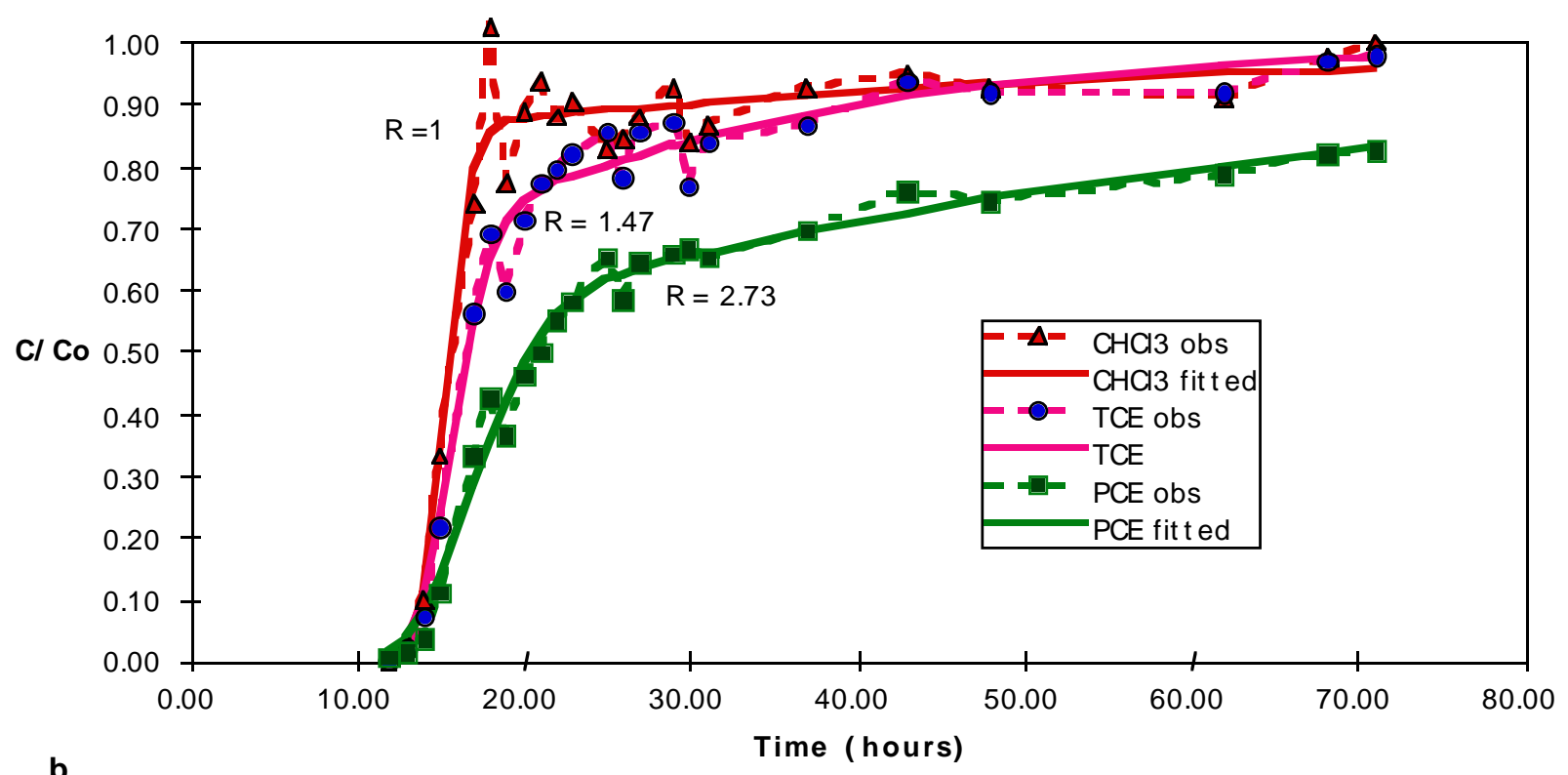

Figure 2. (b) in non-equilibrium mode.

PCE is consistently more retarded than the other VOCs and is greatly delayed in achieving full concentration during breakthrough and zero concentration during cleanup (Figures 2 and 3 ). Carbon tetrachloride exhibits non-reproducible behavior from one experiment to the next, possibly resulting from volatile losses during sampling (CCl4 has a higher Henry's Law constant than the other VOCs used in the experiment). In the later experiments of the project, we eliminated CCl4 from the influent water and concentrated on examining the behavior of TCE and PCE.

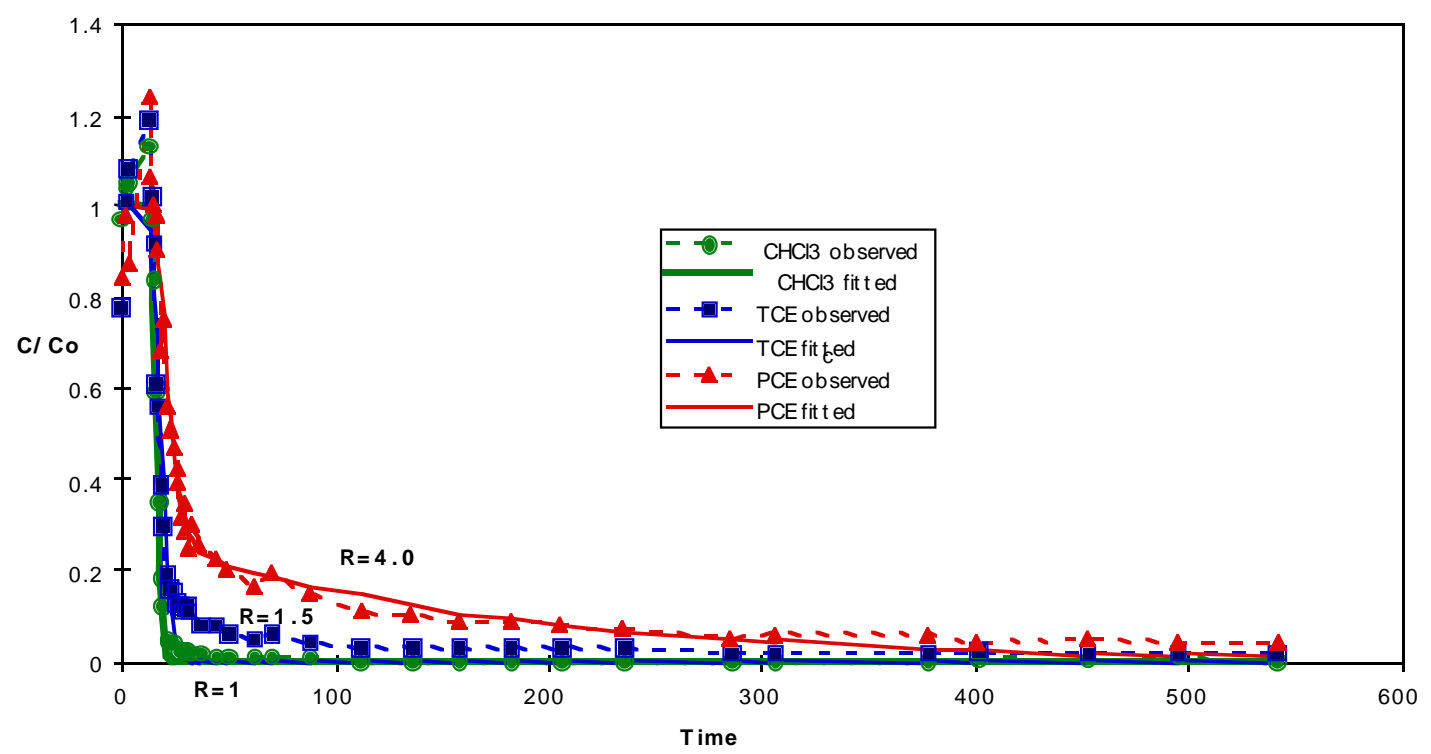

Figure 3. Clean up curves showing the long tail of concentration approaching the Maximum Contaminant Level for TCE and PCE of $5.0 \mu \mathrm{g} / \mathrm{l}$. 


\section{Literature Cited}

Allen-King, R. M., R. W. Gillham, and D. M. Mackay. 1996. Sorption of dissolved chlorinated solvents to aquifer materials. in J. F. Pankow and J. A. Cherry. 1996. Dense Chlorinated Solvents and other DNAPLs in Ground water: History, Behavior, and Remediation. Waterloo Press. Portland, OR.

Aylmore, L. A. G., Et Al. Surface Area Of Homoionic Illite And Montmorillonite Clay Minerals As Measured By The Sorption Of Nitrogen And Carbon Dioxide. (Clays Clay Miner. Vol. 18, No. 2, P. 91-96 (Incl. Fr., Ger., Russ. Sum.), Illus. 1970)

Gata, G. "Determination Of The Specific Surface Area Of Clay Minerals And Clay Fractions From Sediments And Soils." 1975. (Rom., Inst. Geol. Geofiz., Stud. Teh. Econ., Ser. I ; No. 13, P. 13-19)

Grim, R 1968. Clay Mineralogy. McGraw Hill.

Hillel, D. 1982. Introduction to Soil Physics. Academic Press, Inc.

Khan, Anwar Ul-Hassan, Et Al. "A Laboratory Study Of The Dispersion Scale Effect In Column Outflow Experiments." Jan. 1990. (Journal Of Contaminant Hydrology ; Vol. 5, No. 2, P. 119-131)

Kahr, G., Et Al. "Determination Of The Cation Exchange Capacity And Thethiede, Joern, Et Al. July 1994. (Marine Geology ; Vol. 119, No. 3-4, P. 269-285)

Muhunthan B. Liquid Limit And Surface Area Of Clays. Geotechnique, 1991 Mar, V41 N1:135-138. Pub Type: Note.

Murray Rs; Quirk Jp.Surface Area Of Clays. Langmuir, 1990 Jan, V6 N1:122-124.

Petersen Lw; Moldrup P; Jacobsen Oh; Rolston De. Relations Between Specific Surface Area And Soil Physical And Chemical Properties. Soil Science, 1996 Jan, V161 N1:9-21.

Ponizovskiy Aa; Korsunskaya Lp; Polubesov Ta; Salimgareyeva Oa; And Others. Methods For Determining The Specific Surface Area Of Soil From Water-Vapor Adsorption. Eurasian Soil Science, 1993 Jun, V25 N6:12-29.

Principles Of Environmental Analysis, Analytical Chemistry, Volume 55, Pages 2210-2218, December 1983 American Chemical Society)

Schofield, R. K. Clay Minerals And Colloid Chemistry; A General Introduction. (Clay Miner. B. No. 4, P. 104-106. 1950)

Toride, N., Leij, F.J., and M.Th. van Genuchten, The CXTFIT Code for Estimating Transport Parameters from Laboratory or Field Tracer Experiments, Version 2.0, Research Report No. 137, U.S. Salinity Laboratory, Riverside, CA, 1995. 


\title{
Dynamic Headspace Method for Analyzing Volatile Organic Compounds in Low-Volume Aqueous Samples
}

\author{
M L. Chiarappa, F. Hoffman, K. Carroll, and R. Martinelli
}

\section{Abstract}

A dynamic headspace method using in-vial purging previously developed for solid matrices was modified for analyzing volatile organic compounds (VOCs) in low-volume aqueous samples. Using volumes as low as $1.0 \mathrm{~mL}$ in these vials was validated by comparing VOC recovery efficiencies with the standard $5.0 \mathrm{~mL}$ method from $40-\mathrm{mL}$ vials, measuring precision and accuracy of replicate vials, determining linearity of the calibrations, and checking sample integrity during the holding time. Results indicate that VOC recovery efficiencies from the invial purging method is analogous to the standard method. This method has advantages over conventional methods because much lower sample volumes are required.

\subsection{Introduction}

Use of reliable sample handling techniques of VOCs in aqueous matrices is always a concern in both laboratory and field situations. One of the main concerns when working with this class of compounds is their high volatility. Significant VOC losses and subsequent analytical variability can occur with improper sample preservation, handling and preparation (Zemo, 1995; Patterson, 1993; Rosen, 1992). EPA overcame the problem of sample collection by requiring the use of 40-mL volatile organic analysis vials (VOAs) in the standard methods. These vials have a Teflon-lined septum on the top of the vial to seal the contents and to facilitate the withdrawal of a sample for purge and trap (P \& T) analysis originally described by Bellar (1974). This standard vial size is adequate when sample volume is not limited but is problematic when sample volumes from an experiment, for example, are less than $40 \mathrm{~mL}$. The VOAs must be filled completely and without headspace in order to obtain accurate and precise sample concentrations for a dynamic purging method and reduce errors in the analytical measurement. A static headspace method can be used for sample volumes less than $40 \mathrm{~mL}$, but this technique has several disadvantages one of which is its low sensitivity (Kurán, 1996). This loss in sensitivity is especially a problem when the available sample volume is as small as $1.0 \mathrm{~mL}$.

In this paper, we describe the use of non-standard containers for performing $\mathrm{P} \& \mathrm{~T}$ on low volume aqueous VOC samples. Low flow rates $(<4.0 \mathrm{~mL} / \mathrm{h})$ of column and diffusion experiments required a new method for collecting and analyzing $1.0 \mathrm{~mL}$ aqueous samples containing chloroform $\left(\mathrm{CHCl}_{3}\right)$, carbon tetrachloride $\left(\mathrm{CCl}_{4}\right)$, trichloroethylene (TCE), and tetrachloroethylene (PCE). Dynatech vials (Dynatech Precision, Inc.) or soil-VOAs (SVOAs), were chosen because the in-vial purging feature allowed flexibility in volumes used (up to $10 \mathrm{~mL}$ ), eliminated headspace concerns while maintaining satisfactory detection limits of $1.0 \mu \mathrm{g} / \mathrm{L}$, and the analysis could be automated. These SVOAs were originally designed for P \& T of solid matrices and were used in a study by West (1995) for extracting VOCs from soil. Use of this vial for low-volume aqueous analyses has not been, to the best or our knowledge, reported in the literature.

Suitability of using SVOAs as sampling containers for low-volume aqueous VOC analysis was validated by comparing VOC recovery efficiencies with VOAs, measuring analytical replication, checking sample integrity during the holding time and examining standard calibrations. 


\subsection{Experimental Set-up}

3.2.1. Column Sampling Method. Column experiments were conducted in sand-packed columns, at a flow rate of $4.0 \mathrm{~mL} / \mathrm{hr}$ to simulate ground water velocities. The columns were sampled by using a syringe pump operating in withdrawal mode so that a $1.0 \mathrm{~mL}$ sample was collected in a 2.0 mL gastight Hamilton syringe over a 15 minute period. The resulting $1.0 \mathrm{~mL}$ sample was then transferred to a pre-weighed SVOA. The vials have a glass frit that supports the sample and each end of the vial has a screw cap and Teflon-lined silicone septum for sparging the VOCs directly from the vial (Figure 1). Samples were then spiked with $200 \mathrm{ng}$ of chlorobenzene as the surrogate and then a final weight was taken. The weight of the final sample was converted to milliliters with the assumption that $1.0 \mathrm{~g}$ of the aqueous matrix was equivalent to $1.0 \mathrm{~mL}$.

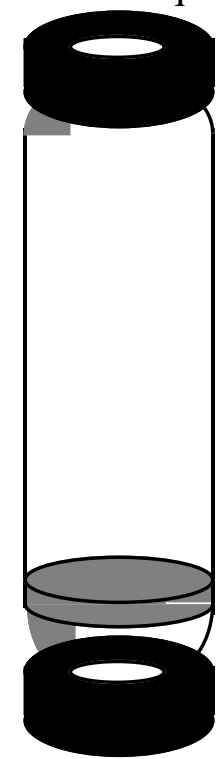

Fig. 1. Dynatech SVOA with Teflon-lined septa on either end and a glass frit in the vial for sparging the sample.

\subsection{SVOA Validation}

Duplicate VOAs were prepared containing 25, 50,75, and $100 \mu \mathrm{g} / \mathrm{L}$ of TCE. One set of vials was used for VOA analysis and a $5.0 \mathrm{~mL}$ volume of the other set was added to SVOAs, purged for $11 \mathrm{~min}$ and analyzed by gas chromatography (GC).

The analytical precision and accuracy of the SVOAs was determined by analyzing five replicates each of a 25 and $100 \mathrm{ng}$ standard solution of TCE and cis-1,3-dichloropropene (DCP) and calculating the percent relative standard deviation (\%RSD). Precision and accuracy comparisons between SVOAs and VOAs were accomplished by analyzing the recovery of seven replicates of 10 and $100 \mathrm{ppb}$ standard solutions of $\mathrm{CHCl}_{3}, \mathrm{CCl}_{4}, \mathrm{TCE}$, and PCE. Chlorobenzene was added at a final concentration of $50 \mathrm{ppb}$ as the surrogate and both vial-types were compared.

Thirty consecutive SVOAs containing $50 \mathrm{ng}$ of $\mathrm{CHCl}_{3}, \mathrm{CCl} 4$, TCE and PCE, were placed on the rack of the Dynatech PTA-30 autosampler. VOC concentrations from each vial were then measured and compared for the 14-hr analysis time.

Quantitation was performed by preparing calibration curves of $\mathrm{CHCl}_{3}, \mathrm{CCl}_{4}, \mathrm{TCE}$, and PCE. Better accuracy was achieved by creating two calibration curves each containing 5.0, 10, $20,25,50,75$, and $100 \mu \mathrm{g} / \mathrm{L}$ and $150,200,250,300,400,450$, and $500 \mu \mathrm{g} / \mathrm{L}$. Neat compounds purchased from Chem Service Incorporated were used to prepare the various solutions. A $100 \mathrm{ppm}$ working stock solution was prepared in $100 \mathrm{~mL}$ of high purity methanol (B \& J Brand, Baxter Scientific Products) in $120 \mathrm{~mL}$ amber glass serum bottles. The serum 
bottles were capped with Teflon lined silicone septa, and aluminum crimp caps which were replaced after each use. The various standard concentrations were prepared by adding the appropriate volume of the working stock solution to $40 \mathrm{~mL}$ of ultrapure water $(0.22 \mu \mathrm{m}$ filtered) water (Barnstead/Thermolyne). The water was purged with helium for 45 minutes prior to use. Calibration checks of 50 and $200 \mu \mathrm{g} / \mathrm{L} \mathrm{CHCl}_{3}, \mathrm{CCl}_{4}, \mathrm{TCE}$, and PCE were analyzed before the samples. If the calibration check standards varied by $10 \%$ of the anticipated value, the instrument was re-calibrated. A National Institute of Standards and Technology traceable external check sample was analyzed with every new calibration.

\subsection{Analytical Methods}

\subsubsection{Instrumentation}

Gas chromatography was performed using a Hewlett Packard 5890 series II Gas Chromatograph (GC) equipped with a photoionization detector (PID, Model 4430, O.I. Corporation) connected in series to an electrolytic conductivity detector (ELCD, Model 4420, O.I. Corporation.). A fused-silica column (30 m X $0.53 \mathrm{~mm}$ i.d.; DB-624, $3 \mu \mathrm{m}$ film thickness; J\&W Scientific) was connected to a low dead volume (LDV) injector port and interfaced to an O.I. Model 4560 liquid sample concentrator (O.I. Corporation). A PTA-30 W/S autosampler (Dynatech Precision Sampling Corp.) was employed for automating the sample analyses.

\subsubsection{Method Programming}

The GC oven was held at an initial temperature of $50^{\circ} \mathrm{C}$ for five minutes followed by a temperature ramp to $110^{\circ} \mathrm{C}$ at $6 \mathrm{deg} / \mathrm{min}$, with a post analysis bake-out of $200^{\circ} \mathrm{C}$ for five minutes. The aqueous samples were purged for $11 \mathrm{~min}$ at $25^{\circ} \mathrm{C}$, desorbed for $2 \mathrm{~min}$ at $180^{\circ} \mathrm{C}$, and the trap baked for $7 \mathrm{~min}$ at $190^{\circ} \mathrm{C}$. HP Chemstation, an automated GC system control and data collection programmable workstation, was used to gather, process, and archive the data. The PTA-30 W/S autosampler added $4.0 \mathrm{~mL}$ of water to the SVOA for a final volume of 5.0 $\mathrm{mL}$. DCP was used as an internal standard to measure GC performance, and to calculate unknown sample concentrations.

\subsubsection{Instrument Calibration Method}

The Internal Standard Method (ISTD) using the HP3365 Series II ChemStation Software calculates each peak separately and reports the absolute amount of material for each calibrated analyte. The results are independent of sample size, giving the most accurate analysis scheme for liquid samples. The PTA-30 W/S autosampler automatically delivers $100 \mathrm{ng}$ of the internal standard, DCP, to every sample. Since this internal standard is present in both unknown and calibrated samples, it serves as a reference or normalizing factor. Normalization of a compound (y) is done by

$\mathrm{y}(\mu \mathrm{g} / \mathrm{L})=$ Amount Ratio $\mathrm{X}$ Actual Concentration of ISTD X dilution factor where:

$$
\text { Amount Ratio }=\frac{(\mathrm{A})_{\mathrm{y}}}{(\mathrm{A})_{\mathrm{ISTD}}} \mathrm{X}-\frac{(\mathrm{R})_{\mathrm{y}}}{(\mathrm{R})_{\mathrm{ISTD}}}
$$

(A) $\quad$ Area of compound y peak 
(A)ISTD Area of internal standard peak

(R) $\quad$ Ratio of y amount (ug/L) to unit area of peak y (detector response factor)

(R)ISTD Ratio of ISTD amount (100 ng) per unit area of the internal standard peak (detector response factor)

\subsubsection{Detection Limits}

Limits of detection (LOD) were measured using the American Chemical Society recommendation that quantitation levels be set at 10 times the standard deviation of seven replicates (ACS, 1983). LOD's determined for $\mathrm{CHCL}_{3}, \mathrm{CCL}_{4}$, TCE, and PCE, using the tandem PID/ELCD detector system was between 1 and 2 ppb for a $1.0 \mathrm{~mL}$ sample.

\subsection{Results and Discussion}

\subsubsection{Column Sampling Method}

The syringe withdrawal method gave consistent results for the four compounds between 10 and $300 \mathrm{ppb}$ but recovery of the compounds never reached 100\%. Figure 2 indicates there was a $20 \%$ loss of analytes in the sampling procedure when the column was bypassed and this loss was independent of concentration. The lower recovery measured may

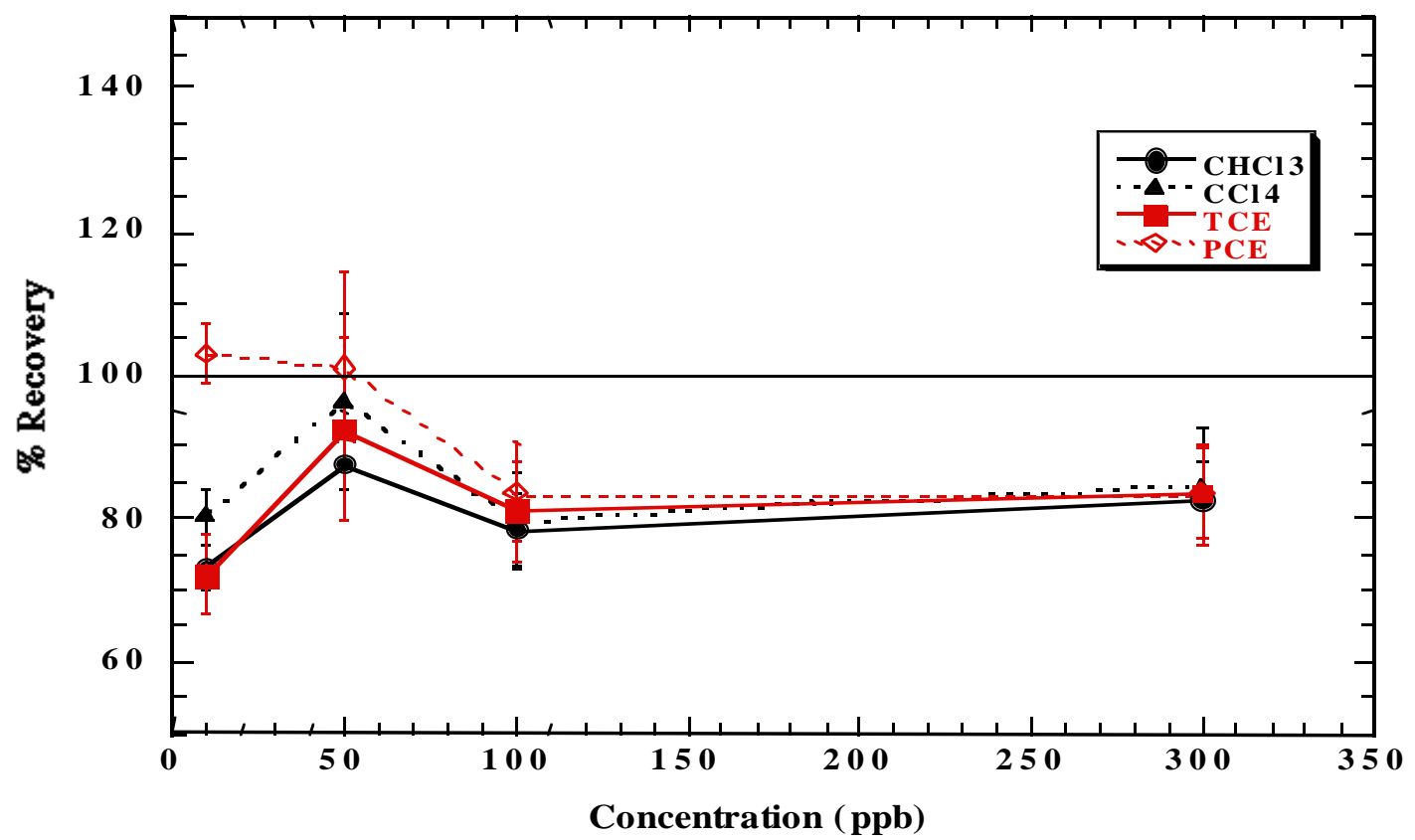

Figure 2. Percent recovery of $\mathrm{CHCl}_{3}, \mathrm{CCl}_{4}, \mathrm{TCE}, \mathrm{PCE}$ from the sample withdrawal method using the syringe pump.

explain why the C/Co in the column breakthrough curves never reached 1.0.

Conversely, the lower recovery might be explained by VOC interaction with the new teflow-tubing used to bypass the column, or also in the column studies; we undoubtedly had large volatile losses during sample injection into the SVOA. 


\subsubsection{SVOA Validation}

The concentrations of TCE recovered from purging samples using VOAs and SVOAs are shown in Figure 3. A linear relationship $\left(r^{2}=0.9994\right)$ exists between SVOAs and VOAs indicating that the two methods are equivalent.

Analysis of five replicate SVOA samples containing $1.0 \mathrm{~mL}$ of 25 or $100 \mathrm{ng}$ of TCE and DCP are shown in Table 1.

Mean accuracy for these measurements was $95 \pm 5 \%$ and mean recovery efficiencies ranged between 88 and $102 \%$. Analytical precision was consistently $6 \%$ except for the $9 \%$ calculated for the $25 \mathrm{ng}$ TCE replicates. The mean precision for the SVOAs was $6.8 \pm 1.3 \%$ which is well below our objectives of 10\%. Likewise, the histogram in Figure 4 indicates close agreement between the mean of seven replicates of VOAs and SVOAs at each of the concentrations for the analytes used in the column experiments and similar analyte recoveries. The \%RSD for the 10 ppb VOA analyses ranged between 1.4-3.2\% and the SVOA \%RS was 3.6-7.4\%, which is

Table 1. Replication of 5 SVOAs each containing 25 and $100 \mathrm{ng}$ of TCE and DCP. Precision was measured by calculating the \%RSD from the mean and standard deviation.

\begin{tabular}{|c||l||l|}
\hline VOC Content (ng) & TCE & DCP \\
\hline 25 & 22 & 21 \\
\hline 25 & 24 & 23 \\
\hline 25 & 24 & 24 \\
\hline 25 & 24 & 22 \\
\hline 25 & 20 & 21 \\
\hline mean & 23 & 22 \\
\hline SD & 2 & 1 \\
\hline Precision $(\%$ RSD) & 9 & 6 \\
\hline Accuracy $(\%)$ & 92 & 88 \\
\hline 100 & 91 & 97 \\
\hline 100 & 99 & 100 \\
\hline 100 & 106 & 106 \\
\hline 100 & 101 & 110 \\
\hline 100 & 94 & 97 \\
\hline mean & 98 & 102 \\
\hline SD & 6 & 6 \\
\hline Precision $(\%$ RSD $)$ & 6 & 6 \\
\hline Accuracy $(\%)$ & 98 & 102 \\
\hline
\end{tabular}

approximately double but still below the $10 \%$ objective. Similar precision was observed for the $100 \mathrm{ppb}$ samples with \%RSD values ranging between 1.3 and 3.7 for VOAs and 4.9 and 8.6 for SVOAs. 
Accuracy of the VOAs was $88 \pm 4 \%$ compared to $92 \pm 6 \%$ of the SVOAs. A student t-test proved that that two vial-types were not statistically different at the $95 \%$ confidence level. Concentration differences did not affect the precision and accuracy of the analysis using SVOAs. Mean surrogate recovery of multiple analyses comprising 40 samples was around $100 \pm 5 \%$ validating the analysis for each sample.

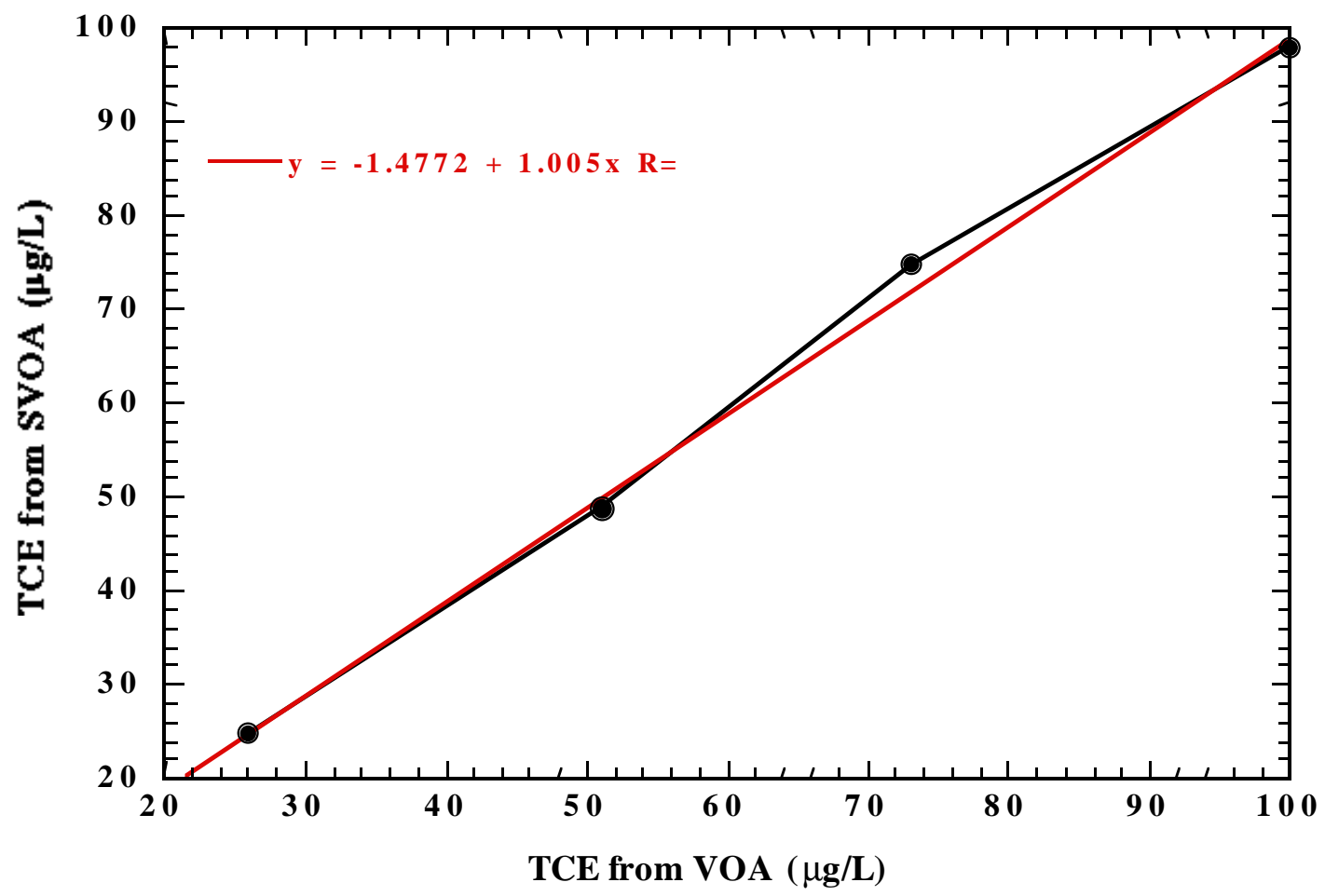

Figure 3. Concentration of TCE recovered from VOAs and SVOAs was compared by purging $5.0 \mathrm{~mL}$ of 20 , 50,75 , and $100 \mathrm{ppb}$ solutions. A correlation coefficient of 0.9994 demonstrates that the two vial-types are equivalent.

Using SVOAs does not compromise accuracy as shown in Table 1 and Figure 4. It is noteworthy to add that capping of the SVOA be done immediately to prevent losses as shown in Figure 5. A 5\% decrease in TCE concentration was measured within 10 seconds of capping the SVOA. The concentration decreased linearly at a rate of approximately 27 $\mathrm{ng} / \mathrm{mL} / \mathrm{sec}$. This high loss-rate is especially important at the lower concentrations. Handling calibrations and samples in the same manner with a quick capping procedure greatly reduces these losses. 


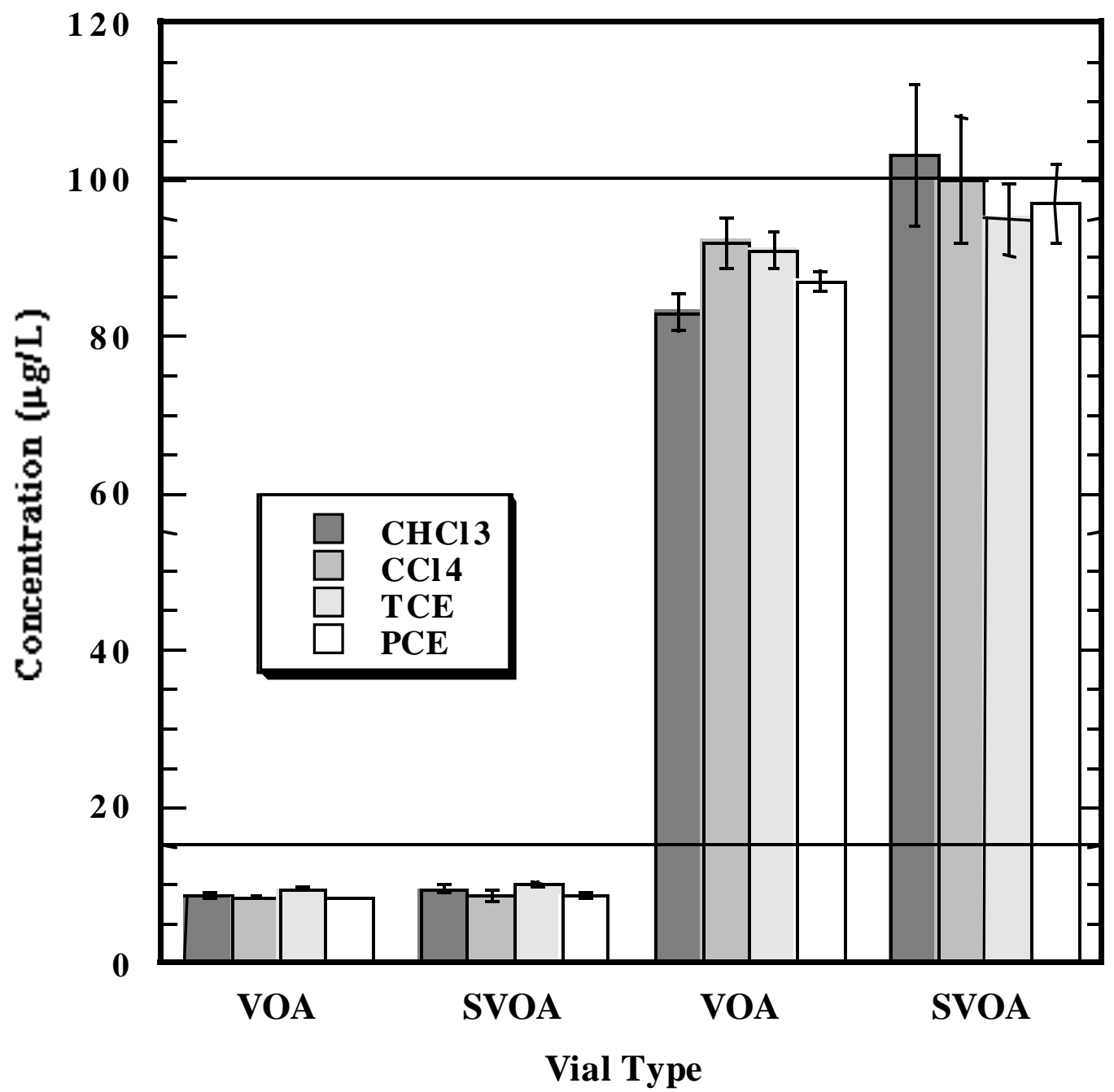

Figure 4. Mean concentrations and standard deviations ( $\mathrm{n}=7)$ of $\mathrm{CHCl}_{3}, \mathrm{CCl}_{4}, \mathrm{TCE}$, and $\mathrm{PCE}$ replicates of 10 and $100 \mathrm{ppb}$ standards analyzed with SVOAs and VOAs.

In Figure 6, $\mathrm{CHCl}_{3}, \mathrm{TCE}$ and PCE remained relatively constant during the course of 14 hours in SVOAs on the autosampler even though $\mathrm{CHCl}_{3}$ data shows high bias and PCE concentrations indicate a slight decrease. This decrease is still within the $10 \%$ acceptance interval. On the other hand, $\mathrm{CCl}_{4}$ is significantly lower than the rest of the analytes and indicates a slow but steady decrease between 5 and 14 hours. $\mathrm{CCl}_{4}$ has a higher Henry's Law Constant $\left(0.024 \mathrm{~atm} \bullet \mathrm{m}^{3} / \mathrm{mol}\right)$ than the other analytes which may partially explain the gradual loss. Standard calibration curves of $\mathrm{CHCl}_{3}, \mathrm{CCl}_{4}, \mathrm{TCE}$, and PCE were linear $\left(\mathrm{r}^{2}=0.9997\right)$ between 5 and $500 \mathrm{ng} / \mathrm{mL}$ although a slight decrease in detector linearity was observed starting at about $450 \mathrm{ng} / \mathrm{mL}$ (Figure 7 and 8). Quantitation using the SVOAs is possible within the concentration range described. 


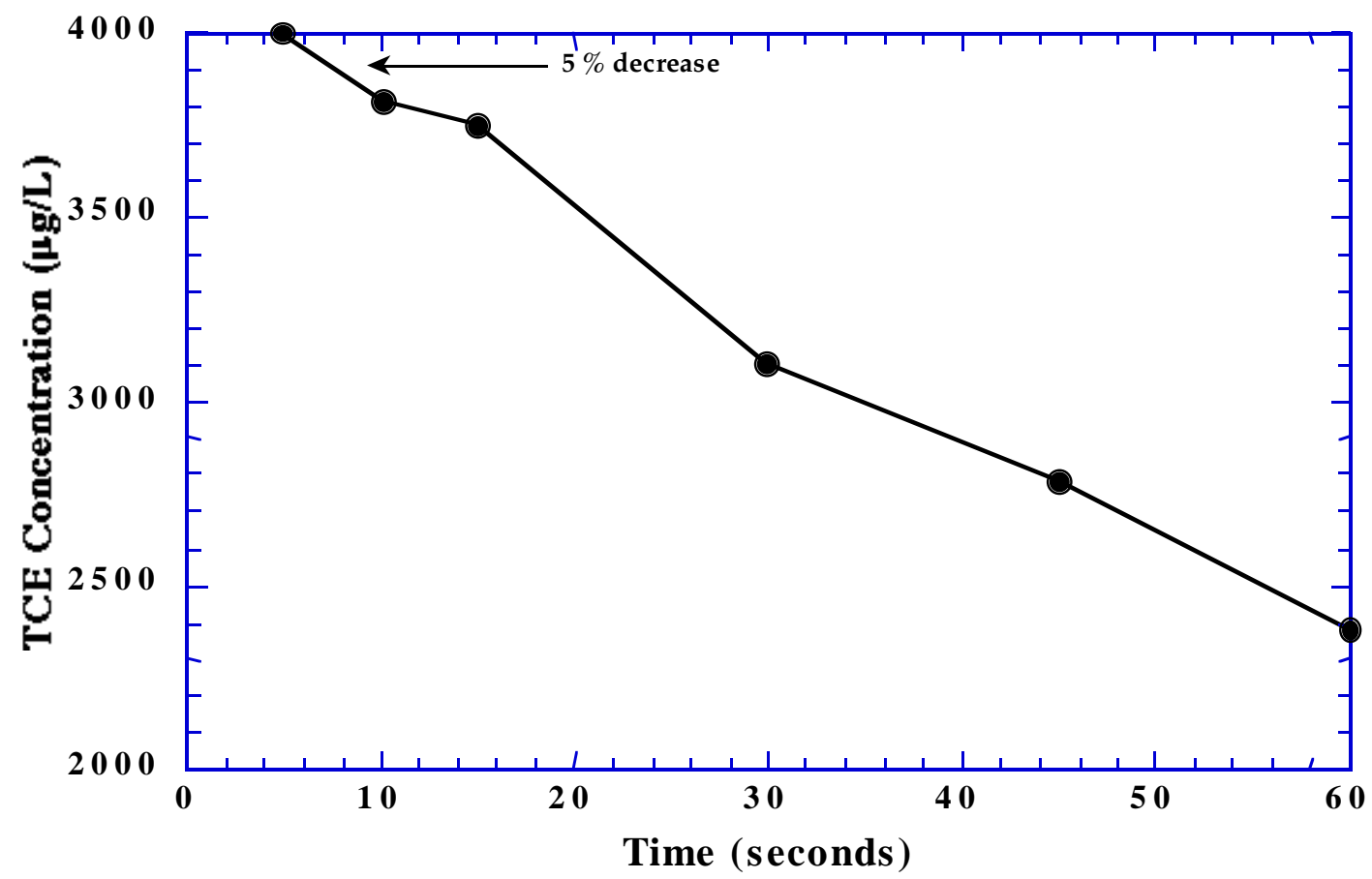

Figure 5. Effect of time on capping the SVOA once the aqueous sample was introduced. A 5\% decrease in concentration was observed within the first 10 seconds of capping the SVOA.

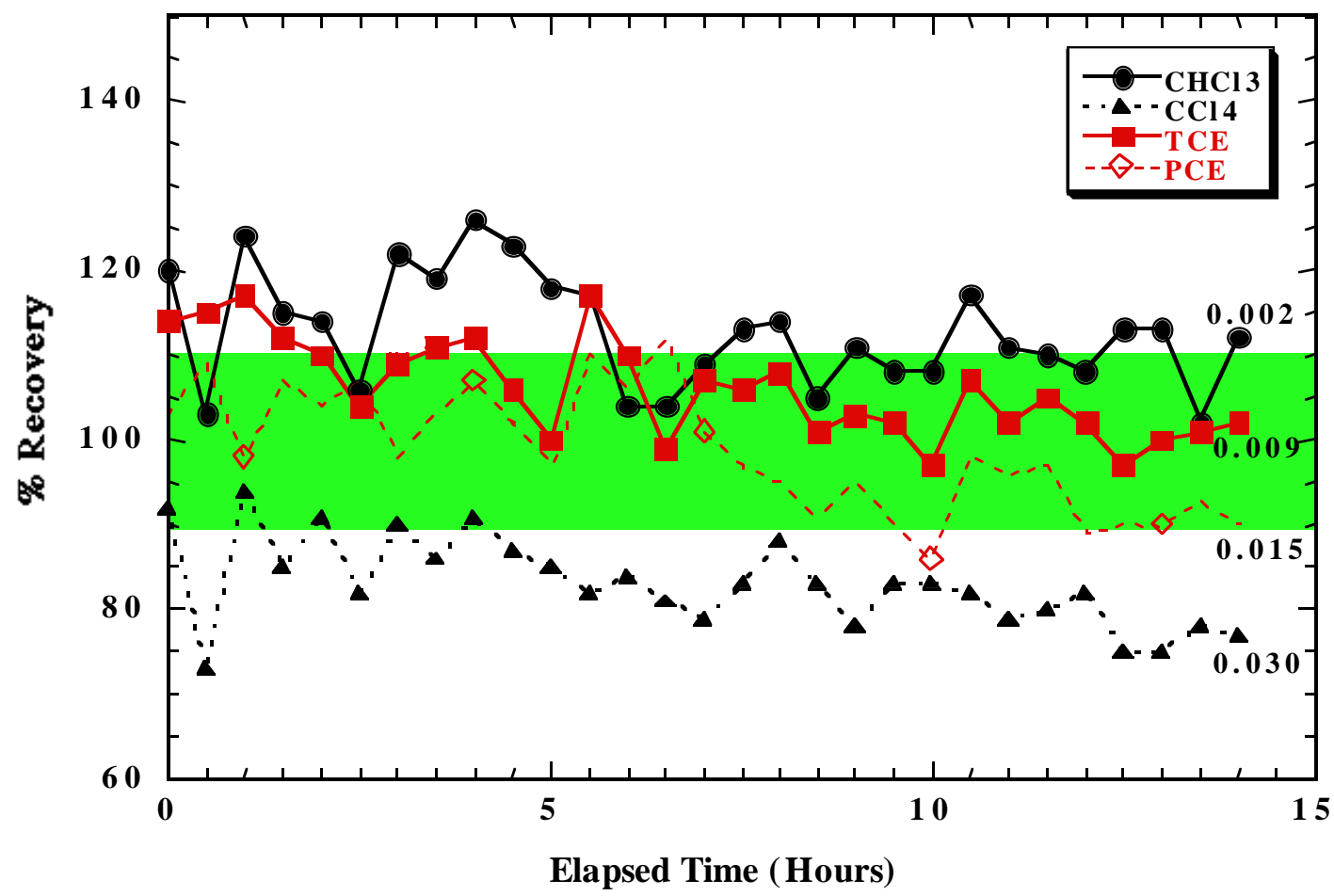

Figure 6. Percent recovery of $\mathrm{CHCl}_{3}, \mathrm{CCl}_{4}, \mathrm{TCE}$, and PCE from SVOAs on the autosampler during a 14-h period. The stipled area delineates the $\pm 10 \%$ range of acceptance and the numbers on the right of the plot refer to the Henry's Law Constant of each chemical in atm $\bullet \mathrm{m}^{3} / \mathrm{mol}$ at room temperature. 


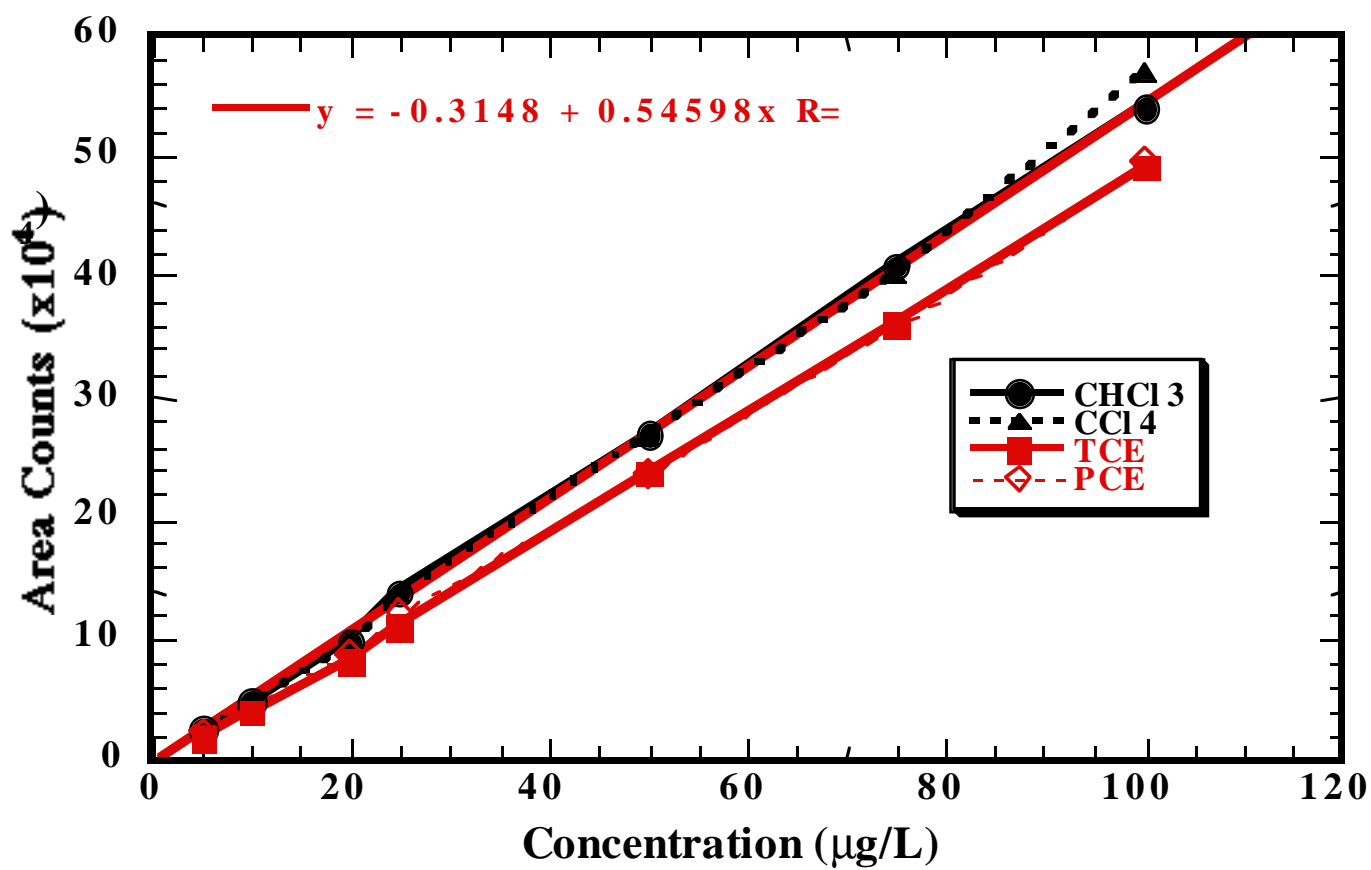

Figure 7. SVOA calibration curve for $\mathrm{CHCl}_{3}, \mathrm{CCl}_{4}, \mathrm{TCE}$, and PCE from 5 to $100 \mathrm{ng} / \mathrm{mL}$.

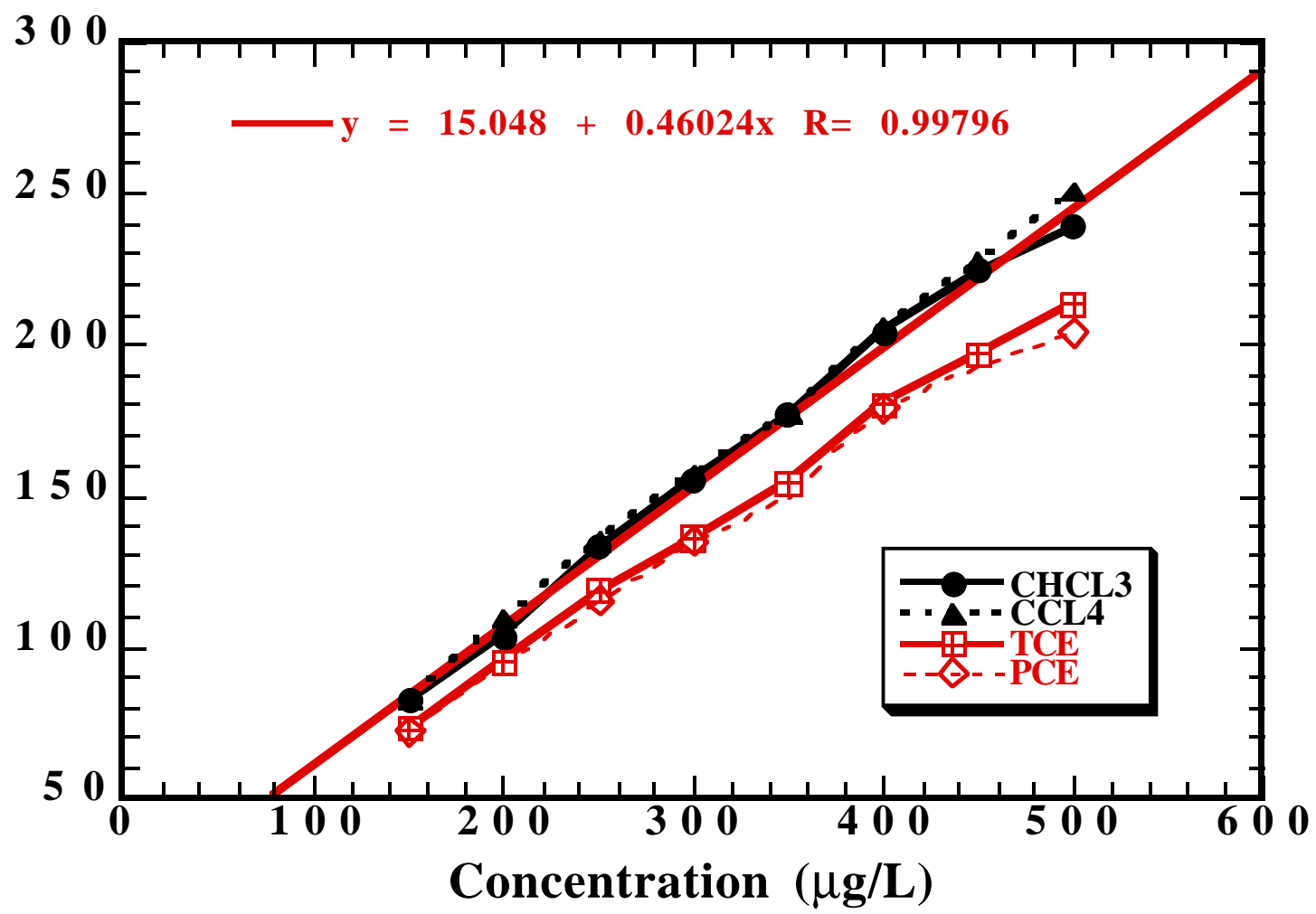

Figure 8. SVOA calibration curve for $\mathrm{CHCl}_{3}, \mathrm{CCl}_{4}, \mathrm{TCE}$, and PCE from 150 to $500 \mathrm{ng} / \mathrm{mL}$. 


\subsection{Conclusion}

This study demonstrates that the Dynatech in-vial purging containers are suitable for measuring VOCs in low volume samples. Similar accuracy and precision are achieved when compared to the standard VOA analysis with little loss in sensitivity. The linearity of the analysis is very good. This method has extensive applications in research experiments that yield low-volume samples that are difficult to analyze by standard EPA methods.

\subsection{Literature Cited}

American Chemical Society, "Principles of Environmental Analysis," Analytical Chemistry, Volume 55, Pages 2210-2218, December 1983.

Bellar, T. A.; Lichtenberg, J.J.; Kroner, R.C. "Occurrence of Organohalides in Chlorinated Drinking waters." J. Am. Water Works Assoc. 1974, 66, 703.

Kurán, P.; Soják L. "Environmental Analysis of Volatile Organic Compounds in Water and Sediment by Gas Chromatography" J. of Chromat. A. 1996,733, 119.

Montgomery J.H.; Welkom L.M., Groundwater Chemicals Desk Reference (Lewis Publishers, Inc., Chelsea, Michigan), 1990, 640 pp.

Rosen, M.E.; Pankow, J.G.; Imbrigiotta, T.E. "Comparison of Downhole and Surface Sampling for the Determination of Volatile Organic Compounds (VOCs) in Ground Water." Ground Water Monitoring Review 1992, 7, 126.

Patterson, B.M.; Power, T.R.; Barber, C. "Comparison of Two Integrated Methods for the Collection and Analysis of Volatile Organic Compounds in Ground Water."Ground Water Monitoring Review 1993, 8, 118.

West, O.R.; Siegrist R. L.; Mitchell T. J.; Jenkins R. A. "Measurement Error and Spatial Variability Effects on Characterization of Volatile Organics in the Subsurface." Environ. Sci. Tecnol. 1995, 29, 647.

Zemo, D.A.; Delfino, T. A.; Gallinatti, J. D.; Baker, V.A.; Hilpert L. R. "Field Comparison of Analytical Results from Discrete-Depth Ground Water Samplers." Ground Water

Monitoring Review 1995, 10, 133. 


\title{
Diffusive Transport of Dissolved Volatile OrganicCompounds In Sediments
}

\author{
F. Hoffman, M.L. Chiarappa, J. O'Boyle, K. Fox and K. Bair
}

\section{Abstract}

Diffusion of dissolved volatile organic compounds (VOCs) in ground water through low organic carbon sediments is slowed by the tortuosity of the flowpath through the sediments and sorption of the VOCs to the sediment solids. We have combined these factors into a new coefficient, defined as the diffusion reduction coefficient. We have also developed an experimental method to examine retardation under diffusive flux. Chloroform, carbon tetrachloride, TCE, and PCE are pumped over vials packed with different grain-size low organic carbon sands. Determination of VOC mass in the vials allows us to calculate the rate of diffusion into the sediment as well as the tortuosity of the sediments and retardation of the VOCs. Results indicate that only minor differences exist between retardation factors of the different VOCs, but statistically significant differences in retardation are caused by the different sands.

\subsection{Introduction}

Ground water at Lawrence Livermore National Laboratory (LLNL) in Livermore, California, is contaminated with volatile organic compounds (VOCs) that were released into the subsurface. Pump-and-treat remediation has proven to effectively reduce the size of contaminant plumes (Hoffman et al., 1997). With this method, contaminated ground water is removed from coarse-grained sediments, but in the source area contaminants have diffused into fine-grained sediments. The poor hydraulic conductivity of these lenses prevents rapid removal of contaminants by pumping. Furthermore, after contaminants are pumped from highly conductive hydrostratigraphic units, the concentration gradient is reversed and contaminants begin to diffuse out of the fine-grained sediments back into the coarse-grained sediments. If this process keeps the VOC concentrations above designated maximum contaminant levels, the time needed to clean the aquifers will be greatly extended. In an attempt to develop more effective cleanup techniques for contaminated ground water, we are examining the factors involved in contaminant transport and behavior.

This paper describes an experimental method devised at LLNL to study the processes influencing molecular diffusion in sediment. VOCs dissolved in water are used to investigate rates of diffusion through low organic carbon sands. Rates of VOC diffusion in porous media are controlled by the rate of diffusion in water, tortuosity (a measure of the length of the tortuous path a solute travels around aquifer solids versus the actual distance traveled downgradient), and the amount of sorption to aquifer solids. The diffusion rate in water $\left(\mathrm{D}_{\mathrm{w}}\right)$ can be calculated from empirical correlations. Tortuosity cannot be measured directly and must be determined by other experimental means. Sorption may result from adsorption to inorganic mineral surfaces or absorption into organic matter (Allen-King et al., 1996). An apparent retardation is a result of sorption and is defined by the retardation factor $(\mathrm{R})$. The rate of apparent diffusion will be slowed by the effects of both tortuosity and sorption. In this paper we introduce the diffusion reduction coefficient $(\Omega)$, which is defined as a combination of these two effects. 
Our diffusion experiment uses 4 VOCs found in contaminated ground water at LLNL, chloroform $\left(\mathrm{CHCl}_{3}\right)$, carbon tetrachloride $\left(\mathrm{CCl}_{4}\right)$, tetrachloroethylene $(\mathrm{PCE})$, and trichloroethylene (TCE). Sands of varying grain size, porosity, and clay content are used to determine how these characteristics may influence molecular diffusion. Apparent diffusion coefficients and diffusion reduction coefficients are calculated by a computer model based on the complementary error function equation for diffusion (Crank, 1956) and experimental VOC data. The retardation factors of the VOCs are then calculated.

\subsection{Theory}

\subsubsection{Calculating Diffusion Coefficients}

Experimental values of diffusion coefficients in water $\left(\mathrm{D}_{\mathrm{w}}\right)$ for the VOCs used in the diffusion experiment are not available. Therefore, a theoretical value must be calculated. Six different $D_{w}$ correlations and variations of these were evaluated (Table 1). These correlations establish $\mathrm{D}_{\mathrm{w}}$ as a relation between fluid viscosity $(\mathrm{m})$ and molar volume of solute $(\mathrm{V})$; most of these also include temperature $(\mathrm{T})$ and individualized dimensionless parameters. Variation between the highest and lowest of all calculated $D_{w}$ values is $20 \%$. $D_{w}$ values for our experiment were calculated from the Hayduk-Minhas correlation (Reid, 1987):

$$
\mathbf{D}_{\mathbf{w}}=\left(1.25 \cdot 10^{-8}\right)\left(\mathbf{V}_{\mathbf{b}}^{-0.19}-0.292\right) \mathbf{T}^{1.52} \mu^{\left(\frac{9.58}{\mathbf{V}_{\mathbf{b}}-1.12}\right)}
$$

where:

$$
\begin{array}{ll}
\mathbf{V}_{\mathbf{b}} & =\text { molar volume at solute boiling point }\left(\mathrm{cm}^{3} / \mathrm{mol}\right) \\
\mathbf{T} & =\text { temperature }(\text { Kelvin }) \\
\mu_{\mathbf{w}} & =\text { viscosity of water }(\mathrm{cP})
\end{array}
$$

This correlation was selected because values calculated from Eq. 1 are within $4.5 \%$ of the average $D_{w}$ for all 10 equations and have the lowest average error $(9.4 \%)$ when compared to other experimental values. (Calculated values are shown in Table 4.)

When a compound dissolved in water diffuses through a porous medium, the diffusion rate is reduced by the elongation of a molecule's path as it travels around solid particles during diffusion. The length of this pathway is defined as the tortuosity factor, $t$ (Bear, 1972):

$$
\tau=\left(\frac{\mathbf{L}}{\mathbf{L}_{\mathbf{e}}}\right)^{2}
$$

where:

$$
\begin{aligned}
\tau & =\text { tortuosity factor } \\
\mathbf{L} & =\text { length of straight path } \\
\mathbf{L} & =\text { length of tortuous path }
\end{aligned}
$$


Table 1. Correlations for diffusion coefficients in water.

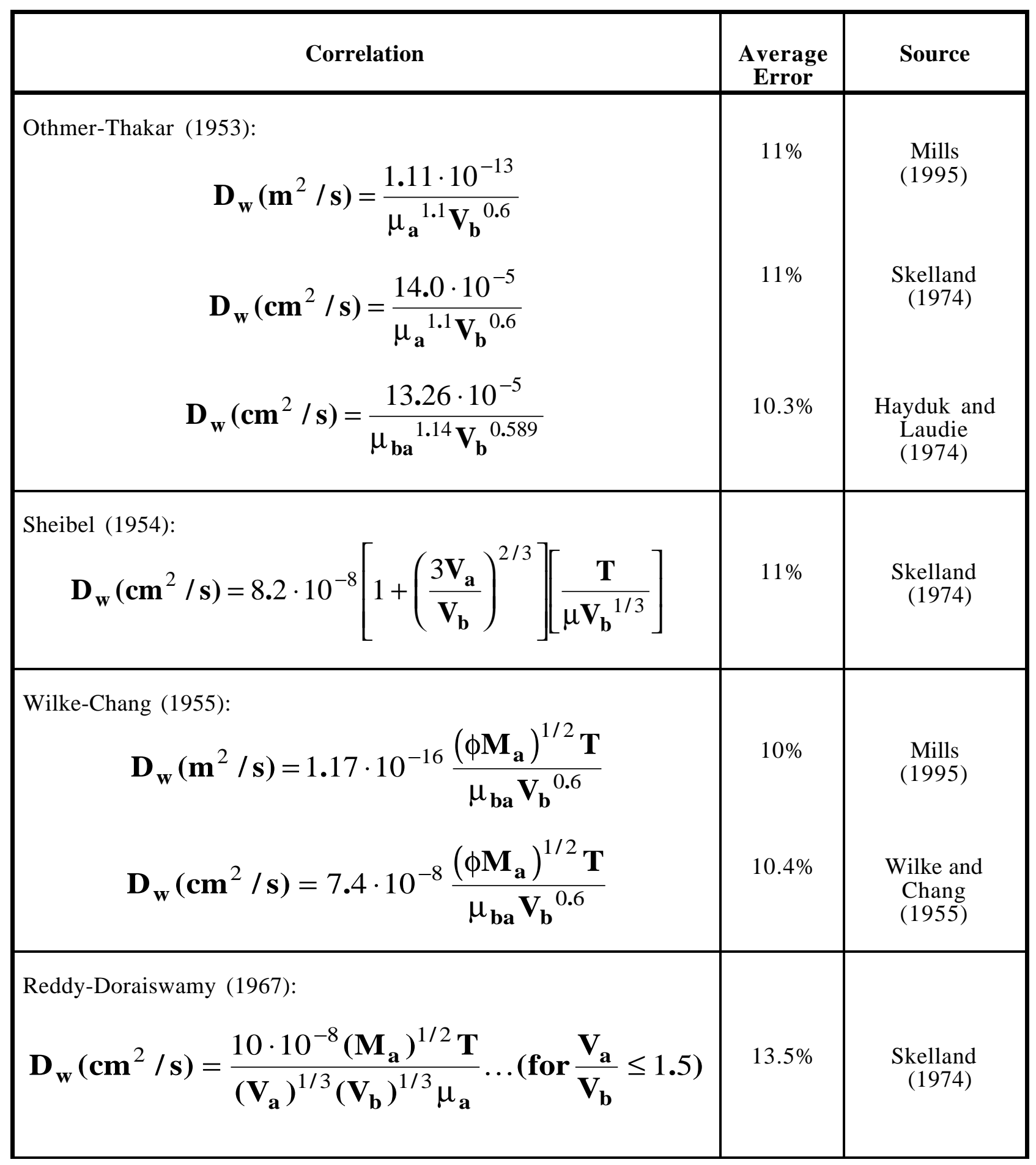

(continued on next page) 
Table 1. (cont.)

\begin{tabular}{|c|c|c|}
\hline $\begin{array}{l}\text { Nakanishi (1978): } \\
\qquad \mathbf{D}_{\mathbf{w}}\left(\mathbf{c m}^{2} / \mathbf{s}\right)=\frac{9.97 \cdot 10^{-8}}{\left(\mathbf{I}_{\mathbf{b}} \mathbf{V}_{\mathbf{b}}\right)^{1 / 3}}+\frac{2.4 \cdot 10^{-8} \mathbf{A}_{\mathbf{a}} \mathbf{S}_{\mathbf{a}} \mathbf{V}_{\mathbf{a}} \mathbf{T}}{\mathbf{I}_{\mathbf{b}} \mathbf{S}_{\mathbf{b}} \mathbf{V}_{\mathbf{b}} \mu_{\mathbf{a}}}\end{array}$ & $11 \%$ & $\begin{array}{l}\text { Reid } \\
\text { (1987) }\end{array}$ \\
\hline $\begin{array}{l}\text { Hayduk-Minhas }(1982) \text { : } \\
\left.\mathbf{D}_{\mathbf{w}}\left(\mathbf{c m}^{2} / \mathbf{s}\right)=\left(1.25 \cdot 10^{-8}\right)\left(\mathbf{V}_{\mathbf{b}}^{-0.19}-0.292\right) \mathbf{T}^{1.52} \mu^{\left(\frac{9.58}{\mathbf{V}_{\mathbf{b}}}-1.12\right)}\right) \\
\mathbf{D}_{\mathbf{w}}\left(\mathbf{c m}^{2} / \mathbf{s}\right)=\left(1.25 \cdot 10^{-8}\right)\left(\mathbf{V}_{\mathbf{b}}^{-0.19}-0.365\right) \mathbf{T}^{1.52} \mu^{\left(\frac{9.58}{\mathbf{V}_{\mathbf{b}}^{-1.12}}\right)}\end{array}$ & $9.4 \%$ & $\begin{array}{l}\text { Reid } \\
\text { (1987) }\end{array}$ \\
\hline $\begin{array}{l}\text { where: } \\
\mathbf{A}_{\mathbf{a}}=\text { Nakanishi Parameter Value for Solvent }(2.8 \text { for water }) \\
\left.\mathbf{D}_{\mathbf{w}}=\text { Diffusion coefficient of solute b into solvent a (water }\right)\left(\mathrm{cm}^{2} / \mathrm{sec}\right. \\
\mathbf{I}_{\mathbf{b}}=\text { Nakanishi Parameter Value for Solute }(1 \text { for VOC) } \\
\mathbf{M}_{\mathbf{a}}=\text { Molecular weight of solvent }(18 \mathrm{~g} / \mathrm{mol} \text { for water) } \\
\mathbf{S}_{\mathbf{a}}=\text { Nakanishi Parameter Value for Solvent }(1 \text { for water }) \\
\mathbf{S}_{\mathbf{b}}=\text { Nakanishi Parameter Value for Solute }(1 \text { for VOC) } \\
\mathbf{T}=\text { Temperature }(300 \text { degrees Kelvin) } \\
\mathbf{V}_{\mathbf{a}}=\text { Molar volume of solvent at normal boiling point }\left(\mathrm{cm}^{3} / \mathrm{mol} \mathrm{or}^{3}\right. \\
\mathbf{V}_{\mathbf{b}}=\text { Molar volume of solute at normal boiling point }\left(\mathrm{cm}^{3} / \mathrm{mol} \mathrm{or}^{3} / 1\right. \\
\mu_{\mathbf{a}}=\text { Viscosity of solvent at temperature T }(0.867 \mathrm{cP} \text { or } 8.67 \mathrm{E}-04 \mathrm{~kg} / \\
\mu_{\mathbf{b a}}=\text { Viscosity of the solution at temperature T (same as above) } \\
\phi=\text { Wilke-Chang association parameter for solvent, dimensionless }(2\end{array}$ & $\begin{array}{l}\left.\mathrm{m}^{2} / \mathrm{sec}\right) \\
\text { mol) } \\
\text { fol) } \\
\text { for water }\end{array}$ & \\
\hline
\end{tabular}

Tortuosity is a function of the geologic medium, so if the sands for the experiment are packed consistently, the value of $t$ for each type of sand should be constant.

For diffusion in sediments $\mathrm{D}_{\mathrm{w}}$ is redefined as the effective diffusion coefficient (Bear, 1972):

$$
\mathbf{D}^{*}=\mathbf{D}_{\mathbf{w}} \cdot \tau
$$

where:

$$
\begin{aligned}
& \mathbf{D}^{*}=\text { effective diffusion coefficient }\left(\mathrm{cm}^{2} / \mathrm{sec}\right) \\
& \mathbf{D}_{\mathbf{w}}=\text { diffusion coefficient in water }\left(\mathrm{cm}^{2} / \mathrm{sec}\right)
\end{aligned}
$$


D* is also affected by the amount of sorption occurring during diffusion. The effect of sorption is represented by the retardation factor, $\mathrm{R}$. $\mathrm{D}^{*}$ can be redefined as the apparent diffusion coefficient, $\mathrm{D}_{\mathrm{A}} *$ (Shackelford, 1991):

where:

$$
\mathbf{D}_{\mathbf{A}} *=\frac{\mathbf{D} *}{\mathbf{R}}
$$

$$
\begin{aligned}
\mathbf{D}_{\mathbf{A}}{ }^{*} & =\text { apparent diffusion coefficient }\left(\mathrm{cm}^{2} / \mathrm{sec}\right) \\
\mathbf{R} & =\text { retardation factor }
\end{aligned}
$$

Since the reduction in diffusion rate described by $\mathrm{D}_{\mathrm{A}} *$ is defined as a function of retardation and tortuosity (see Eq. 3), these factors can be combined into a single coefficient, the diffusion reduction coefficient, $\mathrm{W}$, such that:

$$
\Omega=\frac{\tau}{\mathbf{R}}
$$

Eq. 3 can then be rewritten to apply to the results of our experiment so that

$$
\mathbf{D}_{\mathbf{A}} *=\mathbf{D}_{\mathbf{w}} \cdot \Omega
$$

\subsubsection{Calculating Retardation Factors}

Generally, the retardation factor is described as a ratio of the velocity of water to the velocity of the compound or as a function of the porous medium and partitioning (Freeze and Cherry, 1979)

$$
\mathbf{R}=\frac{\mathbf{V}_{\mathbf{H}_{2} \mathbf{O}}}{\mathbf{V}_{\text {VOC }}}=1+\mathbf{K}_{\mathbf{d}} \frac{\rho_{\mathbf{b}}}{\mathbf{n}}
$$

where:

$$
\begin{aligned}
\mathbf{V}_{\mathbf{H}_{2} \mathbf{O}} & =\text { velocity of water } \\
\mathbf{V}_{\mathbf{V O C}} & =\text { velocity of compound } \\
\mathbf{K}_{\mathbf{d}} & =\text { distribution coefficient } \\
\rho_{\mathbf{b}} & =\text { bulk density } \\
\mathbf{n} & =\text { porosity }
\end{aligned}
$$

Our traditional column experiments have shown that chloroform is not retarded (so $\mathrm{R}=1$ ) and thus acts as a tracer, approximating the velocity of water molecules. As a result, the tortuosity value obtained from the diffusion of chloroform should be representative of the sand. This value of $t$ is obtained by assuming that the value of $\mathrm{W}$ is equivalent to $t$ when there is no retardation (see Eq. 5).

$$
\text { Since } \Omega_{\mathrm{CHCl}_{3}}=\frac{\tau}{1} \text { and } \Omega_{\mathrm{VOC}}=\frac{\tau}{\mathbf{R}_{\text {vOC }}}
$$


Then $\Omega_{\text {VOC }}=\frac{\Omega_{\mathbf{C H C l}_{3}}}{\mathbf{R}_{\text {VOC }}}$

(or)

$$
\mathbf{R}_{\mathrm{VOC}}=\frac{\Omega_{\mathrm{CHCl}_{3}}}{\Omega_{\mathrm{VOC}}}
$$

\subsection{Methods}

An anodized aluminum box containing 20 cylindrical sockets is used to hold glass vials packed with saturated sand (Figure 1). The vials are $4.3 \mathrm{~cm}$ long with a diameter of $0.7 \mathrm{~cm}$, and a volume of $5.8 \mathrm{~cm}^{3}$. Two types of sand were used in the vials: Oklahoma No. 1, a finegrained, high purity quartz sand and a No. 3 coarse-grained sand. No detectable organic matter is present in either sand. Standard U.S. sieves were used to evaluate grain size of the sands (Table 2) and also to separate some of the Oklahoma No. 1 sand in order to create two well-sorted sands. A portion of the unsorted Oklahoma No. 1 sand was cleaned to remove a layer of clay minerals that coats the grains. The clay accounts for $0.2-0.3 \%$ of the original mass of the sand and is composed of illite, kaolinite, and clay-sized quartz.

In order to uniformly saturate and pack the vials with sand, a specialized packing device was developed. A plastic block holding 4 vials is attached to an industrial vibrator operated by

Table 2. Grain size and porosity values of the Oklahoma No. 1 and No. 3 sands used in the diffusion experiment.

\begin{tabular}{|c|c|c|c|c|}
\hline Sand Type & Description & $\begin{array}{c}\text { Sieve Number } \\
\text { (retained on) }\end{array}$ & $\begin{array}{c}\text { Grain Size } \\
\text { (m m) }\end{array}$ & Porosity \\
\hline OK\#1 & fine-grained, well-sorted & 140 & $0.11-0.15$ & 0.364 \\
\hline OK\#1 & fine-grained, well-sorted & 100 & $0.15-0.21$ & 0.361 \\
\hline OK\#1 & poorly-sorted & $50-270$ & $0.05-0.30$ & 0.351 \\
\hline OK\#1 & clean, poorly-sorted & $50-270$ & $0.05-0.30$ & 0.351 \\
\hline$\# 3$ & coarse-grained & 20 & $0.85-2.0$ & 0.394 \\
\hline
\end{tabular}




\section{Influent Ports Connected to Syringes}

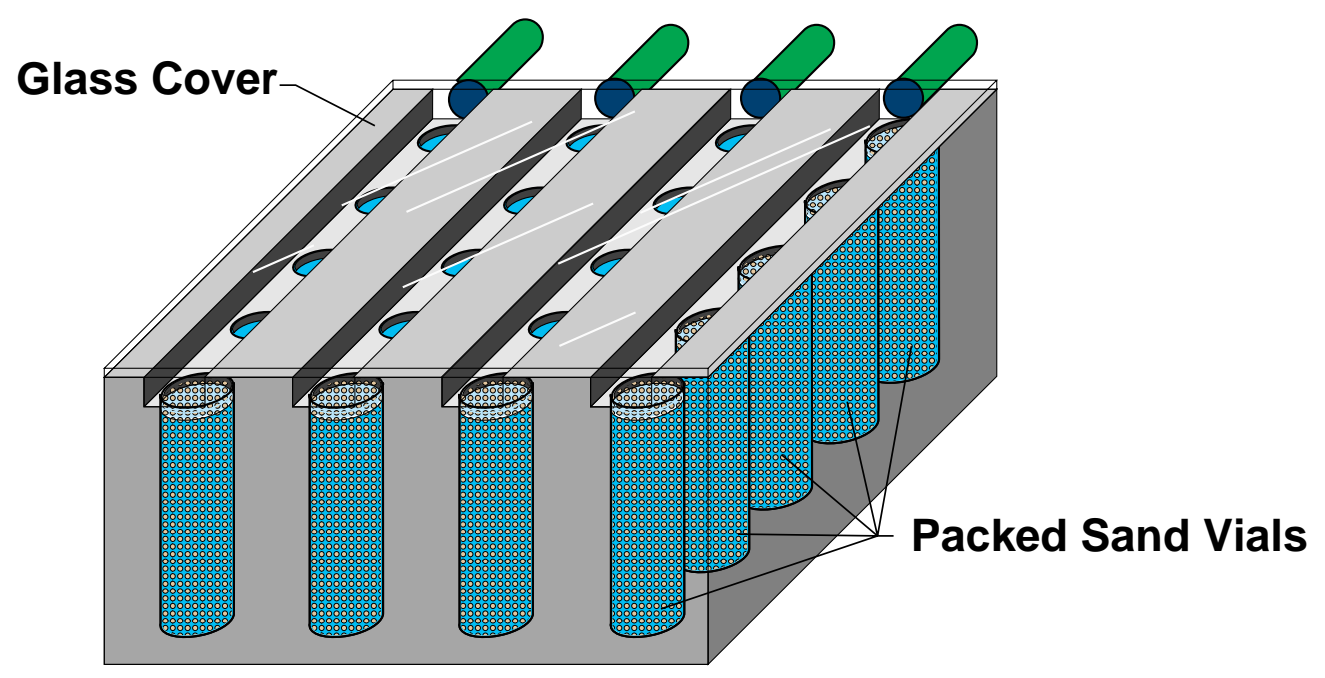

Figure 1. Schematic diagram of the box used to hold vials for the diffusion experiments. One syringe is attached to each influent port. After water is pumped over the tops of the vials, it exits through an effluent port on the opposite side.

compressed air. After the vials are partially filled with deionized water, the vibrator is started. Sand is pored into each vial until well above the rim (the sand is leveled to the top of the vials after removal from the packing block). All packed vials are vibrated for the same length of time in order to optimize uniform packing of the sand. Repeated quality checks of the vial packing technique have proven that the method is consistent. These comparisons are obtained by determining the porosity of the sand in the vials by using the standard method of calculating masses of dry and saturated samples. Porosities for each sand are listed in Table 2.

The packed vials are then placed in the aluminum box. The vials are arranged in 4 rows of 5 each and, generally, 4 vials of a particular sand are placed across the rows. The vials in each row are connected only by narrow channels across the top of the box. The tops of the vials are flush with the bottom of these channels. A glass lid is screwed onto the top of the box to enclose the channels and prevent volatilization of the VOCs. Pipes connect a syringe to each row so that water travels through narrow passageways to openings on the box's upper surface. The syringes are run by a pump, allowing the rate of flow to be set electronically.

Initially, the syringes are filled with deionized water. When pumping begins, the water flows over the top of the vials, since the vials are already saturated, and exits on the opposite side of the box. Water is continually pumped through the diffusion box, until all air bubbles have dissolved. The syringes are then filled with contaminated water. This stock solution is a mixture of $\mathrm{CHCl}_{3}, \mathrm{CCl}_{4}, \mathrm{PCE}$, and TCE, each at concentrations of $300 \mathrm{ppb}$. Samples are taken from each syringe and spiked with $2 \mathrm{~mL}$ of $100 \mathrm{ppb}$ chlorobenzene for quality control. The samples are analyzed by gas chromatography (GC) (U.S. EPA method no. 601) to determine the initial VOC concentrations for each syringe. The samples may be refrigerated up to 24 hours before analysis.

The contaminated water is pumped into each row of the diffusion box at a rate of $0.5 \mathrm{~mL} / \mathrm{hr}$ for 7 to 15 days. This pumping rate is faster than the rate of diffusion, which allows the vials to be in contact with a constant VOC concentration throughout the experiment. At the end of the experiment the glass cover is removed in order to extract the vials. Since vials are removed 
one at a time, deionized water is continually placed by pipette over the tops of remaining vials to prevent drying of the surfaces, which would allow volatilization of the VOCs. Once removed, each vial is crushed, dropped into a Dynatech soil volatile organic analysis vial (SVOA) and spiked with $2 \mathrm{~mL}$ of chlorobenzene. The VOC content of the saturated sand and crushed vial is then analyzed by GC.

\subsubsection{The Diffusion Model}

Diffusion in one-dimension can be described by Fick's second law of diffusion, which relates a change in concentration with time to a change in concentration with distance (Crank, 1956).

$$
\frac{\partial \mathbf{C}}{\partial \mathbf{t}}=\mathbf{D} \frac{\partial^{2} \mathbf{C}}{\partial \mathbf{x}^{2}}
$$

where:

$$
\begin{aligned}
\mathbf{C} & =\text { concentration } \\
\mathbf{t} & =\text { time } \\
\mathbf{D} & =\text { diffusion coefficient } \\
\mathbf{X} & =\text { distance }
\end{aligned}
$$

For this experiment the vials are considered a semi-infinite medium with the opening kept at a constant concentration. Therefore, at $\mathrm{t}=0$, no VOCs are within the vials $(\mathrm{C}=0)$ and for $\mathrm{t}>0$ the VOC concentration at the open end of the vials is equal to the concentration within the influent syringes. Application of these boundary conditions to Eq. 9 results in a complementary error function solution (Crank, 1956):

$$
\mathbf{C}_{(\mathbf{x}, \mathbf{t})}=\mathbf{C}_{\mathbf{o}} \cdot \operatorname{erfc} \frac{\mathbf{x}}{2 \sqrt{\left(D_{w} \cdot \Omega\right) t}}
$$

where:

$$
\begin{aligned}
\mathbf{C}_{(\mathbf{x}, \mathbf{t})} & =\text { concentration at time }(\mathrm{t}) \text { and location }(\mathrm{x}) \\
\mathbf{C}_{\mathbf{0}} & =\text { initial concentration in syringe }(\mu \mathrm{g} / \mathrm{L}) \\
\mathbf{x} & =\text { distance along length of vial }(\mathrm{cm}) \\
\mathbf{D}_{\mathbf{w}} & =\text { diffusion coefficient in water }\left(\mathrm{cm}^{2} / \mathrm{sec}\right) \\
\Omega & =\text { diffusion reduction coefficient } \\
\mathbf{t} & =\text { total time of diffusion experiment }(\mathrm{sec})
\end{aligned}
$$

We developed a computer model based on Eq. 10, which we used to determine W. The model is designed so that a vial is divided into $0.05 \mathrm{~mm}$ thick horizontal sections in order to generate an average VOC concentration for each section (determined by Eq. 10). The model uses a vial length which is twice the length of the actual vial, in order to compensate for any molecules that may have reached the bottom of the vial. The computed concentration is then multiplied by the volume of the section to produce an average VOC mass. Masses for all the sections are then integrated and multiplied by the porosity, so that the total mass is equal to the experimental VOC mass. The program duplicates the contaminant mass reported by the laboratory by adjusting the value of $\mathrm{W}$ in Eq. 10, until the distribution of mass in the vial 
equals the actual mass. The model evaluates each contaminant for each vial individually. The values of $\mathrm{W}$ derived from the computer model are used in Eq. 8 to calculate retardation factors for $\mathrm{CCl}_{4}$, TCE, and PCE.

\subsection{Results and Discussion}

Median tortuosity factors and retardation factors are shown in Table 2 and Figure 2. The tortuosity factors derived from $\mathrm{CHCl}_{3}$ range from 0.2 to 0.8 . Other researchers report experimental tortuosity factors to be $0.5-0.01$ for porous geologic materials (Freeze and Cherry, 1979) and 0.84-0.01 for saturated soils (Shackelford, 1991). Perkins and Johnston (1963) review 4 diffusion studies that generated tortuosity factors of 0.5-0.8. Experiments by Gillham and others (1984) produced tortuosity factors of 0.84 and 0.70 for fine-grained silica sand (34\% porosity) for studies with chloride and tritium, respectively. Bear (1972) suggests a theoretical estimate of 0.67 is appropriate for unconsolidated materials.

According to Fetter (1993), higher tortuosity factors (indicating shorter flow paths) are found in well-sorted sands, since smaller grains are not partially filling the pore spaces. Our experimental results show that tortuosity factors for the fine-grained, well-sorted sand range between 0.6 and 0.8 , whereas the tortuosity factors of coarse-grained sands have an average value of 0.4 . The tortuosity factors of poorly sorted sands show a wide range of values (0.20.8 ). This scatter may be a result of variations between the sands in each vial, in terms of the proportion of grain sizes and the availability of fines for filling pore spaces.

The cumulative distribution curves shown in Figure 3 show differences in retardation factors between sand types. Statistical analyses (Kruskal-Wallis, Mann-Whitney) suggest that these differences are statistically significant, except possibly between coarse and unsorted, clay-coated sands. These curves indicate that more sorption occurs in fine-grained sand. This increase in retardation may be a result of increased surface area. It is uncertain from the experimental results if the clay coating has an effect on sorption, although the statistical analyses indicate the differences between the unsorted clean and clay sands are significant.

All the retardation factors for TCE and PCE are relatively low because no organic carbon is present in the sediments. These low values are also seen in our column experiments. However, unlike retardation factors from the column experiments, the differences in the diffusion experiment results for TCE and PCE in the same sand type are insignificant. The $\mathrm{CCl}_{4}$ retardation factors are larger than expected. We believe that a characteristic of $\mathrm{CCl}_{4}$ is influencing its behavior in a way which we are not able to interpret at this time. It is possible that the high volatility of $\mathrm{CCl}_{4}$ is causing more $\mathrm{CCl}_{4}$ to volatilize relative to the other $\mathrm{VOCs}$, perhaps during the transfer to an SVOA.

Many of the VOC retardation factors are less than 1, which means the VOCs are diffusing faster than chloroform. However, we believe that physical and chemical characteristics of $\mathrm{CCl}_{4}$, TCE, and PCE prevent these VOCs from diffusing faster than $\mathrm{CHCl}_{3}$. These characteristics include size, solubility, and volatility. They are described in Table 3 and quantified in Table 4. 
Table 3. Values of diffusion reduction coefficients (W) determined from the diffusion model and retardation factors $(\mathrm{R})$ calculated from Eq. 8. These are median values calculated from 5 experiments.

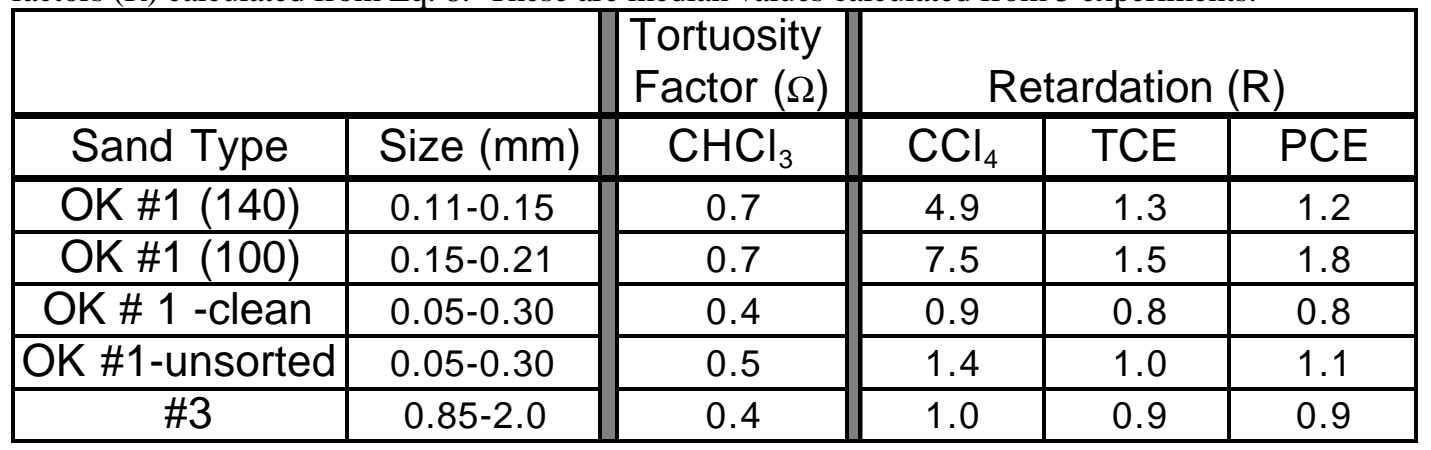

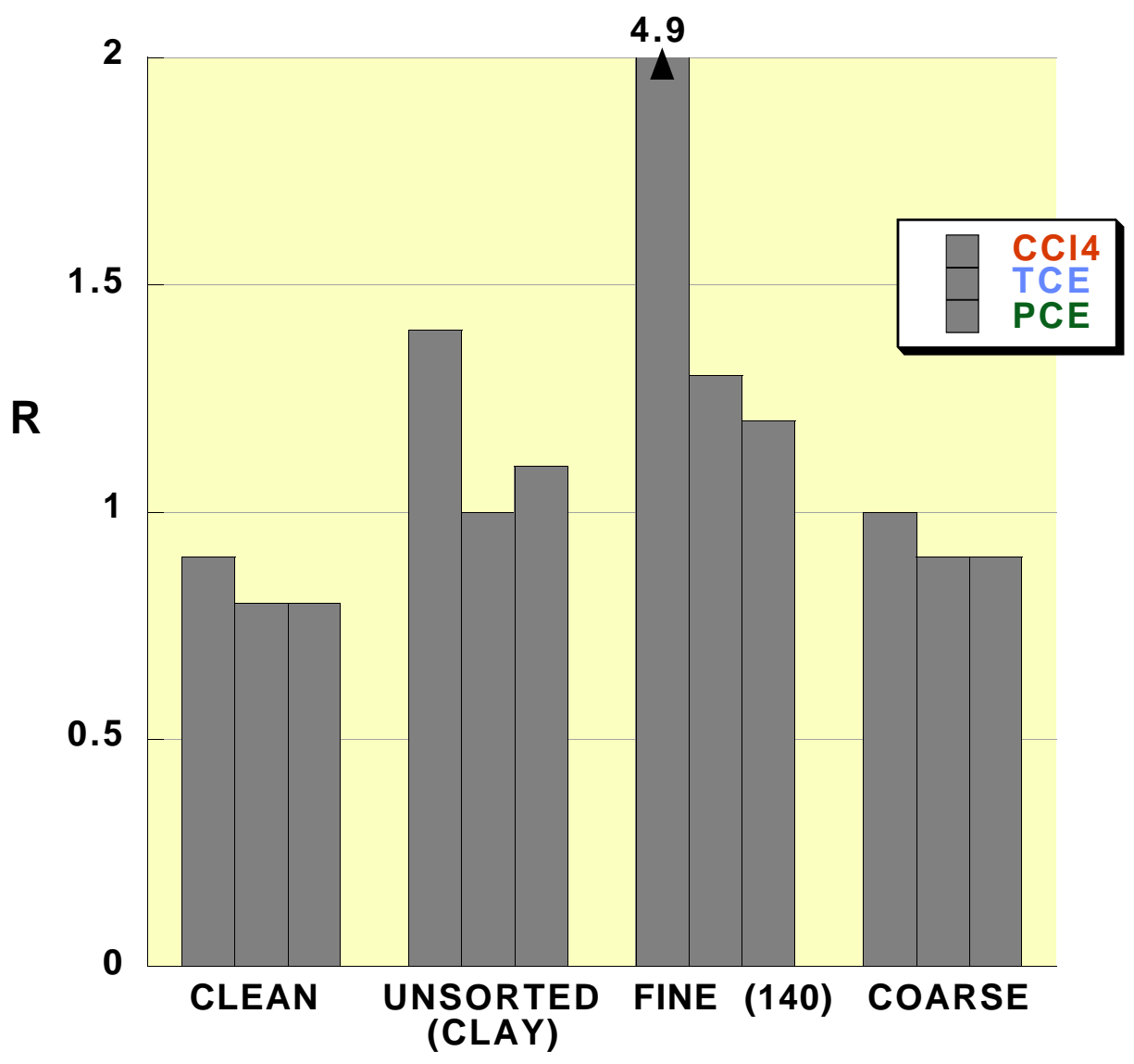

Sand Type

Figure 2. Chart of median retardation factors listed in Table 3 for different VOCs and different sands used in the diffusion experiments. 


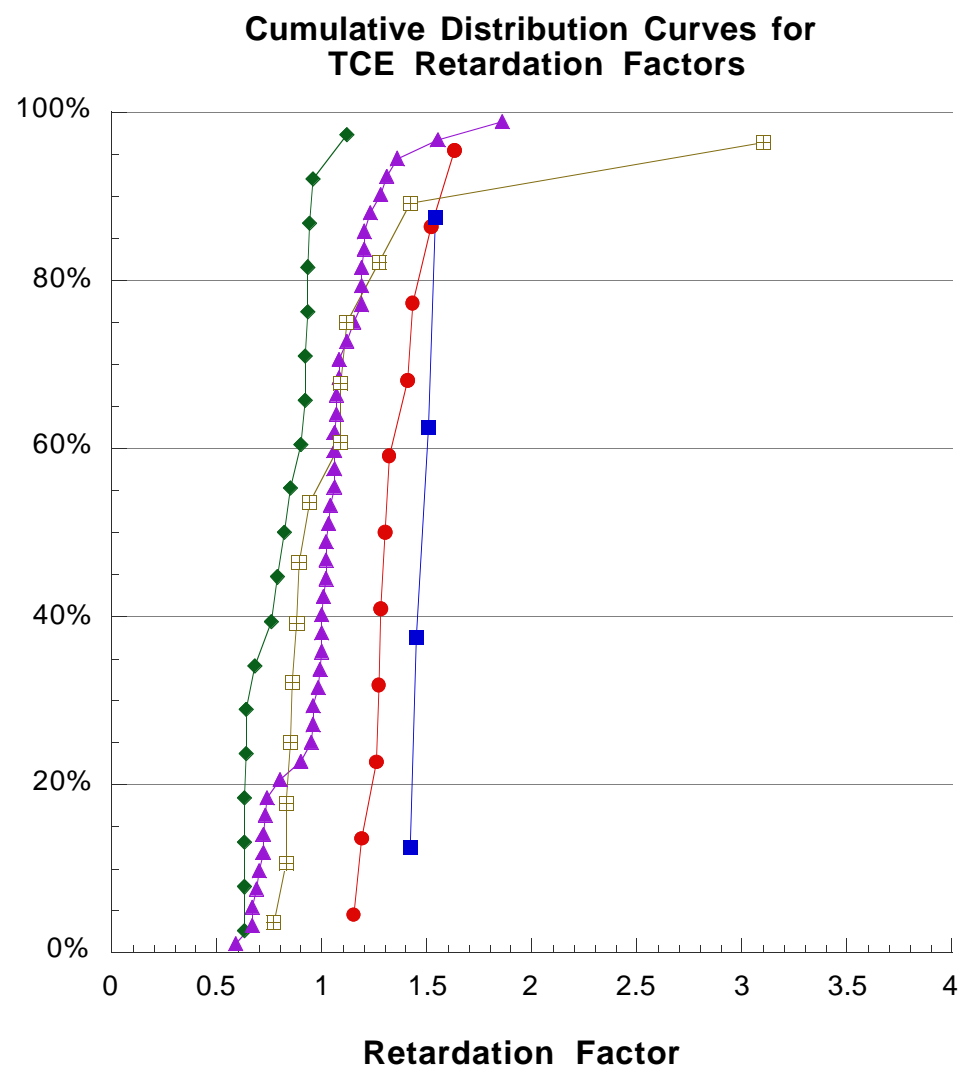




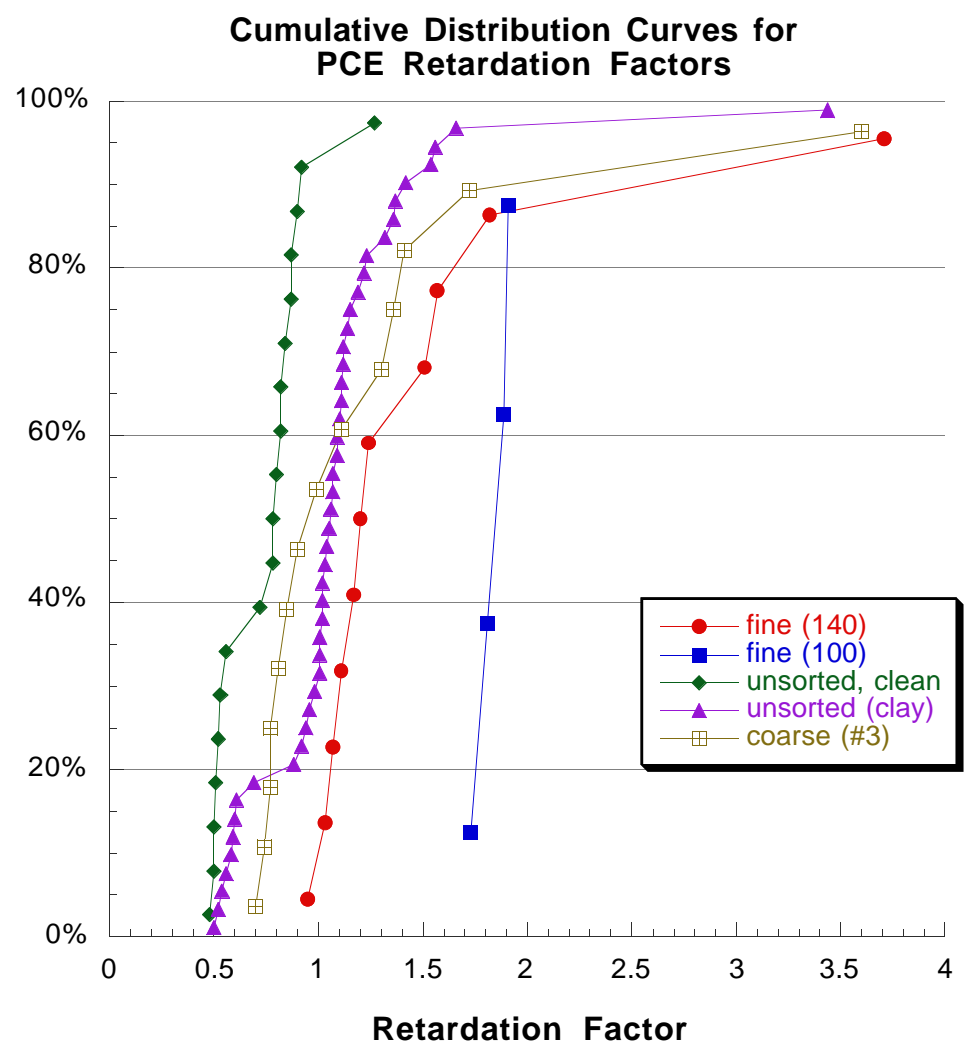

Figure 3. These cumulative distribution curves show differences in retardation values for TCE and PCE in the different sand types used in the experiment. These curves are representative of statistical analyses, which show that the larger retardation factors for fine-grained, wellsorted sands and the smaller values for clean sand are statistically significant. Markers on the curves represent all data collected from 5 diffusion experiments. 
The retardation factors are perhaps quantitatively inaccurate, but provide good qualitative indications of VOC behavior. When analyzing the data with correlation coefficients (Pearson, Spearman), strong correlations exist between TCE and PCE for each sand type, except for finegrained, well-sorted sand. The strong correlations indicate that our results do not contain random errors and that all VOCs are being affected by an experimental factor in the same way. The weaker correlation for fine-grained sand may indicate more error is involved in calculated retardation factors for that sand.

\subsection{Errors in Experimental Methods}

Problems with the setup and execution of the experiment may be contributing to inaccuracies in VOC mass results. If a reported mass is low, the retardation value will significantly increase. Potential problems include:

- Poor accuracy of VOC detection by GC

**Differences in mass values between 2 detectors are as large as $70 \mathrm{ng}$, which changes a retardation factor by $150 \%$.

- Increased mass: potential for the contaminated water to leak into the space between the vials and the slots the vials are contained in (although the outside of the vials are wiped before being placed in sampling containers)

- Decreased mass: loss of mass to volatilization during the vial crushing procedure

- Decreased mass: placement of clean water over the vials while they are being removed from the diffusion box may cause mass to be lost in run-off

- Disturbed transport: layering formed in vials during packing of sand can disrupt transport processes

One advantage of the experiment is that the tendency for some VOCs to stick to the inner surface of the vials will not obscure results because the entire vial is analyzed. However, the differing amount of sorption onto the glass vial compared to the sediments may affect the results.

Problems may also exist with the conceptual and computer models used for the experiment. Tortuosity and retardation may not be the only factors involved in slowing the diffusion of VOCs. Also, assuming the vials to be semi-infinite and using Eq. 10 for calculations can affect the accuracy of the results. Currently, the model integrates mass over 2 vial lengths.

Despite uncertainties in the determination of the diffusion coefficient $\left(\mathrm{D}_{\mathrm{w}}\right)$ minor variation in $\mathrm{D}_{\mathrm{w}}$ values causes insignificant changes in the results of the computer model. 


\subsection{Conclusions}

1) After describing reduced rates of diffusion in sediments by tortuosity and retardation, we were able to determine these factors through a combination of laboratory experimentation and computer modeling. Our apparatus can be used to measure the apparent diffusion of VOCs into aquifer materials.

2) Tortuosity factors calculated from these experiments are consistent with those reported in the literature. In well-sorted materials, coarse-grained sediments have a smaller tortuosity factor than do fine-grained sediments.

3) Insignificant differences in retardation factors are seen between TCE and PCE; $\mathrm{CCl}_{4}$ results are anomalous and require further investigation. Differences in sorption between sand types are shown to be statistically significant. Fine-grained sands seem to promote more sorption.

4) Experimental methods need to be revised in order to more accurately quantify retardation factors of VOCs. 
Table 4. Physical and chemical characteristics of compounds which may affect diffusion of VOCs.

\section{CHARACTERISTIC \\ EFFECT \\ IMPLICATIONS}

molecular volume

(diffusion coefficient)

solubility

(octanol-water partition coefficient)

volatility

(Henry's Law Constant) larger molecules tend to diffuse more slowly

increased size reduces solubility; less soluble compounds are more prone to sorb to solids

tendency to evaporate results in a loss of mass
PCE has the largest molar volume and thus the smallest diffusion coefficient. It will diffuse at a rate slower than the other VOCs regardless of sorption potential.

PCE has the lowest solubility and therefore the highest sorption potential.

$\mathrm{CCl}_{4}$ has the highest volatility. This may explain the low mass results for $\mathrm{CCl}_{4}$, which give it large retardation values. $\mathrm{CHCl}_{3}$ has the lowest volatility, so mass values would be more accurate. 
Table 5. Characteristics of VOCs used in the diffusion experiment. Relative differences in these values may correlate to variations in diffusion rates and behaviors. (Montgomery and Welkom, 1990)

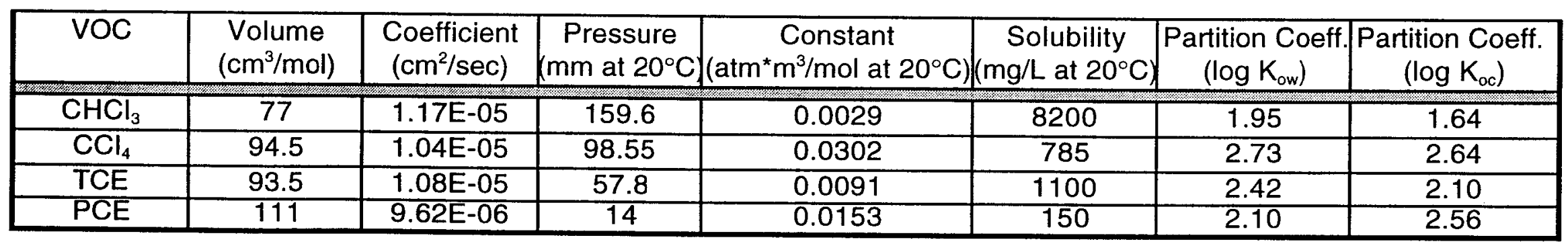




\section{Literature Cited}

Allen-King, R. M., R. W. Gillham, and D. M. Mckay (1996), "Sorption of Dissolved Chlorinated Solvents to Aquifer Materials" in Dense Chlorinated Solvents and other DNAPLS in Ground water, J. F. Pankow, and J.A. Cherry, Eds. (Waterloo Press, Oregon) pp. 234-266.

Bear, J. (1972), Dynamics of Flow in Porous Media (American Elsevier Publishing Co., New York).

Crank, J. (1956), The Mathematics of Diffusion (Clarendon Press, Oxford).

Fetter, C. W. (1993), Contaminant Hydrology (Prentice Hall, Englewood Cliffs, N.J.).

Fetter, C. W. (1994), Applied Hydrogeology, 3rd ed., (Prentice Hall, Englewood Cliffs, N.J.).

Freeze, R. A., and J. A. Cherry (1979), Ground water (Prentice Hall, Englewood Cliffs, N.J.)

Gillham, R. W., M. J. L. Robin, D. J. Dytynyshyn, and H. M. Johnston (1984), "Diffusion of Nonreactive and Reactive Solutes through Fine-grained Barrier Materials," Canadian Geotechnical Journal 21, 541-550.

Hayduk, W., and H. Laudie (1974), "Prediction of Diffusion Coefficients for Non-Electrolytes in Dilute Aqueous Solutions," A.I.Ch.E. Journal 20, 611-615.

Hayduk, W., and B. S. Minhas (1982), "Correlations for Prediction of Molecular Diffusivities in Liquids," Canadian Journal of Chemical Engineering 60, 295-299.

Hoffman, F., R. G. Blake, Z. Demir, R. J. Gelinas, P. F. McKereghan, and C. D. Noyes (1997), “A Conceptual Model and Remediation Strategy for VOCs in Low Organic Carbon Unconsolidated Sediments," Lawrence Livermore National Laboratory, Livermore, California (UCRL-JC-125199).

Mills, A. F. (1995), Heat and Mass Transfer (Richard D. Irwin, Inc., Chicago, Ill.).

Perkins, T. K., and O. C. Johnston (1963), "A Review of Diffusion and Dispersion in Porous Media," Society of Petroleum Engineers Journal, 3, 70-84.

Reid, R., J. M. Prausnitz, and B. E. Poling (1987), The Properties of Gases \& Liquids, 4th ed., (McGraw-Hill, New York, N.Y.).

Shackelford, C. D. (1991), "Laboratory Diffusion Testing for Waste Disposal -- A Review," Journal of Contaminant Hydrology 7, 177-217.

Schwarzenbach, R. (1993), Environmental Organic Chemistry (John Wiley \& Sons, Inc., New York, N.Y.).

Skelland, A. P. (1974), Diffusional Mass Transfer (John Wiley \& Sons, Inc., New York, N.Y.).

Wilke, C. R., and P. Chang (1955), "Correlation of Diffusion Coefficients in Dilute Solutions," A.I.Ch.E. Journal 1, 264-267.

Montgomery, J.H., and L.M. Welcom. 1990. Groundwater Chemicals Desk Reference. Lewis Publishers, Chelsea, Michigan. 


\title{
Adaptive Grid Computational Model of VOC Transport Across Fine- and Coarse-grained Sediment Contacts
}

\author{
E.T. Brown, S.K. Doss, F. Hoffman, R.J. Gelinas, K. Fox, \\ J. O'Boyle
}

\section{ABSTRACT}

The diffusion of contaminants across geological contacts between high-hydraulic conductivity (HK) and low-hydraulic conductivity (LK) zones is an important factor in determining time to remediate contaminated ground water. To better understand this process, we constructed a model of volatile organic compound (VOC) transport through the low organic carbon sediments found at the Lawrence Livermore National Laboratory (LLNL) Superfund Site in Livermore, California. Adaptivegrid finite element modeling (FEM) analysis provided us with the capacity to accurately resolve disparate-scale transport mechanisms at geological interfaces. We considered the dominant terms of the advection-dispersion (ADE) partial differential equation (PDE) in HK and LK zones to define an effective domain (solution space) and valid boundary conditions.

We represented the heterogeneous facies change between LK and HK zones with a graduated transition zone based on geological and lithologic plots of the Superfund Site. This representation speeds computation and allows us to examine the effect of transition zone gradation on VOC transport. To gain further insight into the complex properties of VOC transport across the transition zone, we solved the 1-D diffusion equation analytically under various initial conditions.

We verified that our algorithm solves the ADE in accordance with both the analytical solution of the diffusion equation and our conceptual model of VOC transport. Preliminary model results also approximately match field data collected during LLNL Environmental Restoration Division (ERD) pump and treat remediation. We performed analytic and numerical sensitivity analyses on the parameters that characterize the domain of our model. This analysis showed that $20 \%$ uncertainty in several model parameters and especially in HK zone hydraulic conductivity has a significant effect on remediation predictions.

\subsection{INTRODUCTION}

Field data collected during the first seven years of pump and treat remediation of ground water containing volatile organic compounds (VOCs) at the Lawrence Livermore National Laboratory (LLNL) Superfund Site in Livermore, California indicate that ground water contaminant plumes can be divided into two distinct parts: distal areas and source areas. While source areas are the starting points for distal plume formation, it should be noted that the definition of source area used here does not imply the presence of a source term, or flux, of contaminant into the subsurface. As shown in Figure 1, distal-plume contamination is largely found in high-hydraulic conductivity (HK) sediments, while source areas are characterized by high contaminant concentrations in zones of varying hydraulic conductivity (Hoffman et al, 1997) (National Resource Council, 1994). Thus, remediation of source areas involves contaminant transport through the entire matrix of HK and low-hydraulic conductivity (LK) formations and the geological contacts between them.

As advection rates in HK zones are orders of magnitude higher than those in the LK regions which they border, HK zones tend to quickly flush clean under the large hydraulic gradients used in pump and treat remediation. Meanwhile, VOCs remain in LK zones for long periods of time. Contaminants 
diffuse slowly from these stagnant zones into neighboring HK regions, where they are advected downgradient to the distal plume (Hoffman et al, 1997). The rate at which this process, called matrix diffusion, occurs is of great practical significance. In order to maintain aquifer (HK) contaminant concentrations below regulatory limits at all points in the ground water plume, source area LK zones must be remediated until their capacity to contaminate adjacent aquifers has been sufficiently diminished. To better understand this capacity of contaminant source areas, we constructed a model of VOC transport across geological contacts.

Although many models currently exist that use a fixed solution grid for the simulation of advectiondominated contaminant transport (CFEST (Gupta, 1997), FEFLOW(Diersch, 1996)), our problem cannot be solved efficiently and accurately using these algorithms. This is because we require the ability to resolve processes which occur simultaneously at disparate scales: the relatively-fast process of advection through HK zones, the slow mechanisms of diffusive transport out of LK zones, and the intermediate-rate processes occurring at the interface. In the regime of sharp geological interfaces, near-discontinuities in hydraulic conductivity further contribute to disparate scaling in our problem, as we require resolution of advection rates differing by many orders of magnitude over a very small range. To resolve these disparate rates, we solve the governing equations of ground water flow and VOC transport using the PDEase code (Macsyma, 1995). PDEase is an adaptive-grid Finite Element Analysis (FEM) program with the capability to generate the necessary nodal density and configuration of the solution grid.

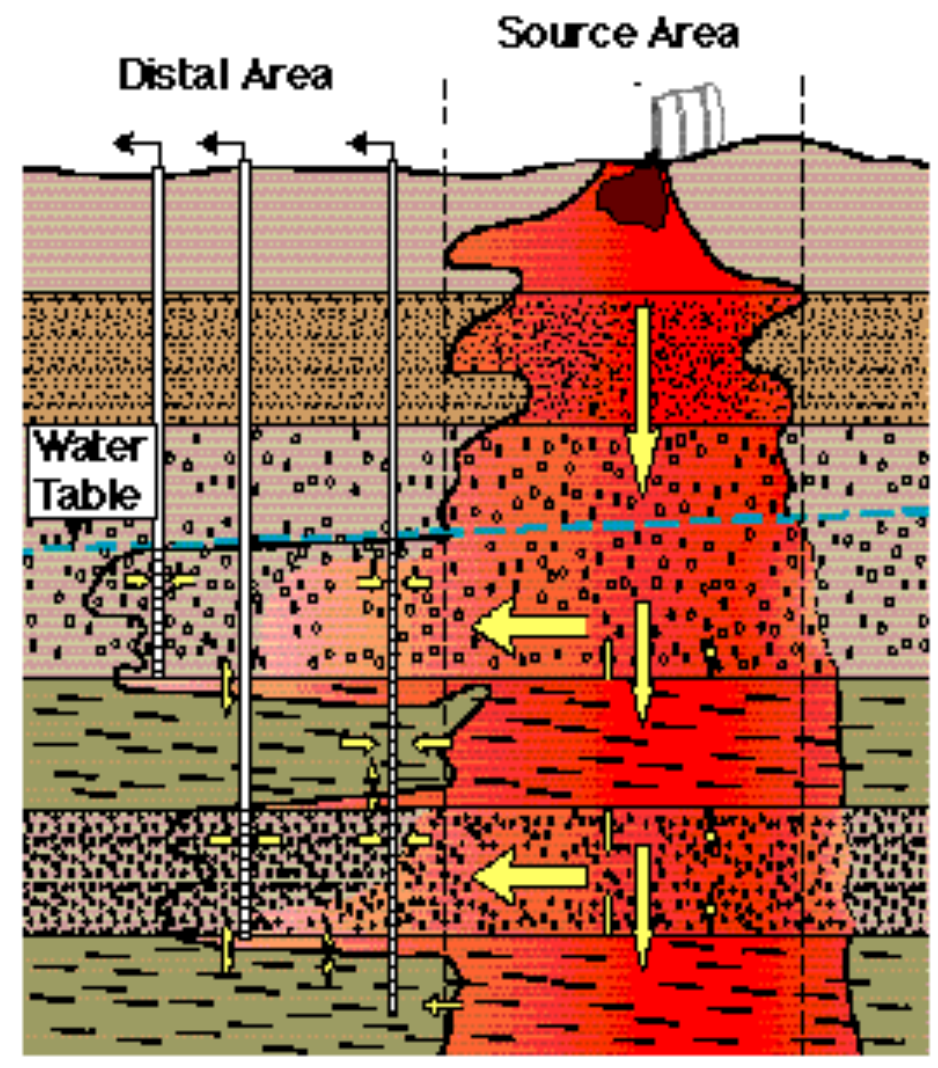

Figure 1. Conceptual Model of VOC Plumes.

The specific goals of this modeling effort are to:

- examine contaminant transport across geological boundaries between areas of low and high hydraulic conductivity 
- resolve the interface between HK and LK zones into a transition zone of variable gradient

- $\quad$ solve the advection-dispersion transport equation with sufficient accuracy to allow analysis of the sensitivity of our solution to uncertainty of some of the parameters governing VOC transport

- use this information to estimate the capacity of LK zones to act as contaminant reservoirs during source-area pump-and-treat cleanup operations.

\subsection{NUMERICALANALYSIS METHODOLOGY}

\subsubsection{DESCRIPTION OF COMPUTATIONAL ALGORITHM}

The adaptive-gridding capability of our algorithm is essential to accurate modeling of source area VOC transport. This is because the grid characteristics required to resolve disparate-scale VOC transport processes change as the solution to the governing partial differential equations (PDEs) evolves, yet it is generally difficult to predict what the necessary solution grid configuration and local density distribution will be as a function of time. Our algorithm eliminates the need to this by automatically refining its solution grid to user-defined error limits at every time step. As an example, we show in Figure 2 the high density of the solution grid at the large concentration gradients adjacent to the HK / LK interface.
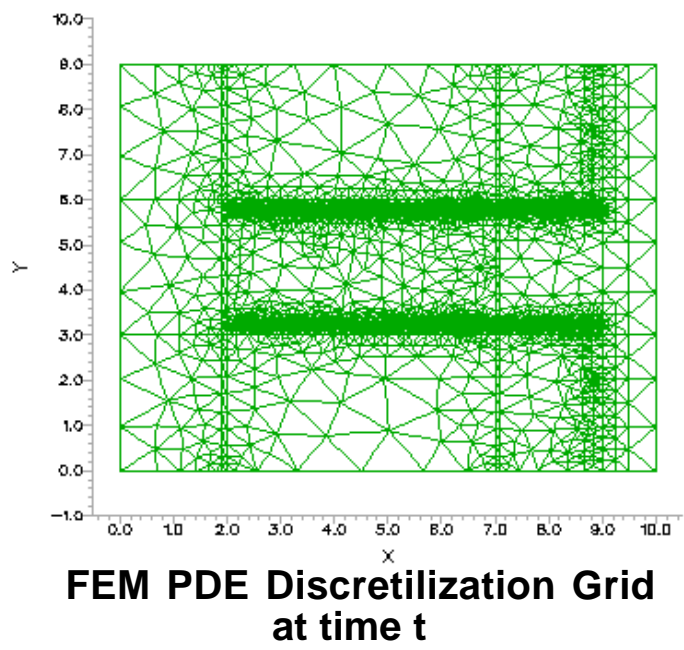

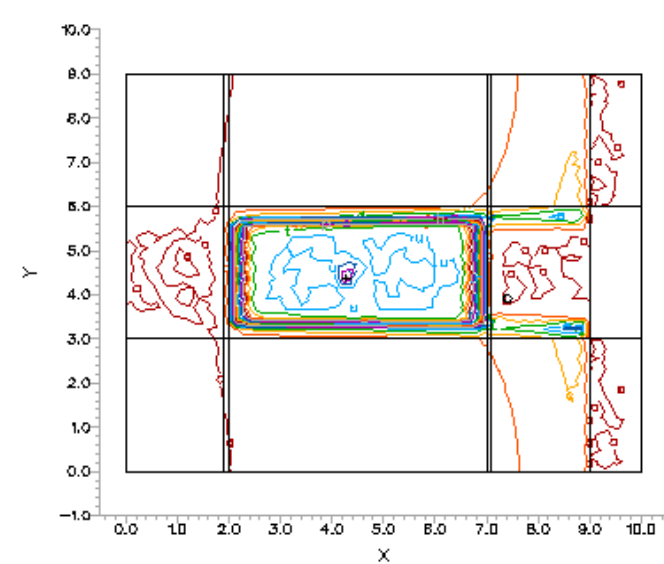

Concentration Isocontours at time $\mathrm{t}$

Figure 2. Refinement of PDEase discretilization grid at time t.

Further, instead of forming an orthogonal solution grid from rectangular elements, our algorithm constructs its grid from triangular and isoparametric elements. This flexible approach allows the generation of the nodal configurations necessary to resolve disparate scales and to accurately conform to complex domain geometry.

Our algorithm allows us to select the order of the polynomial functions used to interpolate its solution between nodes. We found that second-order interpolation functions were the most computationally efficient, and we used these functions throughout the modeling process. 


\subsubsection{APPLICATION OF THE ALGORITHM TO INVESTIGATION OF VOC TRANSPORT ACROSS GEOLOGICAL CONTACTS}

\subsubsection{Description of Decoupled Analysis and Governing Equations of Ground Water Flow}

Our model performs decoupled analysis of ground water flow and contaminant transport equations, in which the groundwater flow problem is solved first and the resulting fluid velocities are used as parameters in the solution of the contaminant transport equation. This approach is admissible because contaminant transport does not effect the ground water flow field. Because we are solving the two equations in independent models, we can adjust and evaluate flow and transport parameters, boundary conditions, and equation forms separately. In doing so, we found that decoupling the PDE system also greatly speeds computation.

We assume a steady state distribution of hydraulic head, and determine spatially-dependent ground water hydraulic head values from the solution of the PDE:

$\nabla \cdot \mathrm{K} \nabla \mathrm{h}=0$

with appropriate boundary conditions as discussed below.

We assume that ground water advection follows Darcy's Law (Fetter, 1994):

$v=\frac{k \nabla h}{\varphi}$

where,

$v=$ ground water advection velocity

$K=$ hydraulic conductivity

$h=$ hydraulic head

$\varphi=$ porous medium porosity.

\subsubsection{Governing Equations of VOC Transport}

Ground water velocities generated from the solution of (1) are provided as parameters in the solution of the Advection-Dispersion Equation (ADE). (Cherry and Freeze, 1979)

$$
R \frac{\partial C}{\partial t}=-\nabla \cdot(v C)+\nabla \cdot(D \nabla C)
$$

where,

$v \quad=$ ground water advection velocity 


$$
\begin{aligned}
& R=\text { retardation factor } \\
& C=\text { VOC concentration } \\
& D=\text { diffusion coefficient }
\end{aligned}
$$

We solve the ADE for $\mathrm{C}(\mathrm{x}, \mathrm{y}, \mathrm{t})$, VOC concentration as a function of time and twodimensional (2-D) spatial coordinates.

\subsubsection{Analysis of the Diffusion Coefficient}

Our model of diffusive contaminant transport includes both velocity-dependent (hydrodynamic dispersion) and velocity-independent (molecular diffusion) terms. In order to construct $D$, a diffusion coefficient incorporating both dispersion and diffusion, we define:

$D=D_{\text {hydrodynamic }}+D_{\text {molecular }}$

where,

$D_{\text {hydrodynaix }}=$ hydrodynamic dispersion coefficient

$D_{\text {molecular }}=$ molecular diffusion coefficient

and,

$D_{\text {hydrodynamic }}=\left[\begin{array}{ll}D_{11} & D_{12} \\ D_{21} & D_{22}\end{array}\right]$

where,

$D_{i j}=\alpha_{T} \bar{v} \delta_{i j}+\left(\alpha_{L}-\alpha_{T}\right) v_{i} v_{j} / \bar{v}$

$D_{i j}=$ hydrodynamic dispersion tensor

$\alpha_{T}=$ transverse hydrodynamic dispersivity

$\alpha_{L}=$ longitudinal hydrodynamic dispersivity

$\delta_{i j}=$ Kronecker Delta operator

$D_{\text {molecular }}=D_{w} \cdot \Omega$

where,

$D_{\text {molecular }}=$ molecular diffusion coefficient

$D_{w} \quad=$ VOC diffusion coefficient in water

$\Omega \quad=$ porous medium tortuosity. 
and,

Dhydrodynamic $=\left[\begin{array}{ll}\mathrm{D}_{11} & \mathrm{D}_{12} \\ \mathrm{D}_{21} & \mathrm{D}_{22}\end{array}\right] \nabla \mathrm{C}+\mathrm{I} \cdot \mathrm{D} * \nabla \mathrm{C}$.

where,

I = identity matrix

\subsubsection{Form of ADE}

Our algorithm allows us to choose between two methods of solving the ADE: direct differentiation and integration by parts over the domain. The method is determined by the form in which individual terms of the ADE are written. PDEase integrates the ADE by parts when we input the terms in Gaussian (div, grad, curl) form (eq. 9):

$\mathrm{R} \frac{\partial \mathrm{C}}{\partial \mathrm{t}}=-\nabla \cdot(\mathrm{vC})+\nabla \cdot(\mathrm{D} \nabla \mathrm{C})$

PDEase directly differentiates the ADE when we write the ADE in explicit-form (eq. 10):

$$
R \frac{\partial C}{\partial t}=-\frac{\partial\left(C v_{x}\right)}{\partial x}+-\frac{\partial\left(C v_{y}\right)}{\partial y}+\frac{\partial}{\partial x}\left(D \frac{\partial C}{\partial x}\right)+\frac{\partial}{\partial y}\left(D \frac{\partial C}{\partial y}\right)
$$

Solutions obtained by direct differentiation are generally less stable (containing more numerical artifact, or "noise") than those obtained from integration by parts. However, we found that the most-stable ADE solutions resulted from a mixed solution methodology: direct differentiation of first-order terms but integration of second-order terms by parts. This may be a result of our algorithm's treatment of the boundary term resulting from integration by parts of the first-order ADE term (11). We suspect that our algorithm's application of boundary conditions (BCs) to this boundary term could overdetermine the first-order BCs, possibly leading to inconsistency in boundary condition definition and hence instability in the ADE solution.

$\nabla \cdot(v C)=\nabla \cdot\left(\frac{k \nabla h}{\phi} C\right)$ 
To resolve this problem, while still taking advantage of the increased stability resulting from integration by parts of second order terms, we write the ADE as:

$R \frac{\partial C}{\partial t}=-\frac{\partial\left(C v_{x}\right)}{\partial x}+-\frac{\partial\left(C v_{y}\right)}{\partial y}+\nabla \cdot(D \nabla C)$

\subsubsection{Verification of the Model}

After the governing equations and solution methodology were defined, we verified that our model was capable of generating reliable solutions to the classical ADE. To this end, we used our model to solve a problem for which an analytical solution already exists. We performed a simple coordinate transformation on the 1-D diffusion equation to obtain an analytic, or (here) closed-form, solution to the one-dimensional (1-D) ADE (equations 13-17).

1-D diffusion equation:

$R \frac{\partial C}{\partial t}=D \frac{\partial^{2} C}{\partial x^{2}}$

initial and boundary conditions:

$\mathrm{C}=\mathrm{C}_{0}$ at $\mathrm{x}=0$,

$\mathrm{C}=0$ elsewhere, $\forall t$

analytic solution, $\quad C_{\text {exact }}=C_{0} \cdot \operatorname{erfc}\left(\frac{x}{2 \sqrt{D t / R}}\right)$

Coordinate transformation:

$x=\boldsymbol{s}-v t$

$t=\tau$

where,

$$
\begin{aligned}
& \mathrm{x}=\text { position } \\
& t=\text { time } \\
& v=\text { ground water velocity }
\end{aligned}
$$

Then, where 1-D ADE: 
$R \frac{\partial C}{\partial t}=-v \frac{\partial C}{\partial x}+D \frac{\partial^{2} C}{\partial X^{2}}$

we have,

analytic solution, $C_{\text {exact }}=C_{0} \cdot \operatorname{erfc}\left(\frac{x-v t / R}{2-\sqrt{D t / R}}\right)$

Results from FEM analysis of the 1-D ADE match the analytic solution within the adjustable error limit of the FEM scheme. In Figure 3, we show the solutions converging precisely at the practical error limit of one part in ten-thousand.

\section{Initial 1 Year of 3 Years of Condition Transport Transport}
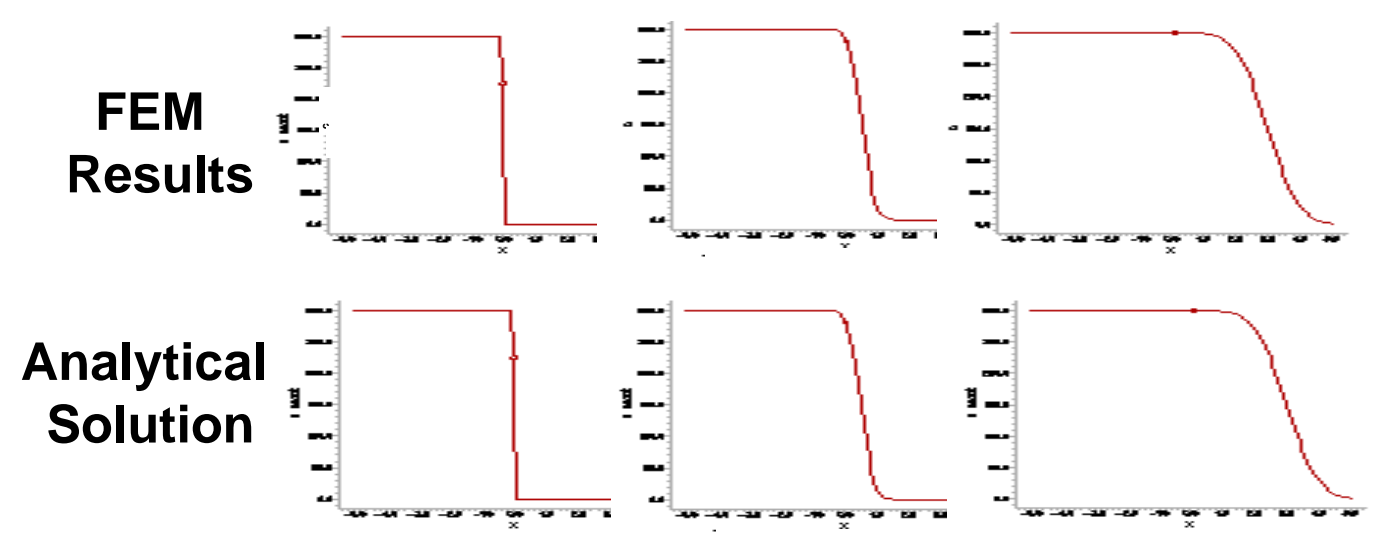

Figure 3. Convergence of FEM analysis and analytical solutions for the 1-D ADE. 


\subsection{DESCRIPTION OF NUMERICAL MODEL OF VOC TRANSPORT ACROSS GEOLOGICAL CONTACTS}

\subsubsection{Definition of Model Domain}

We constructed a domain, or solution space, to simulate characteristic source-area conditions near the LLNL Treatment Facility A (TFA). The boundaries of our domain define a vertical cross section of the subsurface that is 9 meters in the vertical (y) direction by 300 meters in the horizontal (x) direction. We defined these dimensions to be large enough to incorporate several source area geological interfaces but small enough to avoid introducing excessive solution area and hence slowing the computational speed of the model. We examined geological and geophysical data gathered by the LLNL ERD to determine representative location of HK and LK zones and the gradation of their interfaces. Figure 4 shows this data interpreted according to the hydrostratigraphic unit (HSU) approach of "layer cake" regions (Hoffman et al., 1997) to define three horizontal layers. These layers include a fine-grained zone between two coarse-grained regions, and are characterized by subsurface parameters of hydraulic conductivity, tortuosity, porosity, and retardation.

To help us to visualize our results and to slightly increase the efficiency of our algorithm, we operate the FEM scheme on a solution space which is one-tenth the length of the cross section of the subsurface that we are modeling, or 9 units in the y-direction by 30 units in the $\mathrm{x}$-direction. This scaling, shown in figure 4, results in an approximately 1 to 3 object ratio, or ratio of maximum extents, of the $\mathrm{y}$ to $\mathrm{x}$ dimensions.

The 1 to 3 object ratio (as compared to an approximately 1 to 30 object ratio for the unscaled domain) allows for the desired vertical grid resolution to be attained after a smaller number of iterations from the initial grid. This is because the vertical and horizontal density of the original grid is defined in rough accordance with object ratio.

The scaling transformation is accomplished by scaling $\mathrm{x}$ by a factor of ten: we simply multiplythe coordinate $\mathrm{x}$, the infinitesimal $\mathrm{dx}$, and horizontal length-dependent parameters such as $\alpha$ by $1 / 10$ wherever they appear in our code. The inverse transformation (multiplying by horizontal length scales by 10) allows us to interpret our results in terms of the subsurface cross section. Because the transformations embodying this scaling procedure simply involve multiplying by a constant or a constant times the identity matrix, trivial symbolic computation shows that the process does not alter model results.

\subsubsection{Boundary Conditions of Ground Water Flow}

We assume a steady-state hydraulic head distribution during each of the two phases that we model: a period of active pump and treat remediation (hydraulic head gradient $=.025$ ) and the ambient ground water conditions that follow (hydraulic head gradient $=.005$ ). Further, we assume that the head induced by extraction wells is represented by a constant gradient (linear head distribution) throughout the domain. To realize these distributions, we assign different fixed hydraulic head values to the left and right boundaries of our domain during each phase, set no flux boundary conditions on the top and bottom of our domain, and solve eq. 1 for $h$. The ground water flow boundary conditions are shown in figure 5. 

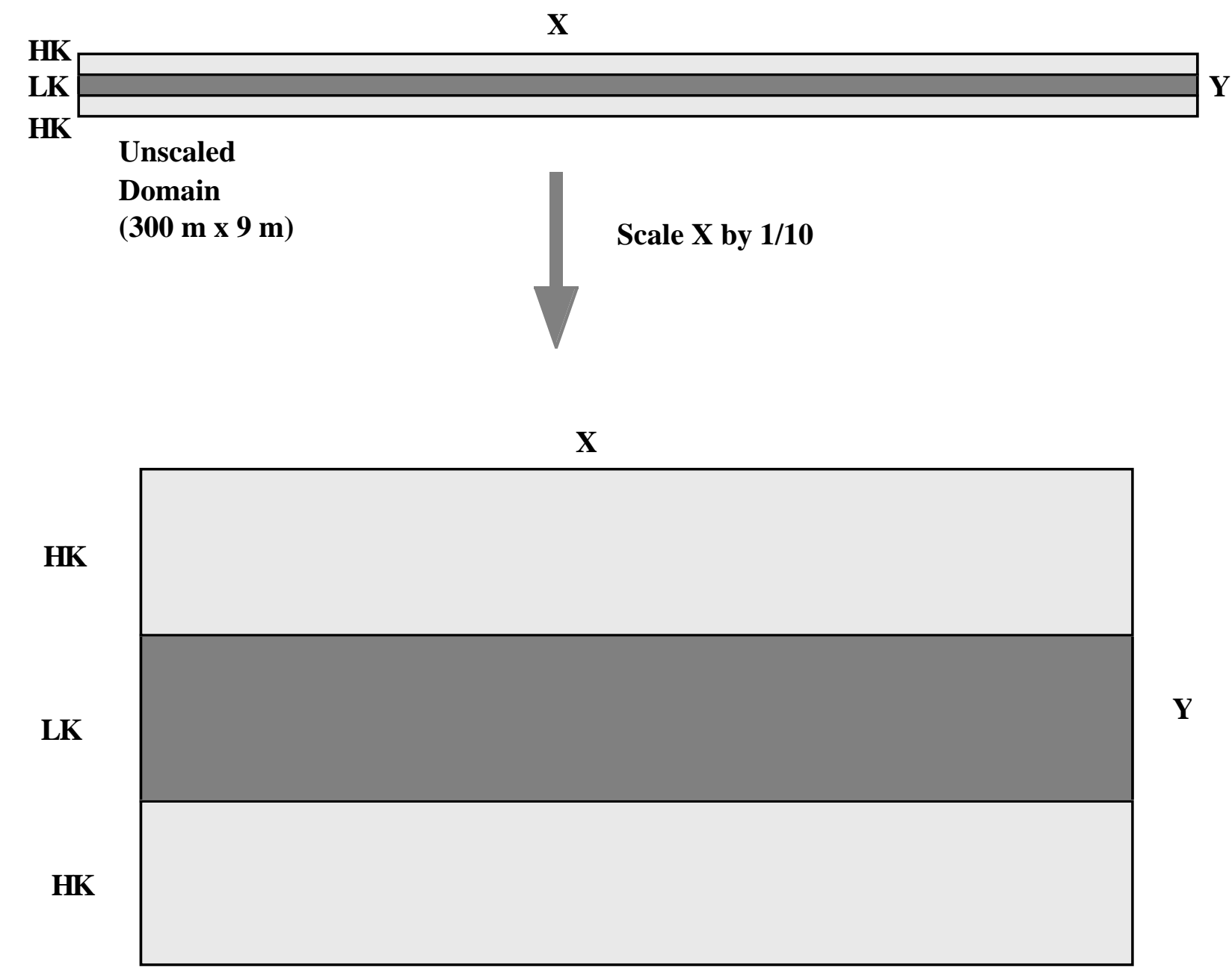

Scaled

Domain

$(30 \mathrm{~m} \times 9 \mathrm{~m})$

Figure 4. The domain of our model. Note scaling to reduce x:y object ratio. 


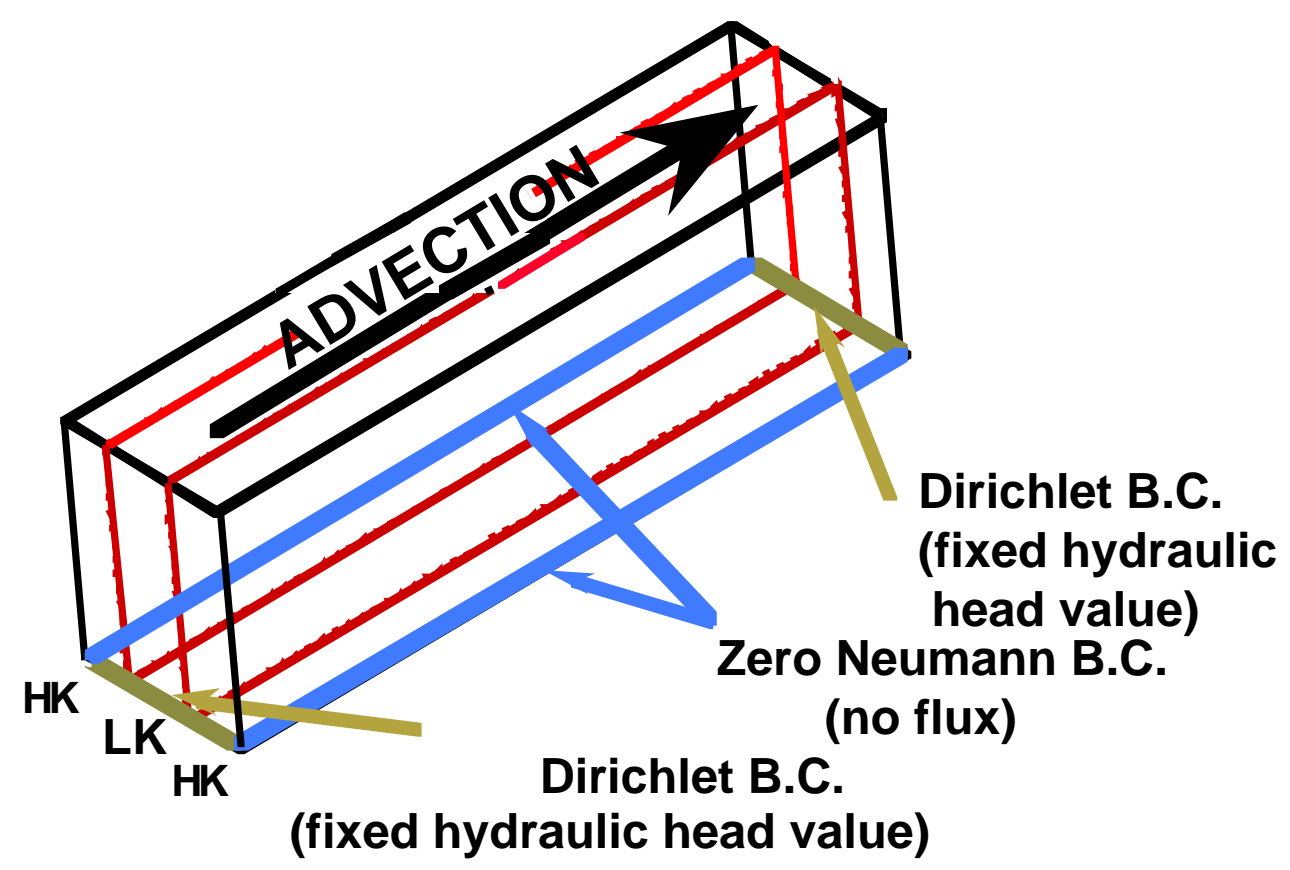

Figure 5. Boundary conditions of ground water flow.

\subsubsection{PROPERTIES OF GROUND WATER FLOW}

\subsubsection{Resolution of Geological Interfaces}

Our algorithm resolves the complex concentration gradients that form near source-area geological contacts by refining its solution grid. The local nodal density resulting from this process scales roughly with the magnitude of the local concentration gradient. Where local concentration gradient becomes nearly discontinuous, then, local nodal density greatly increases. This maintains the accuracy of the solution (while computational speed is reduced).

Nearly discontinuous concentration gradients tend to form adjacent to sharp geological boundaries. This happens as VOCs are rapidly flushed out of HK zones under simulated pump and treat remediation while contaminants in LK zones, where ground water advection rates are orders of magnitude slower, are left behind. Geological and geophysical data from the southwest corner of LLNL indicates that geological contacts are not sharp, but are characterized by transition zones over which the facies change from HK to LK sediments occurs. Figure 6 shows the lithologic and geophysical plots from which we derived characteristic transition zone thicknesses. Over the width of the transition zone from HK to LK, ground water advection rates decrease gradually, resulting in a smoothing of the rate at which contaminants are flushed out of sediments. This, in turn, results in graduation of the VOC concentrations left in the sediment at any given time, and hence in a concentration gradient that is smoothed across the geological interface and easier for our algorithm to resolve. 

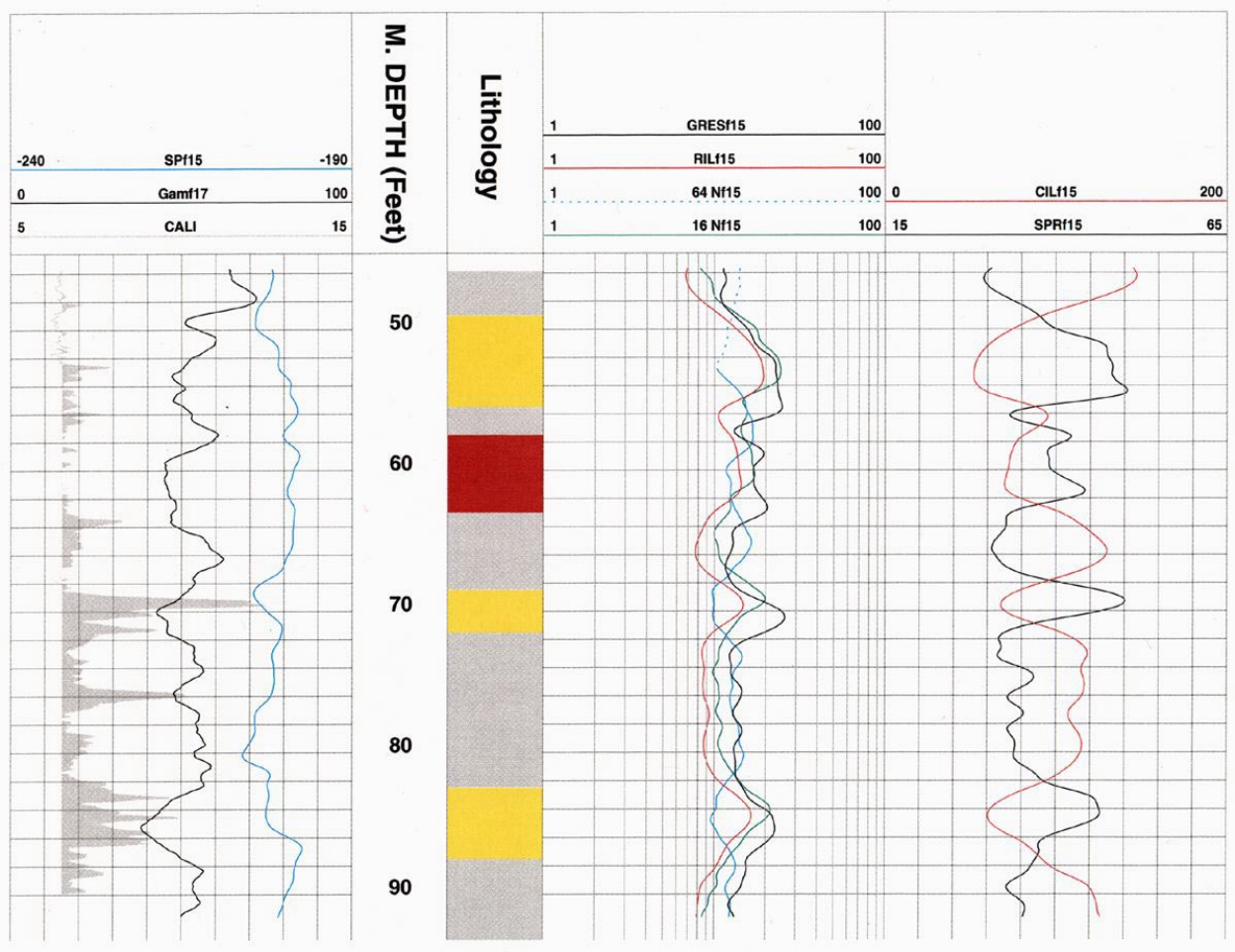

Figure 6. Lithologic and geophysical plots from which we derived the transition zone thicknesses.

We chose a high-order Gaussian, or "Super Gaussian," function to simulate the facies change:

$$
K(y)=K_{h}-\left(K_{h}-K_{l}\right) \cdot e \frac{-\left(y-y_{0}\right) n n}{\varepsilon}
$$

where,

$K_{h}=$ HK Hydraulic conductivity

$K_{l}=$ LK Hydraulic conductivity

$y_{0}=$ midpoint of LK region

$\varepsilon \quad=$ width of LK region

$n n=$ Super Gaussian exponent (determines slope of curve).

This smoothing function introduces the capacity to model transition zones of variable gradient, and hence introduces a new parameter: interfacial texture, or the variable gradation of the transition zone. Because hydraulic conductivity, tortuosity, retardation, and porosity, the parameters which define soil type in our model, are all smoothed in accordance with the Super Gaussian function, we attempt to match the interfacial smoothing parameter to the various geologic boundary geometries we observe in lithologic plots of the area we are studying. 
Different values of $n n$ result in different degrees of interfacial smoothing, ranging from very sharp to very gradual gradation. A sharp boundary, such as that represented below by $n n$ $=40$, is characterized by the little or no interfacial mixing between bordering subsurface layers An example of this situation is a coarse gravel bed lying directly on top of fine clay sediments. A gradual boundary, such as that represented by $n n=8$, results from a smooth transition, or blending, of HK and LK materials at the geological contact. Representative examples of this case include a clay/sand/gravel transition with interfacial-zone mixing of the above materials. $n n=40$ and $n n=8$ boundary characterizations are shown in Figure 7.
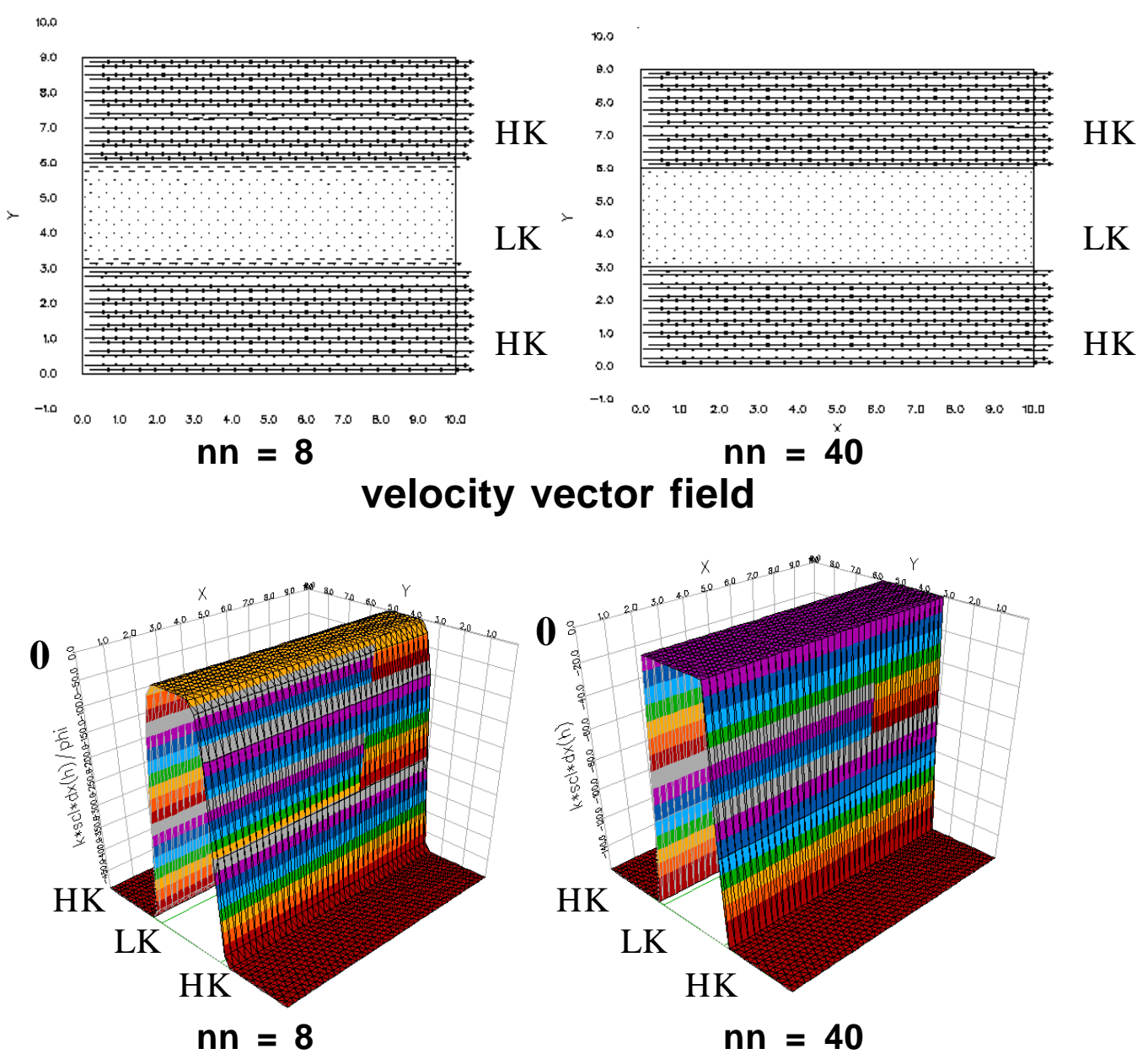

velocity surface plot

Figure 7. Interfacial smoothing between HK and LK zones: gradual $(\mathrm{nn}=8)$ and sharp $(\mathrm{nn}=40)$ boundaries.

\subsubsection{Continuity and smoothing in the ADE solution process}

Our choice of smoothing function was motivated by the fact that the Super Gaussian, as opposed to some other common smoothing functions \{ such as the linear ramp), is an analytic function. Here, analytic implies that all orders of the derivative of the function exist and are continuous throughout the domain. To see the importance of this property, we examine the 
second order term of the ADE: $\quad \nabla \cdot D(x, y, t) \nabla C(x, y, t)$

As discussed above, the form of both $C(x, y, t)$ and $D(x, y, t)$ in the transition zone is determined by the smoothing function. Therefore, if the smoothing function is continuously differentiable, then $D \nabla C$ (the product of two analytic functions) is continuous. This guarantees that divergence of $D \nabla C$ will be resolvable by our algorithm.

\subsubsection{Conceptual Model of the Effect of Variation in Transition Zone Gradient}

If we are to draw the correlation between a smooth, idealized transition zone and the subsurface itself, we must ask ourselves exactly what it is that we are varying the simulation of when we change the transition zone thickness. The obvious answer is simply: the gradation of the facies change. But a thicker transition zone could also represent a baseline facies change with a highly nonideal (heterogeneous) interface. This is because additional transition zone smoothing results in higher advective rates inside a region that would otherwise be homogeneously LK. In other words, the smoothing could represent either a gradual facies change or the existence of geometrical nonideality (cracks or fissures on the macroscopic scale, or fractal complexity on the pore scale) in the geological interface. In this vein, we expect that actual, heterogeneous geological contact surface areas are greater than those represented by a simple layercake model. We may compensate for this discrepancy with the existence of the transition zone, as suggested by figure 8 .

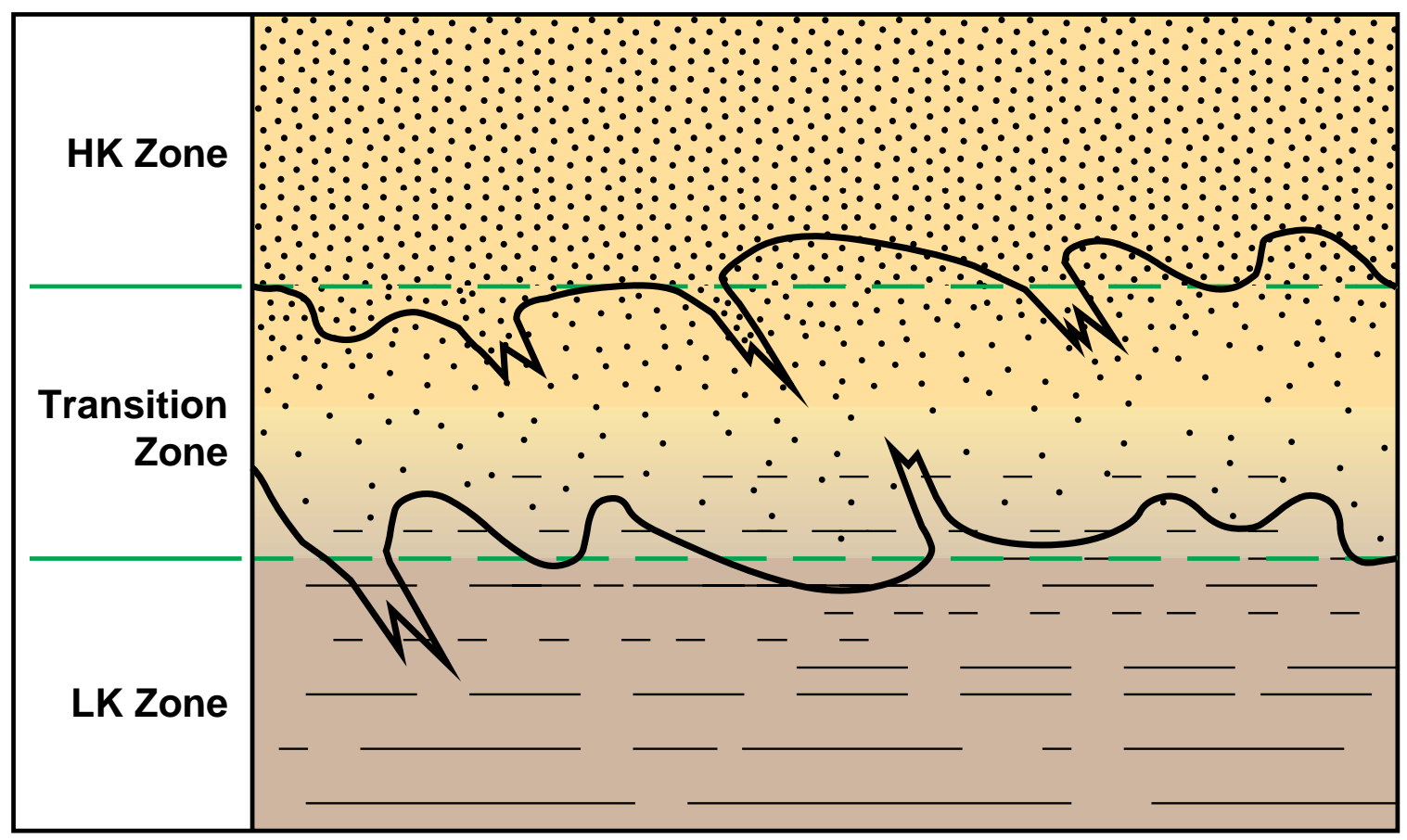

ERD-LSR-98-0030

Figure 8. The transition zone representation of a heterogeneous geological contact. Note that interfacial variation is averaged over the graduation of the transition zone. 
At a given concentration gradient, more contaminant mass will be diffused across geological contacts with higher surface areas. If layercake representation of geological contacts does underestimate this surface area, the correlation between field data and computational results demonstrated below suggests that the transition zone successfully compensates for this effect.

\subsubsection{An analytical examination of the effects of interfacial smoothing in hydraulic conductivity}

Having hypothesized that the degree of interfacial geological contact between coarse-and fine grained zones will have a significant effect on the results of our simulation, we again turn to analytical solution techniques for the 1-D diffusion equation. This time, the goal of our analytic analysis is insight into the transport processes involved. The graduated retention of contaminants in the LK / HK transition zone (as described above under "Resolution of geological interfaces" results in concentration gradients which are also smoothed through the transition zone. Due to the complexity of the ADE solution in our multilayered domain, the response of the transition-zone concentration gradients to various degrees of interfacial smoothing is not necessarily linear, so we cannot predict exactly what the concentration profile through this zone will be. However, our results verify the intuitive idea that smoother transition zones, such as those suggested by TFA area lithologic and geophysical data, tend to produce smoother concentration gradients on the boundaries of LK zones.

We considered the diffusion occurring over two representative concentration gradients: discontinuous gradients described by the step function and very smooth gradients described by the Gaussian function. The step function approximates the distribution of concentration near a sharp geological interface (such as that resulting from the Super Gaussian with $n n=40$ ), while the Gaussian represents a gradual interface (note that the Super Gaussian becomes a Gaussian function when we set $n n=2$ ). The two functions, normalized to represent contaminated zones polluted with the same mass of VOCs, are plotted in figure 9.

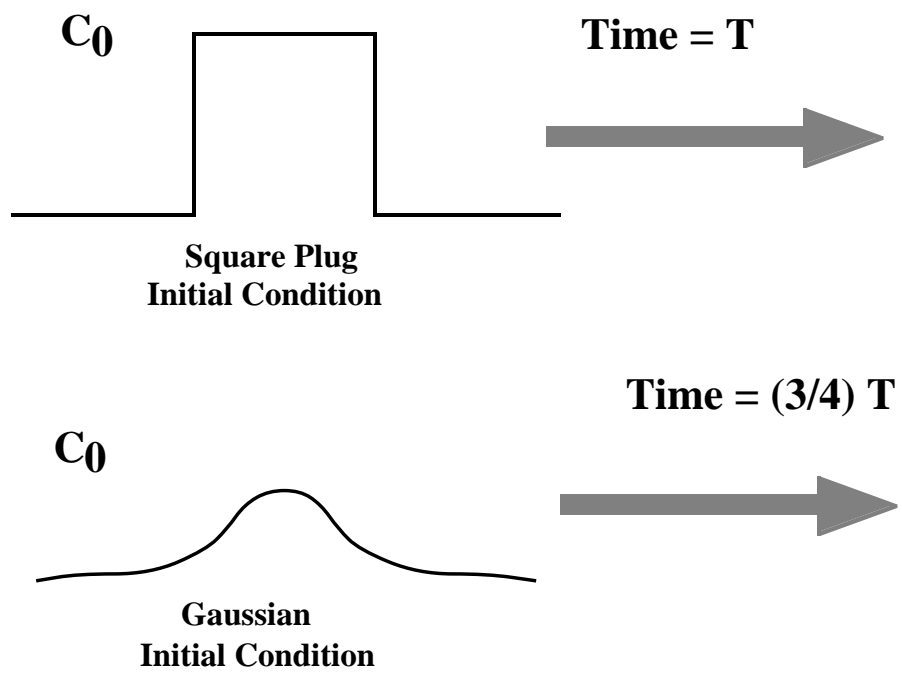

$(1 / 2) C_{0}$

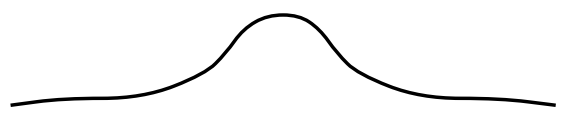

Square Plug

nitial Condition
$(1 / 2) C_{0}$

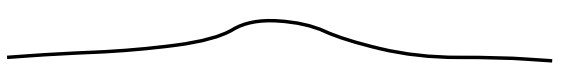

Figure 9. The diffusion of a square plug and a Gaussian initial distribution of the same contaminant mass. Half-lives for the two distributions are $\mathrm{T}$ and $3 / 4 \mathrm{~T}$, respectively. 
Examining concentration half lives at the origin helps us to understand the relationship between rates of interfacial smoothing and rates of VOC diffusion across these interfaces. The cause of this decrease in LK contaminant concentrations at the origin is the transfer of mass away from the center of the LK zone and across the geological boundary into HK sediments. The average rate of this transfer scales approximately (with nonlinearity due to the variation in gradation of differently-diffused contaminant plumes) with the inverse of the half life. To determine exactly how much mass has leaked out into HK regions, we could integrate the analytical solutions over these regions; however, half-life measurement is a close-enough approximation to this measure for the purposes of this study. We determined half lives for the two initial conditions as follows:

\section{1-D Diffusion Equation:}

$R \frac{\partial C}{\partial t}=D \frac{\partial^{2} C}{\partial x^{2}}$

Gaussian Initial Condition:

$C_{0}=C(x, 0)=e^{-a x 2}$

Solution,

$$
\begin{aligned}
& C(x, t)=\int_{-\infty}^{\infty} C_{0}(x) \delta\left(x-x^{\prime}, t\right) d x^{\prime} \\
& \delta\left(x-x^{\prime}, t\right)=\frac{1}{\sqrt{4 \pi D t}} \exp \left(\frac{-\left(x-x^{\prime}\right)}{4 D t}\right) \\
& \longrightarrow C(x, t)=\frac{1}{\sqrt{1+4 \pi D t \alpha}} \exp \left(\frac{-\left(\alpha x^{2}\right)}{1+4 \pi D t \alpha}\right) \\
& \longrightarrow C(0, t)=\frac{1}{\sqrt{1+4 \pi D t \alpha}}
\end{aligned}
$$

Step Function Initial Condition:

$$
\begin{aligned}
& \mathrm{C}=\mathrm{C}_{0},-\mathrm{a} \leq \mathrm{x} \leq \mathrm{a} \\
& \mathrm{C}=0, \text { elsewhere }
\end{aligned}
$$


Solution,

$$
\begin{aligned}
& C(x, t)=\frac{1}{2}\left[\operatorname{erfc}\left(\frac{x+a}{\sqrt{4 D t}}\right)-\operatorname{erfc}\left(\frac{x-a}{\sqrt{4 D t}}\right)\right] \\
& C(0, t)=\operatorname{erfc}\left(\frac{a}{\sqrt{4 D t}}\right)
\end{aligned}
$$

Setting VOC masses equal:

$$
\begin{aligned}
& 2 a=\int_{-\infty}^{\infty} e^{-\alpha x^{2}} d x=\sqrt{\frac{\pi}{\alpha}} \\
& \longrightarrow \alpha=\frac{\pi}{4 a^{2}}
\end{aligned}
$$

To examine the contaminant half-life at the center of the LK zones represented, we set:

$$
\mathrm{C}_{0}=1
$$

Solving for $t$ where $C=(1 / 2) C_{0}=(1 / 2)$ :

Gaussian:

$$
\begin{gathered}
.5=\frac{1}{\sqrt{1+4 \pi D t \alpha}} \\
\longrightarrow T_{1 / 2}=\frac{3}{4 \alpha D}
\end{gathered}
$$

Step Function:

$$
.5=\operatorname{erf}\left(\frac{a}{\sqrt{4 D t}}\right)=\frac{2}{\sqrt{\pi}} \int_{0}^{y} e-\xi_{2} d \xi
$$

where,

$$
y=\frac{a}{\sqrt{4 D t}}
$$

Considering the Taylor series expansion, 


$$
e^{-x^{2}}=1-x^{2}+\frac{x^{4}}{2 !}+\ldots
$$

we see,

$$
.5=\frac{2}{\sqrt{\pi}}\left(y-\frac{y^{3}}{3}+\ldots\right)
$$

Neglecting terms of order $x^{3}$ or greater after the integration,

$$
.5=\frac{a}{\sqrt{\pi D t}}=\frac{1}{\sqrt{4 D t \alpha}}
$$

or,

$$
\longrightarrow T_{1 / 2}=\frac{1}{\alpha D}
$$

$\therefore T_{1 / 2}($ Gaussian $)=\frac{3}{4} T_{1 / 2}($ step $)$

We see that the entire process of diffusion of sufficient contaminant away from the center of the plug so as to reduce that central concentration by a factor of two occurs at a greater rate for contaminant sources described by smooth boundaries than for those described by sharp boundaries. To interpret this result, we look closely at the evolution of the solution to the 1-D diffusion equation, and note that the edges of any sharply-defined initial contaminant distribution will certainly smooth in time (as diffusion serves to spread contaminants through the domain). Thus, a function like the Gaussian in appearance (which is actually the complementary error function "erfc") is a later step in the evolution of the step function initial contaminant distribution. To what, then, can we attribute the difference in the contaminant transport rates between step and Gaussian distributions? The answer lies in the relative rates of diffusion at different phases of the diffusion process (where the rate of diffusion is defined relative to contaminant half lives at the origin). Time-averaged mass transfer rates defined in this manner are clearly greatest for the initial condition representing smoothed geological interfaces.

It is important to remember that the above analysis was performed on the 1-D diffusion equation, while our model solves the 2-D advection-dispersion equation. As discussed above, the advection of ground water through HK regions shapes the transition zone contaminant distribution in accordance with sharp or smooth geological contacts, and carries contaminants in Hk zones downgradient at a rate dominant to that of the diffusion of contaminants out of LK zones. Thus, ground water advection and velocity-dependent dispersion results in relative truncation of the contaminant distribution at HK interfaces. The idealized analysis above neglects this truncation, and is therefore an approximation to, but not an exact solution for, the VOC transport problem that we model numerically. We use the results of this approximation to hypothesize that diffusive mass transfer rates will be greater across smoother geological boundaries. 


\subsubsection{Boundary Conditions of VOC Transport}

Because the ADE is a parabolic PDE (containing first derivatives with respect to time and first-and-second-order spatial derivatives), it is an initial-boundary value problem. Solution of this class of problem requires specification of conditions describing the variable being solved for on the edges of the solution space at all times (and over the entire solution space at $t=0$ ).

We define zero Neumann, or no flux, boundary conditions along the domain's top and bottom edges:

$(n \cdot \nabla C)=0$

where,

$n=$ unit vector normal to boundary.

These Neumann conditions imply that there is no outflow of contaminants through the outer edges of the HK zones. Neumann boundary conditions are also known as reflection boundary conditions. Because $(n \cdot \nabla C)=0$ on the boundary, the solution inside the domain is exactly the same as that which would result if the domain extended past the boundary in a perfect mirror image of itself. Therefore, solution of the ADE inside the three-layer domain is equivalent to that in a domain with any multiple number of similar layers. By employing the reflection boundary condition to represent complex but symmetric domains, we minimize the amount of computation our code must perform to solve the ADE.

We pose Zero Dirichlet, or zero concentration, conditions on the left and right edges of the domain:

$C=0$

We verified that contaminants in LK zones never reach the left or right boundaries of our domain, so LK VOC transport naturally satisfies the Zero Dirichlet conditions.

In HK zones, we interpret the Zero Dirichlet conditions as outflow boundary conditions such as those defined in the solution of hyperbolic PDEs. We justify this hyperbolic interpretation by noting the dominance of the first-order transport term, $-v \nabla C$, over the second-order term, $\nabla \cdot D \nabla C$, in HK zones. Thus, in HK zones the ADE, while strictly parabolic in form, is essentially a hyperbolic PDE for the purpose of our numerical solution methodology.

Concentration of zero on the left simulates the inflow of clean ground water to flush and remediate the source area. The right-most Dirichlet condition represents the complete capture of contaminated ground water by the pumping zone. In the case of our simulation case, the pumping zone represents TFA pump and treat extraction well w-415.

The VOC transport boundary conditions are shown in figure 10. 


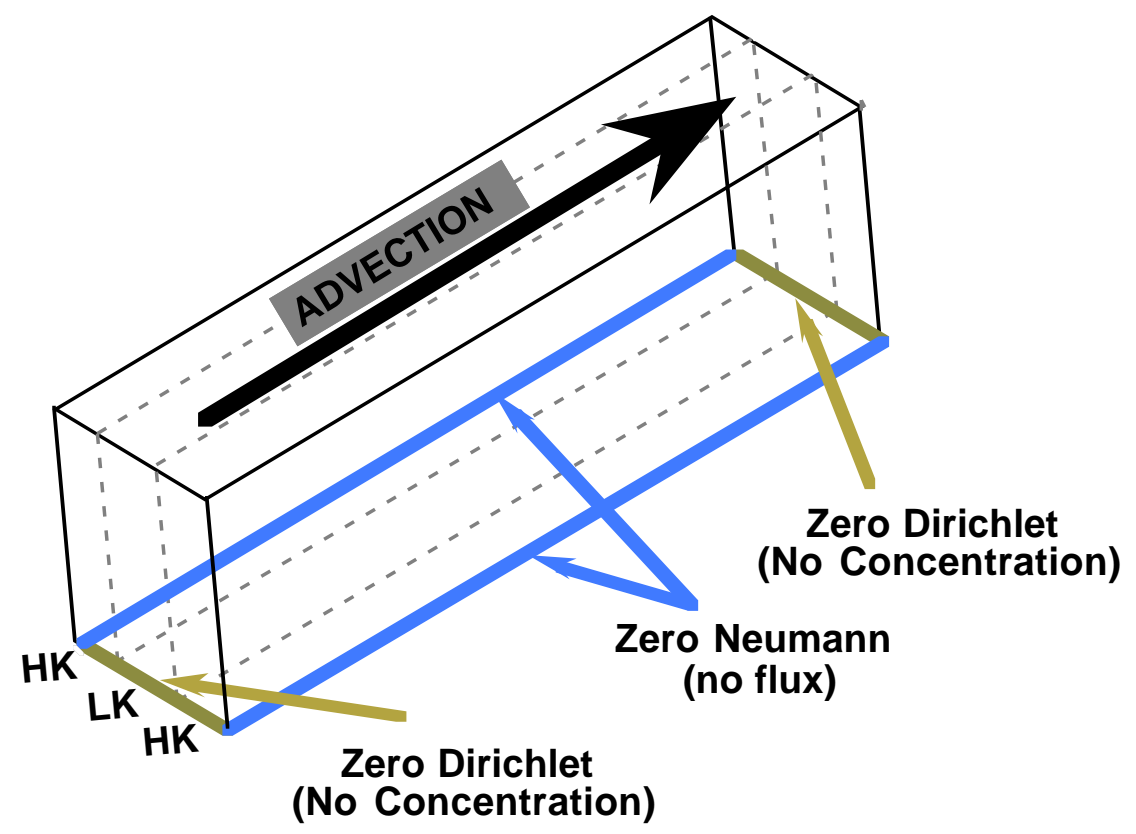

Figure 10. Zero Neumann boundary conditions on the top and bottom and zero Dirichlet conditions on the left and right sides of the domain.

\subsubsection{Initial Conditions}

In addition to well-posed boundary conditions, the solution of transient (time-dependent) parabolic PDEs requires definition of an initial condition. Our model's initial condition, shown in Figure 11, is a 50 meter wide plug of contaminant in the center of the domain. This plug has a concentration of 1000 parts per billion (ppb) and stretches through both LK and HK zones. Data from source area monitoring wells allowed confirms that these conditions simulate representative contaminant distribution near TFA.

\subsection{PRELIMINARY RESULTS AND EVALUATION OF THE TFA MODEL}

\subsubsection{TFA Model Results}

Clean ground water is allowed to flow through the model under a hydraulic head gradient of .05, similar to that near the largest pumping well in the TFA area. After three months of this flushing, contaminants in HK zones are being flushed toward the right boundary of the domain, while VOCs in relatively-stagnant LK regions are left behind (figure 12). 
Time = start

\section{Concentration Scale $=1000 \mathrm{ppb}$}

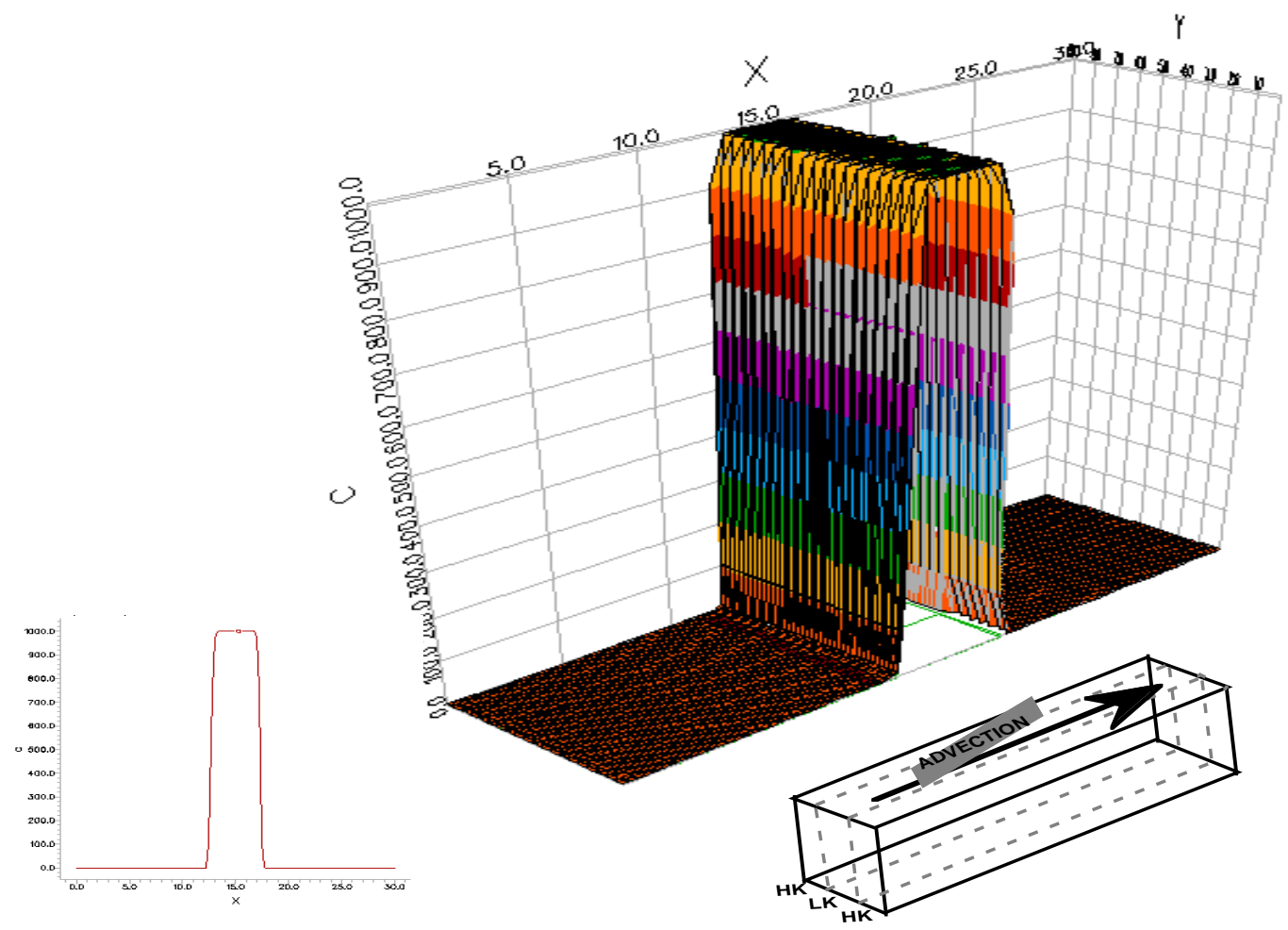

Figure 11. Initial condition of source-area model. The domain is sketched in the lower-right, indicating the direction of ground water flow. The plot in the lower-left is a fixed-scale concentration cross-section through the LK (central) zone.

\subsection{PRELIMINARY RESULTS AND EVALUATION OF THE TFA MODEL}

\subsubsection{TFA Model Results}

Clean ground water is allowed to flow through the model under a hydraulic head gradient of .05 , similar to that near the largest pumping well in the TFA area. After three months of this flushing, contaminants in HK zones are being flushed toward the right boundary of the domain, while VOCs in relatively-stagnant LK regions are left behind (figure 12). 


\section{Time $=3$ months}

\section{Concentration Scale $=1000 \mathrm{ppb}$}

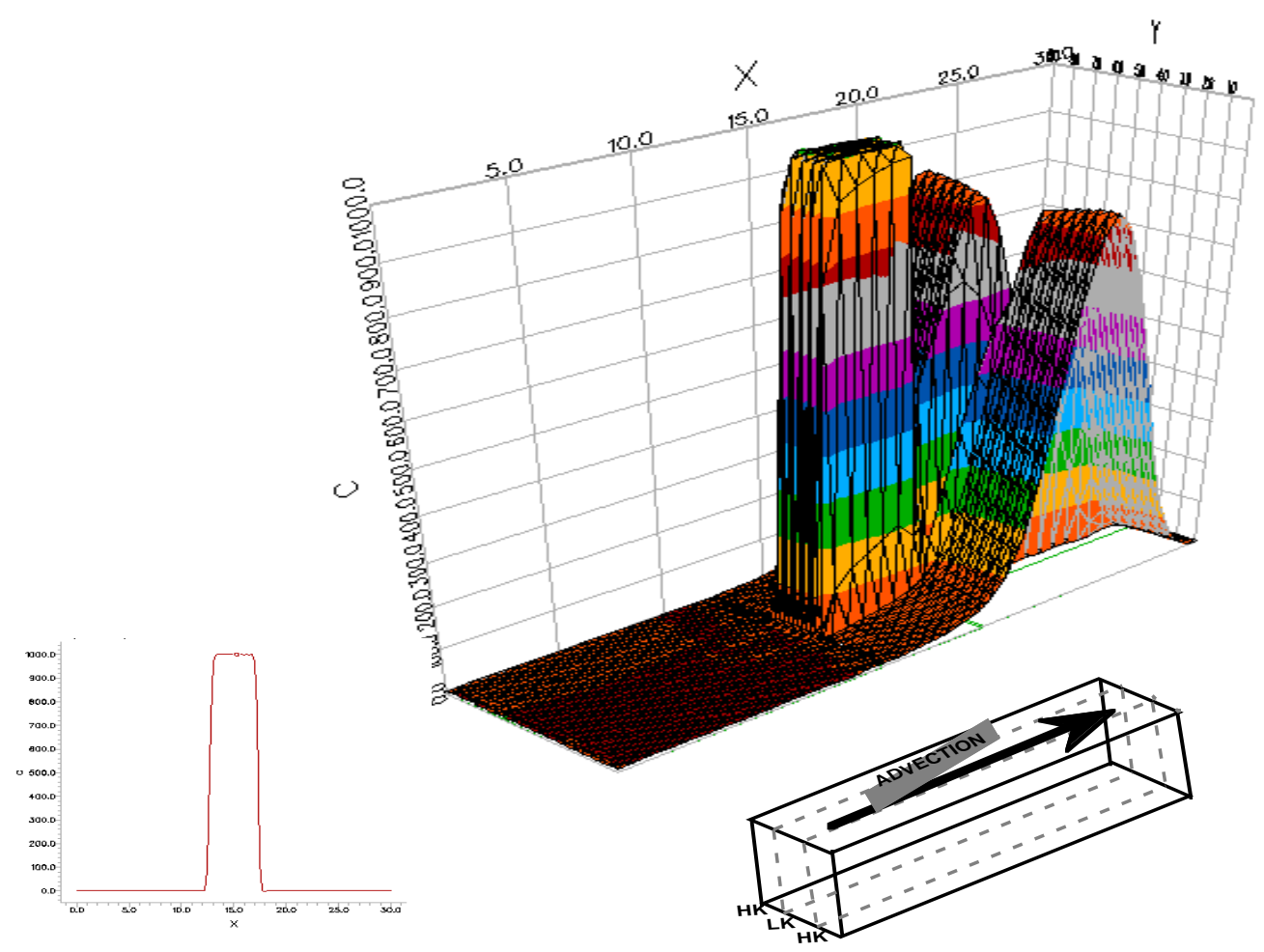

Figure 12. Source-area model after 3 months of pump-and-treat remediation.

After three years of pumping, the "wave" of contaminant advecting through the HK zones has been completely pumped out of the source area. However, LK VOCs remain at near-initial concentrations (figure 13).

After eighty years of this pump-and-treat remediation, concentrations in the LK zone finally approach maximum concentration levels (MCLs) of 5 parts per billion (ppb) (figure 14).

\subsubsection{Comparison of Conceptual and Computational Models, Analysis of Contaminant Concentration in HK Zones}

The preliminary results of the TFA model follow the patterns we expect according to the conceptual model outlined in the introduction. VOCs in HK zones are spread to the distal plume, while source areas retain LK contaminants. Over a long period of time, these VOCs diffuse through the transition zone into HK zones and are advected downgradient.

To determine whether LK zones serve as a significant contaminant source to these aquifers, we plotted the HK concentrations predicted by our model with a very smoothed $(\mathrm{nn}=20) \mathrm{HK} / \mathrm{LK}$ interface over 50 years of cleanup in Figure 15. The significant

concentrations present in the HK zones indicate that LK concentrations do serve as 


\section{Time $=3$ years \\ Concentration Scale $=950 \mathrm{ppb}$}

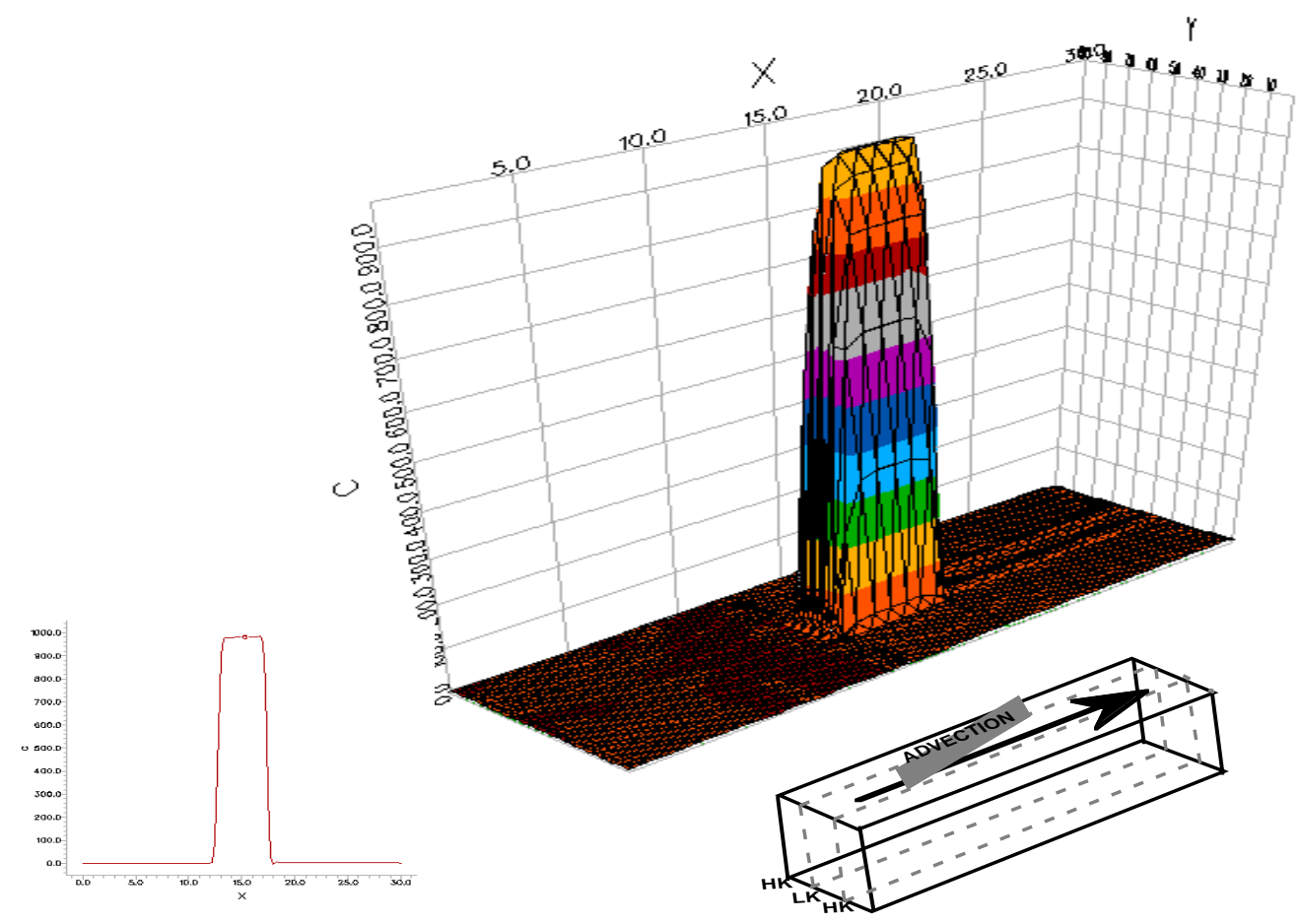

Figure 13. Source-area model after 3 years of pump-and-treat remediation.

significant sources to mobile ground water. This fact is of great importance in the design of remediation strategies.

\subsubsection{Comparison with Field Data}

In plotting HK concentrations during source-area remediation, we created a method for the validation of our model against field conditions. Since 1988, the LLNL Environmental Restoration Division (ERD) has been engaged in the pump-and-treat cleanup of the TFA area. The ERD has continually logged the concentration of the contaminated ground water being pumped out of the extraction well directly downgradient of the TFA source. VOCs in effluent extracted at this well represent average concentration in source-area $\mathrm{HK}$ zones. We plotted field data from TFA against our model's prediction with a very smooth $(\mathrm{nn}=20)$ transition zone in Figure 12. The convergence of the concentration trends predicted by the model to those actually observed in the field suggests that our model with smooth interfaces accurately simulates source-area conditions. As discussed above in section 5.3.3.3., diffusion, advection, and dispersion across and within the enlarged transition zone may compensate for the decreased interfacial surface area in our idealized model of geological boundaries. 


\section{Time $=\mathbf{8 0}$ years \\ Concentration Scale $=7 \mathrm{ppb}$}

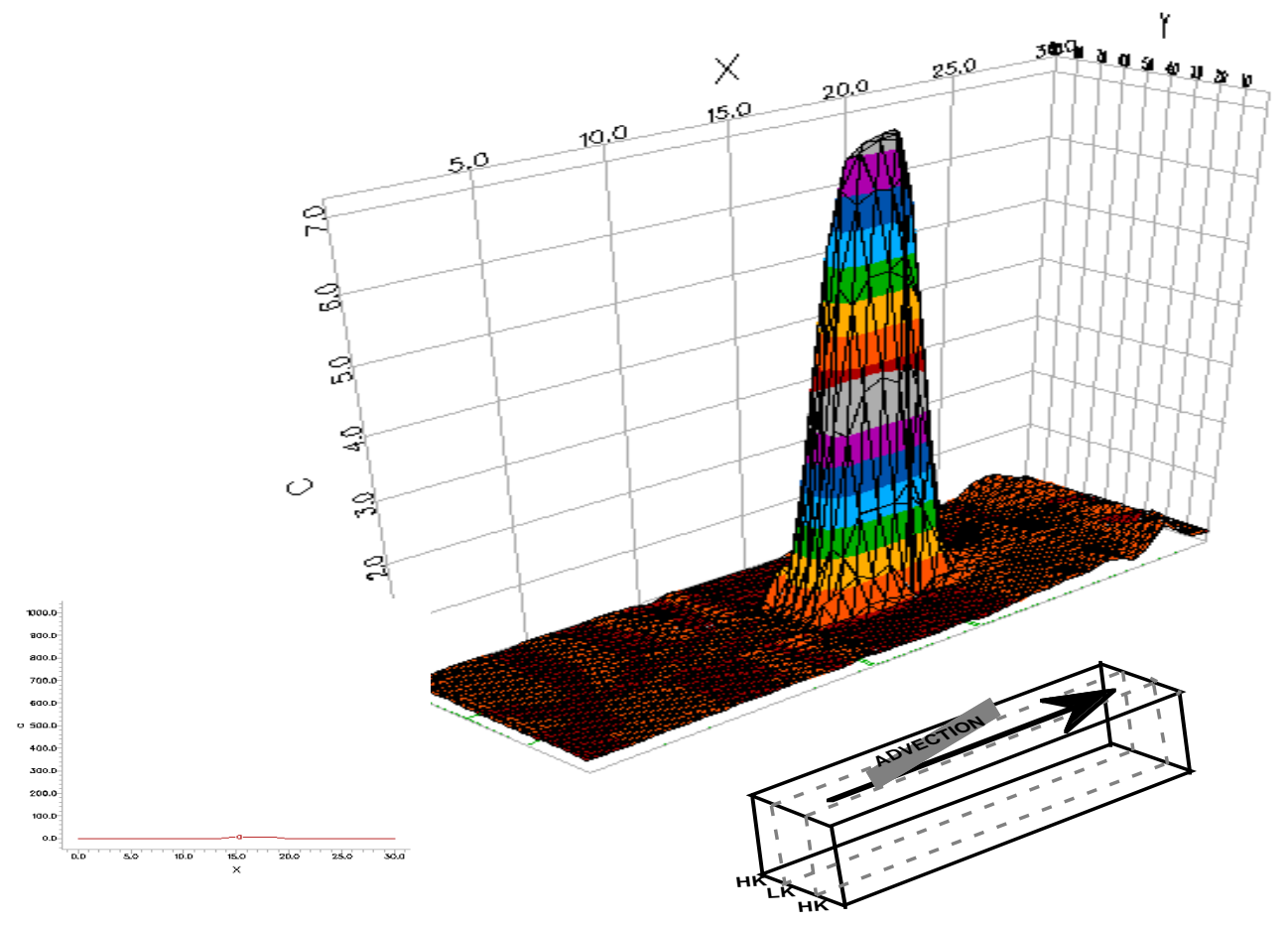

Figure 14. Source-area model after 80 years of pump-and-treat remediation.

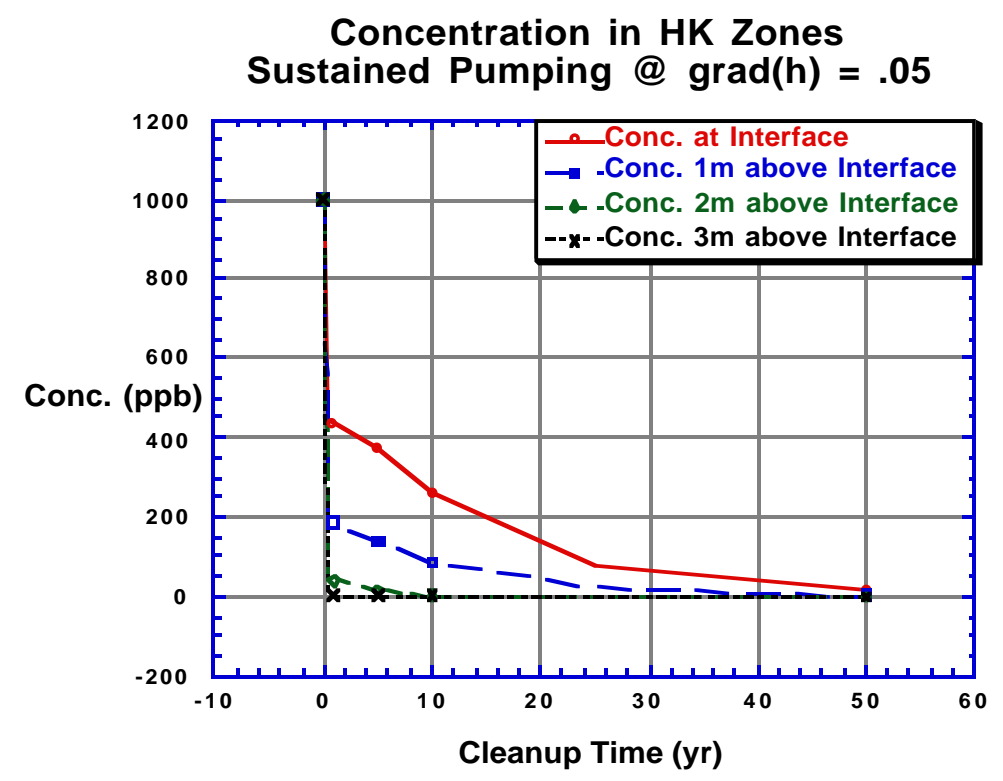

Figure 15. HK concentration at various distances from HK / LK interface. 
PDEase Idealized TFA Remediation Simulation

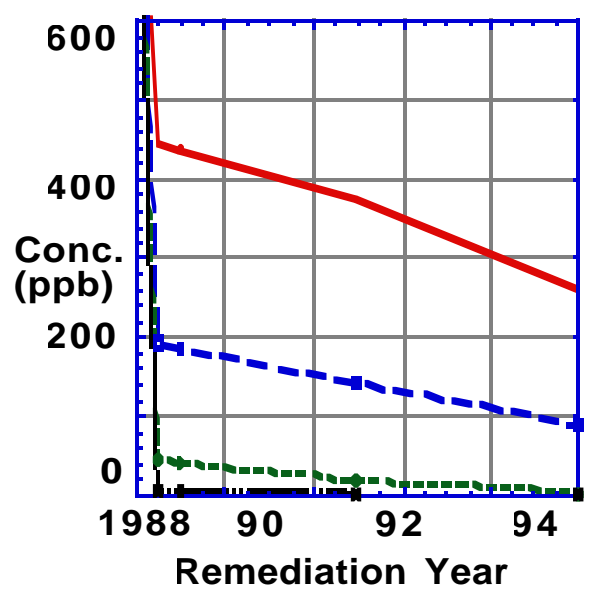

LLNL TFA Pump and Treat Remediation Data

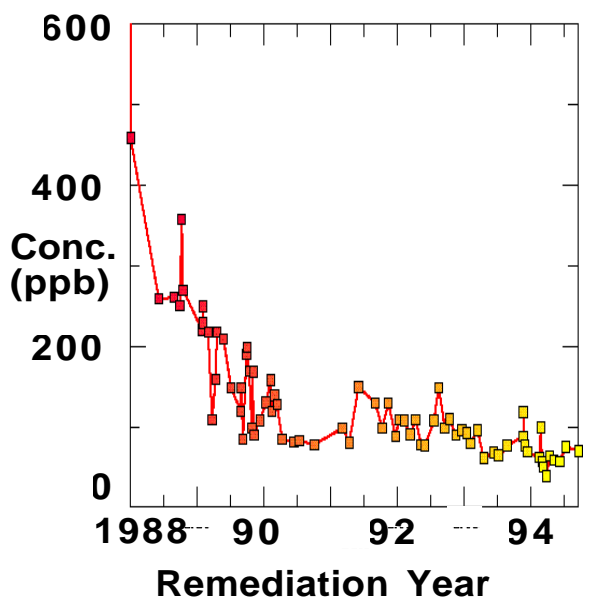

Fig. 16. Comparison of source-area field data and model predictions.

\subsection{SENSITIVITY ANALYSIS OF MODEL PARAMETERS}

\subsubsection{Motivation and background:}

Our ability to accurately represent the subsurface geology is limited by our uncertainty in what values parameters should take in precise regions of our domain and by the simplicity of our domain's layer-cake level of resolution. We do not attempt to simulate some macroscopic features that we suspect are present in the subsurface (i.e. cracks and fissures). Furthermore, the constitutive assumptions and resulting differential equations that our model analyzes represent an ideal system. We assume diffusive processes in ideal accordance with Fick's Law and advective processes quantified by an average ground water velocity determined by Darcy's Law. Our analysis of contaminant sorption and desorption on and off sediments, as well as diffusion into and out of immobile pockets of ground water, is quantified by the retardation coefficient R. Our analysis of VOC transport is then an average of complex processes over representative elemental volumes of macroscopic scale (Bear, 1972), so our simulation incorporates pore scale complexity only by averaging over the sum of microscopic processes. Within the framework of these limitations, the results of our simulation of VOC transport are governed by the parameters we assign to the subsurface to simulate the microscopic processes which are actually occurring.

Comparison of our model results with field data shows that our model of VOC transport is a plausible representation of actual transport processes. This suggests not only that application of the macroscopic model of microscopic transport processes is appropriate to the problem of VOC transport across geological boundaries, but that the HK / TZ / LK layercake domain geometry successfully simulates that found in the subsurface.

After the geometry of our representation of subsurface geology has been determined, we are faced with the task of representing the different subsurface media that we've included. 
Even with samples of a representative elemental volume (REV) (which are obviously only attainable at widely-spaced points in the subsurface) it is difficult to determine exactly which parameters to assign to our domain. The experimental and computational methods are an attempt to help define these parameters. To determine the sensitivity of our model to various uncertainties in different parameter values, and hence to help us to understand how accurately we are modeling subsurface processes, we performed analytical and numerical sensitivity analyses of our simulation.

\subsubsection{Analytic Sensitivity Analysis of Diffusion and Reduction of Parameter Space}

As discussed above, there exist no known analytical solutions to the ADE in our domain. However, we can learn some preliminary facts about the sensitivity of the model to the parameters governing diffusion by examining the 1-D diffusion equation in an idealized domain.

1-D diffusion equation:

$R \frac{\partial C}{\partial t}=D \frac{\partial^{2} C}{\partial x^{2}}$

Initial and boundary conditions:

$\mathrm{C}=\mathrm{C}_{0}$ at $\mathrm{x}=0$,

$\mathrm{C}=0$ elsewhere, $\forall t$

analytic solution, Cexact $=\frac{1}{2} \operatorname{Co} \cdot \operatorname{erfc}\left(\frac{x}{2 \sqrt{D t / R}}\right)$

In this case, then,

$C=f\left(x, t, C_{0}, D w, \Omega, R\right)$

And the parameters $\mathrm{Dw}, \Omega$, and R can be grouped as a single constant $\varepsilon$, such that equation 44 becomes,

$C_{\text {exact }}=\frac{1}{2} \operatorname{Coerfc}\left(\frac{x}{2 \sqrt{t}} \cdot \varepsilon^{-1}\right)$

where, 
$\varepsilon=\sqrt{\frac{D w \cdot \Omega}{R}}$

This reduces the parameter space, so that

$C=f(x, t, \varepsilon)$.

It is advantageous to group the variables in this way because model sensitivity depends upon the interplay and relative magnitude of all of the diffusion parameters. Here, it is simpler to examine sensitivity to $\varepsilon$ around various baseline values of $\varepsilon$.

In examining the sensitivity of this solution to the uncertainty in input parameters, we determine:

$$
\frac{\partial C}{\partial \varepsilon} \approx \frac{\Delta C}{\Delta \varepsilon}
$$

But as the erfc function is nonlinear in all of its dependent variables ( $\mathrm{x}, \mathrm{t}$, and $\varepsilon$ ), eq. 49 implies fixed $\mathrm{x}$ and $\mathrm{t}$. So, we determine:

$$
\left.\frac{\Delta C}{\Delta \varepsilon}\right|_{x, t}
$$
Table 1.

We examined all permutations of the set of spatial and temporal coordinates listed in

\begin{tabular}{|rrr|}
\hline$t$ (years) & $x(\mathrm{~m})$ \\
\hline 5 & 5 \\
\hline 10 & 10 \\
\hline 20 & 15 \\
\hline 50 & 50 \\
\hline 100 & 100 \\
\hline & 500 \\
\hline
\end{tabular}

Table 1. Spatial and temporal coordinates examined in the analytical sensitivity analysis of model parameters.

We examined $\left.\frac{\Delta \mathrm{C}}{\Delta \varepsilon}\right|_{\mathrm{x}, \mathrm{t}}$ over the range of $\varepsilon$ allowed by the range of possible parameter values shown in Table 2. 


\begin{tabular}{|lrrrr|}
\hline & Dw & \multicolumn{2}{c}{ Tau } & \multicolumn{2}{c|}{$\varepsilon$} \\
Maximum & $1.77 \mathrm{E}-05$ & 2.8 & 0.5 & 0.00178 \\
Minimum & $8.91 \mathrm{E}-06$ & 2 & 0.05 & 0.00047 \\
\hline
\end{tabular}

Table 2. Range of parameters and resulting values of $\varepsilon$.

Next, we plotted $C=\left.f(\varepsilon)\right|_{x, t}$ for each of the 30 possible spatial and temporal permutations.

We then located values of $\varepsilon$ which maximize $\left.\frac{\Delta \mathrm{C}}{\Delta \varepsilon}\right|_{\mathrm{x}, \mathrm{t}}$. Because of the shape of the erfc curve, these occur at inflection points in the first derivative of the analytical solution (in $\varepsilon$ ). We created and indexed for future reference a database of $\left.\frac{\Delta \mathrm{C}}{\Delta \varepsilon}\right|_{\mathrm{x}, \mathrm{t}}$ values.

The data we compiled in this study gives the sensitivity of a diffusion system with trivial boundary conditions to variations in the parameters governing diffusion. Because the solution that produced the data is analytical, sensitivity data is very easy to generate for any variation in the parameters in any spatial or temporal location in the domain. We used this data to provide a reference point for estimating diffusion-dominated processes in numerical ADE solutions in our multilayered complex domain. Further, the analytical sensitivity data is useful in extrapolating $\mathrm{ADE}$ sensitivities for a certain range and set of parameters to other ranges and sets.

\subsubsection{Sensitivity Analysis of Numerical Model of VOC Transport Across Geological Contacts}

To determine the sensitivity of our model to variation of parameters, we examined the full set of parameters that the FEM solution depends upon, and attempted to reduce the parameter space by employing our knowledge of contaminant transport processes and the solution of parabolic PDEs.

$\mathrm{C}(\mathrm{x}, \mathrm{y}, \mathrm{t})$ is a function of:

Pumping time (yrs)

(Duration of pump and treat remediation)

Hydraulic conductivity of HK zones $(\mathrm{cm} / \mathrm{s})$

Retardation Factor of HK zones (R_HK) (dimensionless)

Porosity of HK zones ( $\varphi_{-} \mathrm{HK}$ )

(dimensionless)
VOC molecular diffusion coefficient in water (Dw) $\left(\mathrm{cm}^{\wedge} 2 / \mathrm{s}\right)$

Hydraulic conductivity of LK zones $(\mathrm{cm} / \mathrm{s})$

Retardation Factor of LK zones (R_LK) (dimensionless)

Porosity of LK zones ( $\left.\varphi \_L K\right)$

(dimensionless) 
Tortuosity of HK zones $(\Omega \mathrm{HK})$

(dimensionless)

Transverse dispersivity $\left(\alpha_{\mathrm{T}}\right)(\mathrm{cm})$

Ambient gradient (dimensionless)

Initial VOC Concentration $\left(\mathrm{C}_{0}\right)(\mathrm{ppb})$
Tortuosity of LK zones ( $\Omega$ LK)

(dimensionless)

Longitudinal dispersivity $\left(\alpha_{L}\right)(\mathrm{cm})$

Pumping Gradient (dimensionless)

Thickness of transition zone $(\mathrm{cm})$

Clearly, we cannot group all of the parameters together in the parabolic ADE as we could in the 1-D diffusion equation. In the effort to reduce our parameter space, then, the first task is to identify those parameters which do not require sensitivity analysis. Examining the ADE, we see that solutions scale linearly with $\mathrm{C}_{\mathrm{O}}$, so solution sensitivity to $\mathrm{C}_{0}$ is trivial and requires no further analysis. It can be argued that a constant $\mathrm{R}$ has a similar scaling effect. However, in our model, R_h and R_l scale time differently in separate regions, and so it is important to gauge the effect of these parameters on our solution. In the framework of this simulation, adjustment of hydraulic gradient is equivalent to changing hydraulic conductivity (except potentially in the order of magnitude of realistic uncertainty, as hydraulic gradient is generally a relatively well-defined parameter).

Because advection alone dominates transport mechanisms in HK zones, it seems that the diffusion parameters $\mathrm{R}$ and $\Omega$ assigned to $\mathrm{HK}$ zones should have a negligible effect on $\mathrm{C}(\mathrm{x}, \mathrm{y}, \mathrm{t})$. Similarly, as diffusion is dominant in LK zones, LK porosity (a parameter which governs advective transport) should also be negligible. To confirm this assumption, we ran our model several times and found no noticeable change in model results using the range of values shown in table 3.

\begin{tabular}{|c|c|c|c|}
\hline R_HK & $\begin{array}{r}\text { original value } \\
1.23\end{array}$ & $\begin{array}{r}\text { low-end parameter } \\
1\end{array}$ & $\begin{array}{r}\text { high-end parameter } \\
2.5\end{array}$ \\
\hline$\Omega$ HK & 0.3 & 0.1 & 0.7 \\
\hline$\varphi \overline{\mathbf{L} K}$ & 0.36 & 0.3 & 0.39 \\
\hline
\end{tabular}

Table 3. Parameters with no noticeable effect on ADE solution over the given ranges.

We also fix longitudinal and transverse dispersion coefficients at the values of five and one percent, respectively, of the plume length we simulate. (Fetter, 1993) The dispersion coefficient is intended to simulate the effects of small-scale heterogeneities that are not specifically encoded into the domain. As our model already incorporates the HK / LK interface, a heterogeneity spanning the entire domain, we may consider lower dispersion values in future runs.

This leaves the following list of parameters that $\mathrm{C}(\mathrm{x}, \mathrm{y}, \mathrm{t})$ depends upon:

- Pumping time (yrs)

- Hydraulic conductivity of HK zones $(\mathrm{cm} / \mathrm{s})$

- $\quad$ Porosity of HK zones ( $\left.\varphi_{-} \mathrm{HK}\right)$ (dimensionless

- Thickness of transition zone $(\mathrm{cm})$
- VOC molecular diffusion coefficient in water $(\mathrm{Dw})\left(\mathrm{cm}^{\wedge} 2 / \mathrm{s}\right)$

- Hydraulic conductivity of LK zones $(\mathrm{cm} / \mathrm{s})$

- Retardation Factor of LK zones

(R_LK) (dimensionless) 
After identifying these as the parameters requiring sensitivity analysis, we designed a method for quantifying the model's response to their variation. The first step was to define a measure relative to which sensitivity was to be determined. There are many possibilities for such a diagnostic in our complex spatial and temporal domain. The evolutionary nature of our simulation requires an examination of sensitivity at all stages of cleanup: therefore we needed a spatial restriction on a region in which to examine concentration throughout the simulation. Because the definition of any particular region in the domain could favor the effects of some transport processes over others, we chose to examine the following representation of average concentration of ground water fluxing across the model's exit boundary condition:

$$
\frac{\int_{\text {boundary }}\left(\left(C \cdot V_{x} \cdot \varphi\right)-\left(D * \cdot \frac{\partial C}{\partial x}+D_{11} \cdot \frac{\partial C}{\partial x}+D_{12} \partial y \frac{\partial C}{\partial y}\right)\right) \partial y}{\int_{\text {boundary }} v \partial y}=C(\dot{M})
$$

where,

$\mathrm{C}(\dot{\mathrm{M}})=$ avg. concentration of mass flux across exit boundary condition.

We repeated the simulation many times, changing varying individual parameters from the predetermined "original," or most-likely) parameter value(as determined by an extensive literature review). To allow for comparison of parameter sensitivities, we varied parameters uniformly from their original values by \pm 20 percent (Table 4 ). This degree of variation is favorable because it provides for a significant change in parameter values while restricting the range of parameters we test to within the range of actual uncertainty for each parameter.

The variation can be represented as,

$$
\frac{\Delta \Phi_{i}}{\Phi_{i}}=0.2
$$

where,

$\Phi_{\mathrm{i}}=$ individual parameter

$\mathrm{i}=$ parameter index 


\begin{tabular}{|l|r|r|r|}
\hline & original value & high-end value & low-end value \\
\hline Pumping Time (yrs) & 10 & 12 & 8 \\
Dw (cm^2/S) & 0.00000962 & 0.000011063 & 0.000007696 \\
\hline TZ thickness (cm) & 40 & 48 & 32 \\
\hline K_LK (cm/s) & 0.000001 & 0.00000115 & 0.0000008 \\
\hline$\varphi$ _HK & 0.32 & 0.432 & 0.256 \\
\hline R_LK & 2.03 & 2.236 & 1.824 \\
\hline$\Omega$ LK & 0.1 & 0.12 & 0.08 \\
\hline
\end{tabular}

Table 4. Variation of parameters for numerical sensitivity analysis.

The results of simulations with individual parameters adjusted to their high-and low-end values are compared with original values, and a measure sensitivity $S$ (as a function of time) is assigned to positive or negative variations of parameters from their original values. This approach is similar to that suggested by Dickenson and Gelinas for analysis of ordinary differential equation systems (Dickenson and Gelinas, 1975)

$\mathrm{S}(\mathrm{t})=\frac{\Delta \mathrm{C}}{\mathrm{C}}$

where,

$\Delta C=C\left(\Phi_{i}\right)-C\left(\Phi_{i} \pm \Delta \Phi_{i}\right)$

and then

$$
\frac{S(t) * 100 \%}{20 \%}=s(t)
$$

where,

$\mathrm{s}(\mathrm{t})=$ percent change in $\mathrm{C}(\dot{M})$ per percent change in value of $\Phi_{i}$, averaged over $20 \%$ variation in $\Phi_{i}$

\subsubsection{Results of Numerical Sensitivity Analysis}

We completed repeated runs of our model with different parameters and compiled values of $\mathrm{C}(\mathrm{M})$ as a function of time for several of the parameter ranges listed in Table 1 . In order to compare the sensitivity of model results to the change in individual parameters, we calculated time averages of $s(t)$ for the increase and decrease of each parameter. Because we are investigating the capacity of source area LK zones to serve as contaminant reservoirs, we average over the period beginning a decade after the conclusion of simulated pump and treat 
cleanup. Figure 14 displays time-averages of $\mathrm{s}(\mathrm{t})$ over the last 80 years of a 100 year simulation of VOC transport. Parameter sensitivities are ranked in order from left to right.

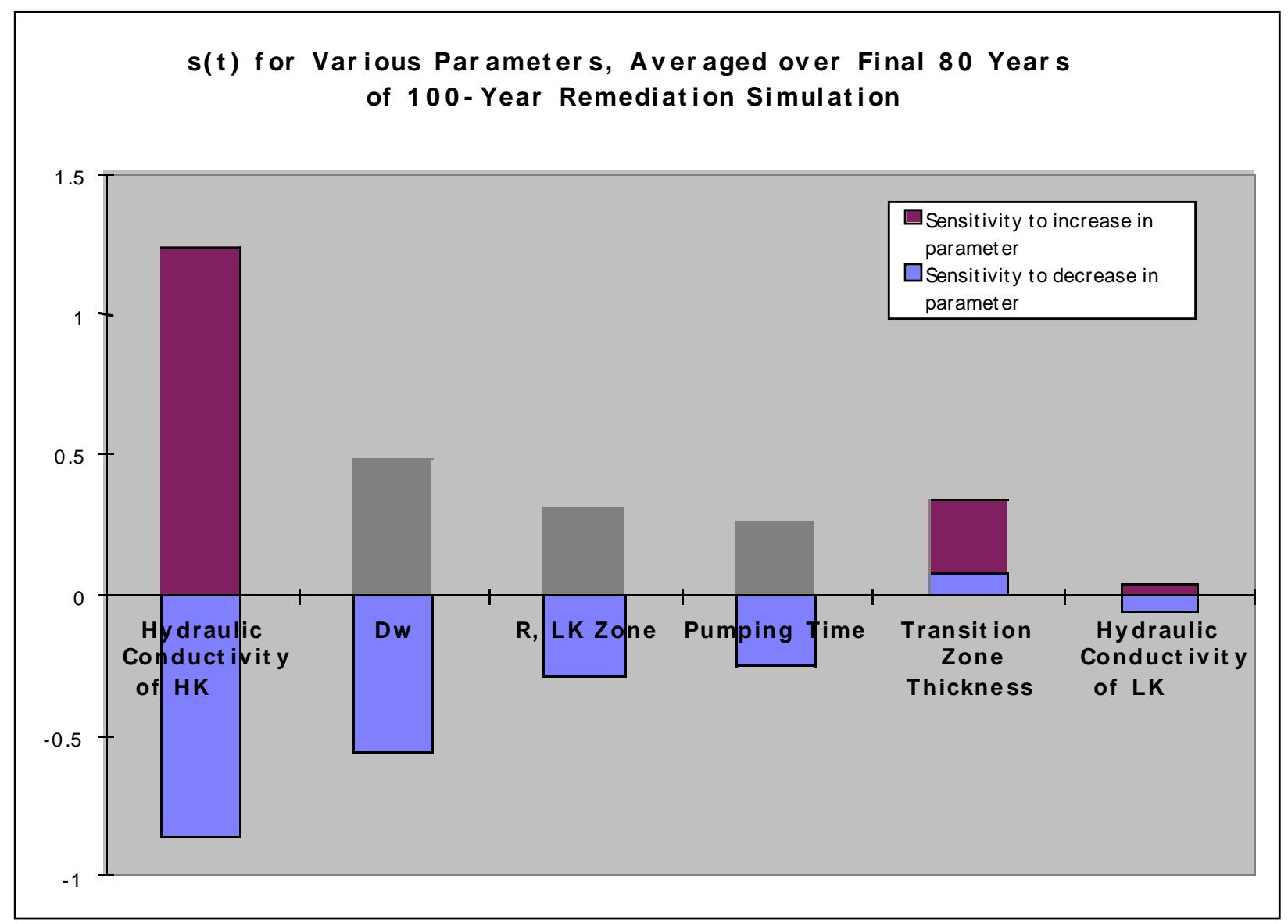

Figure 17. Sensitivity of various parameters, plotted as percent change in ADE solution variable (concentration) per percent change in parameter.

As we expect intuitively, changes in the hydraulic conductivity of the HK zone dramatically affect values $\mathrm{C}(\dot{\mathrm{M}})$. As $\mathrm{HK}$ hydraulic conductivity values are increased, hydraulic conductivities in the layers of the transition zone bordering HK zones also increase, in accordance with eq. (19). This extends the effect of ground water advection and (velocitydependent) dispersion transport processes further into the transition zone. Thus, higher downgradient values of $\mathrm{C}(\mathrm{M})$ result from the increased mass of VOCs removed from the source area LK transition zones. $\mathrm{C}(\dot{\mathrm{M}})$ values for the range of $\mathrm{HK}$ zone hydraulic conductivities we studied are plotted as a function of time in Figure 18. 


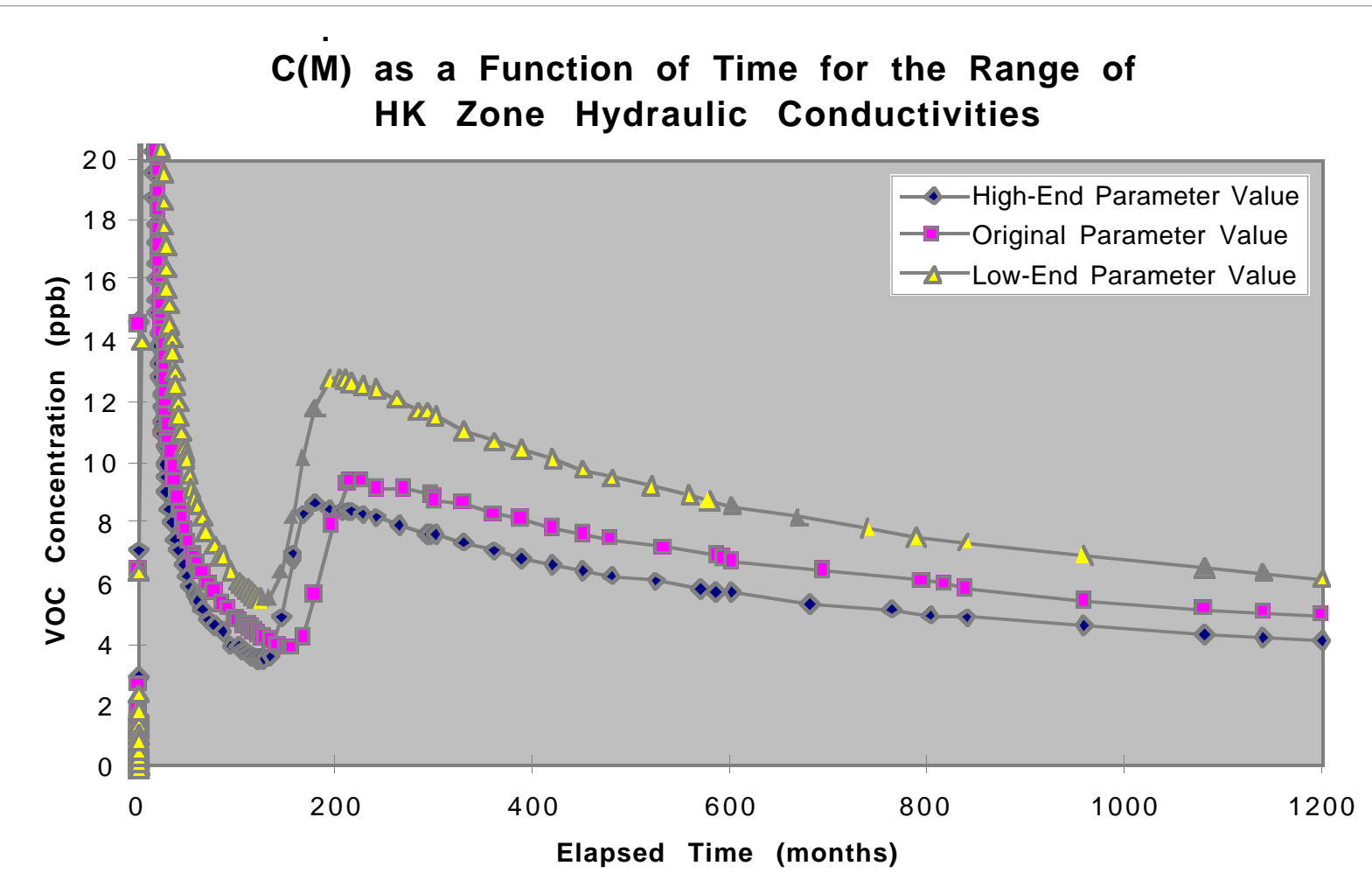

Figure 18. $\mathrm{C}(\dot{\mathrm{M}})$ for various HK zone hydraulic conductivities, plotted as a function of time over a 100 year simulation of VOC transport. Note that the maximum value of the $y$-axis is $20 \mathrm{ppb}$ to allow examination of VOC transport after HK zones have been flushed clean $(\mathrm{C}(\dot{\mathrm{M}})$ values approach $1200 \mathrm{ppb}$ in the initial stages of remediation).

The sensitivity of $\mathrm{C}(\dot{\mathrm{M}})$ to changes in Dw, the VOC molecular diffusion coefficient in water, also follows intuitive expectations. Figure 19 shows that as Dw is increased, more contaminant mass diffuses across geological contacts from LK to HK zones. This diffused contaminant is then advected downgradient, resulting in higher values of $\mathrm{C}(\dot{\mathrm{M}})$.

The response of $\mathrm{C}(\dot{M})$, which increases with higher values of $\mathrm{R} \_L K$, is more difficult to interpret. Initially, as in our analysis of hydraulic conductivity, it is important to note that changing the value of R_LK changes the distribution of R throughout the transition zone. The relationship between the way that $\mathrm{R}$ affects the time scale of diffusive, advective, dispersive transport processes determines the effect of changing this parameter on $\mathrm{C}(\dot{\mathrm{M}})$. As R is smoothed throughout the transition zone, this balance is affected not only by local values of $R$ but by the properties of the entire distribution. We note that ground water velocity (as opposed to VOC advection velocity) is itself independent of R, (see eq. 1) and therefore the averaging process that defines $C(M)$ is unaffected by variation in $R$. 


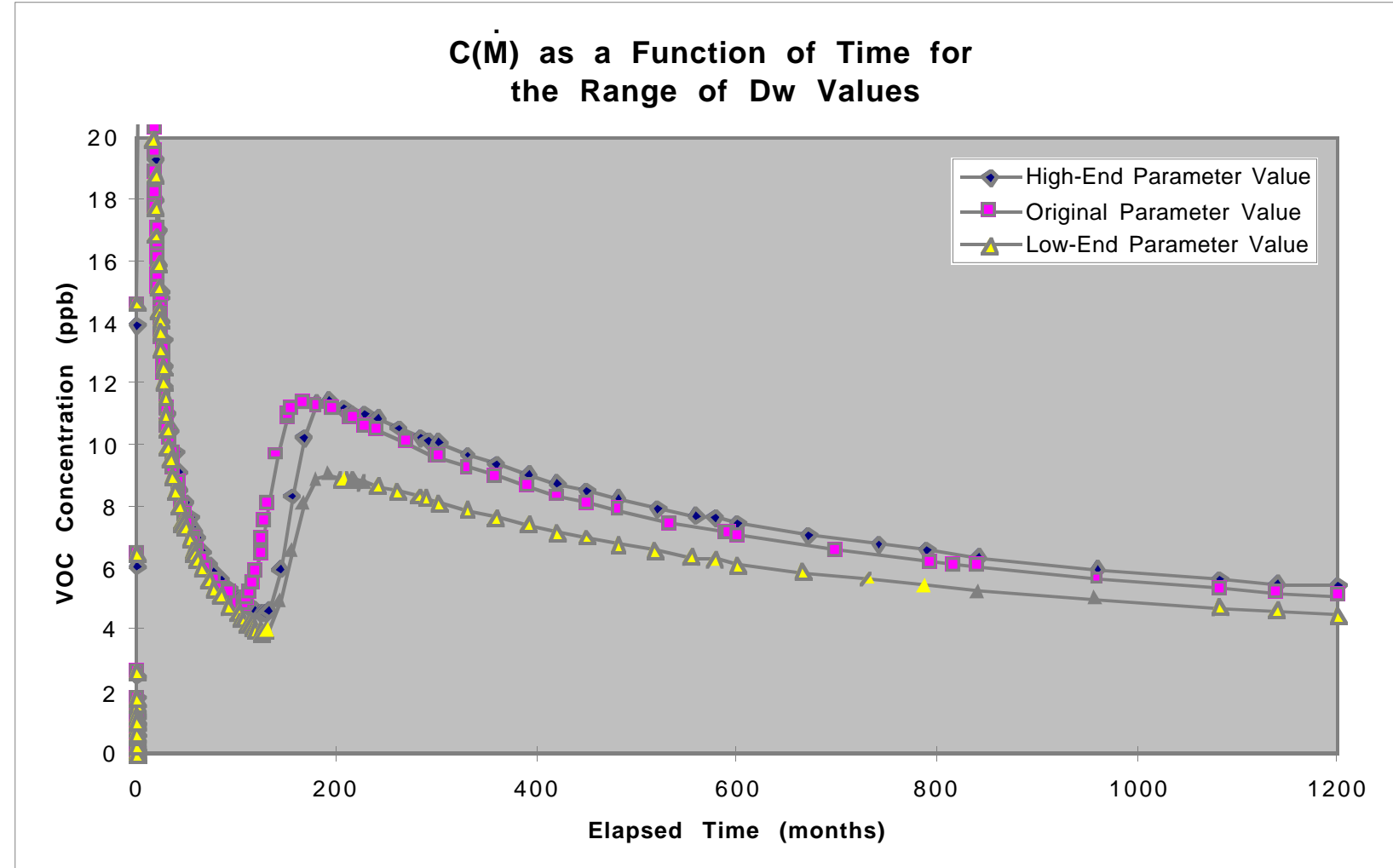

Figure 19. $\mathrm{C}(\dot{\mathrm{M}})$ for various Dw zone hydraulic conductivities, plotted as a function of time over a 100 year simulation of VOC transport.

A higher value of $\mathrm{R}$ at the LK interface of the transition zone will cause the process of contaminant diffusion toward HK zones to occur at a slower rate. However, advective velocities in the transition zone are also slowed by the higher value of $\mathrm{R}$, allowing more contaminant to diffuse into a unit volume of the transition zone before contaminants in that volume are advected downgradient. Furthermore, mechanical dispersive processes are also slowed, again contributing to the development of greater local concentrations in moving ground water. In the case of the variation of $\mathrm{R}$ discussed above, then, the augmenting effect on VOC concentration due to a slowing of dispersive and advective rates overwhelms the diminutive effects of slower molecular diffusion rates across the geological contact. The increase in $\mathrm{C}(\dot{\mathrm{M}})$ with increase in R_LK values is shown in figure 20 .

Similarly, our analysis of the sensitivity of $\mathrm{C}(\dot{\mathrm{M}})$ to variation of the transition zone thickness is concerned with the variation in spatial distribution of parameters. Indeed, changing the transition zone thickness effects the distribution of all of the parameters that define soil type in our model (hydraulic conductivity, tortuosity, retardation, and porosity). To interpret the sensitivity to transition zone thickness, then, we must determine how the distributions of all of these parameters combine to effect change in $\mathrm{C}(\dot{\mathrm{M}})$. 


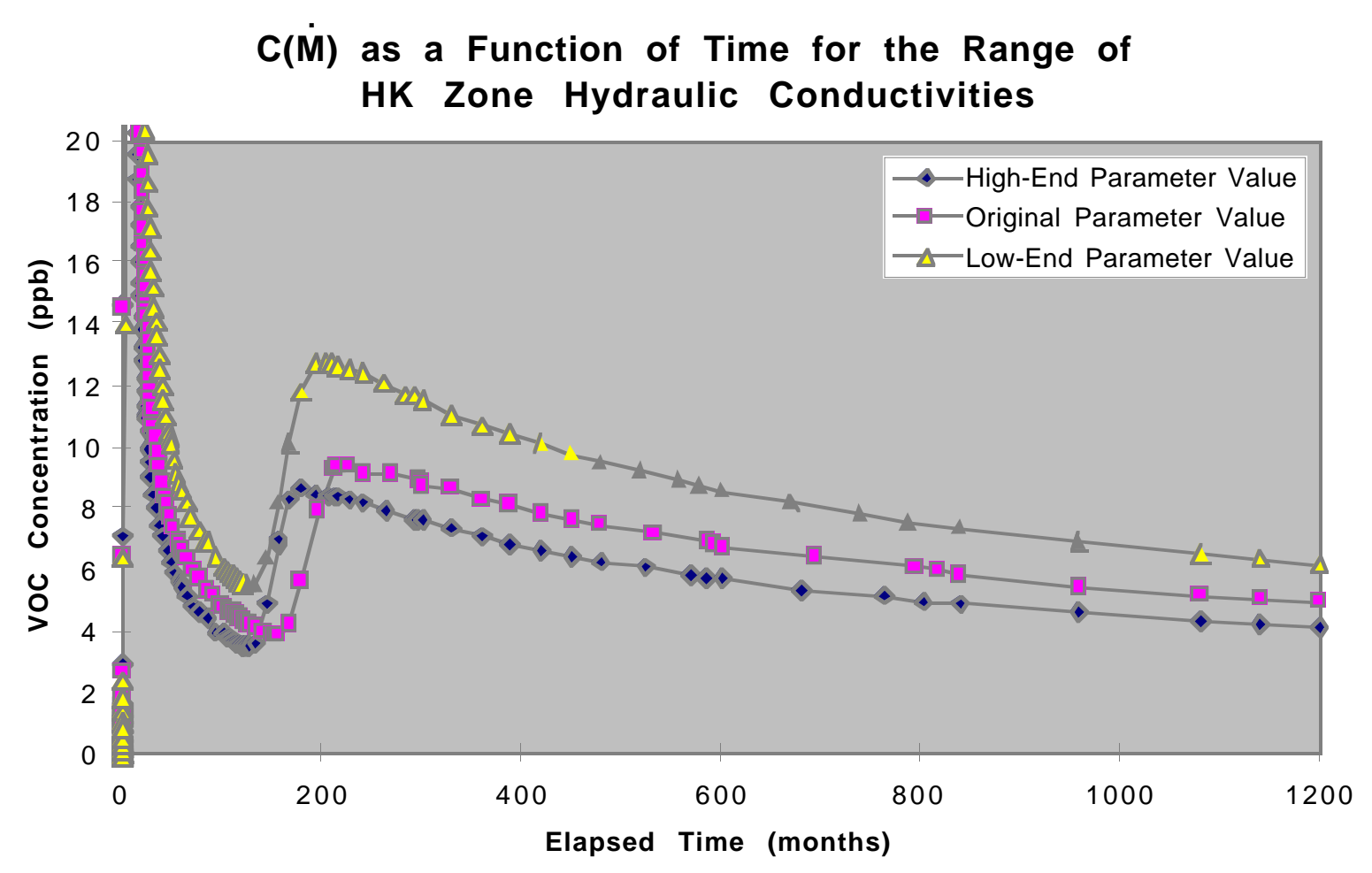

Figure 20. C ( $\dot{M})$ for various values of LK zone VOC retardation, plotted as a function of time over a 100 year simulation of VOC transport.

Because changing the transition zone thickness in either direction results in an increase in $\mathrm{s}(\mathrm{t})$, we say that the original value of transition zone thickness is a local minimum in the net space of parameter distribution. Although variation of the conductivity distribution alone (to which $\mathrm{C}(\dot{\mathrm{M}})$ is clearly highly-sensitive from figure 17) could theoretically result in such a minimum, the minimum is more likely to result from the summed variation in distribution of all of the parameters. This is because increasing the gradation of some of these parameters tends to increase $C(\dot{M})$ values while decreasing the gradation of others tends to decrease $C(\dot{M})$. Thus, we deduce that the variation in the distribution of several of the parameters that define soil type has a significant effect on $\mathrm{C}(\dot{\mathrm{M}})$. Furthermore, because of the complexity of this interplay we see that it is difficult to predict what the effect of varying transition zone thickness through other ranges will be. $\mathrm{C}(\dot{\mathrm{M}})$ sensitivities to transition zone thickness are plotted in figure 21 .

The response of $\mathrm{C}(\dot{\mathrm{M}})$ to variation in pumping time is important in the design of pump and treat remediation strategies. When we return to ambient hydraulic gradients, simulating the conclusion of pump and treat cleanup procedures, contaminant concentrations generally increase as the relative significance of diluting velocity-dependent advective and dispersive processes in HK zones decreases. 


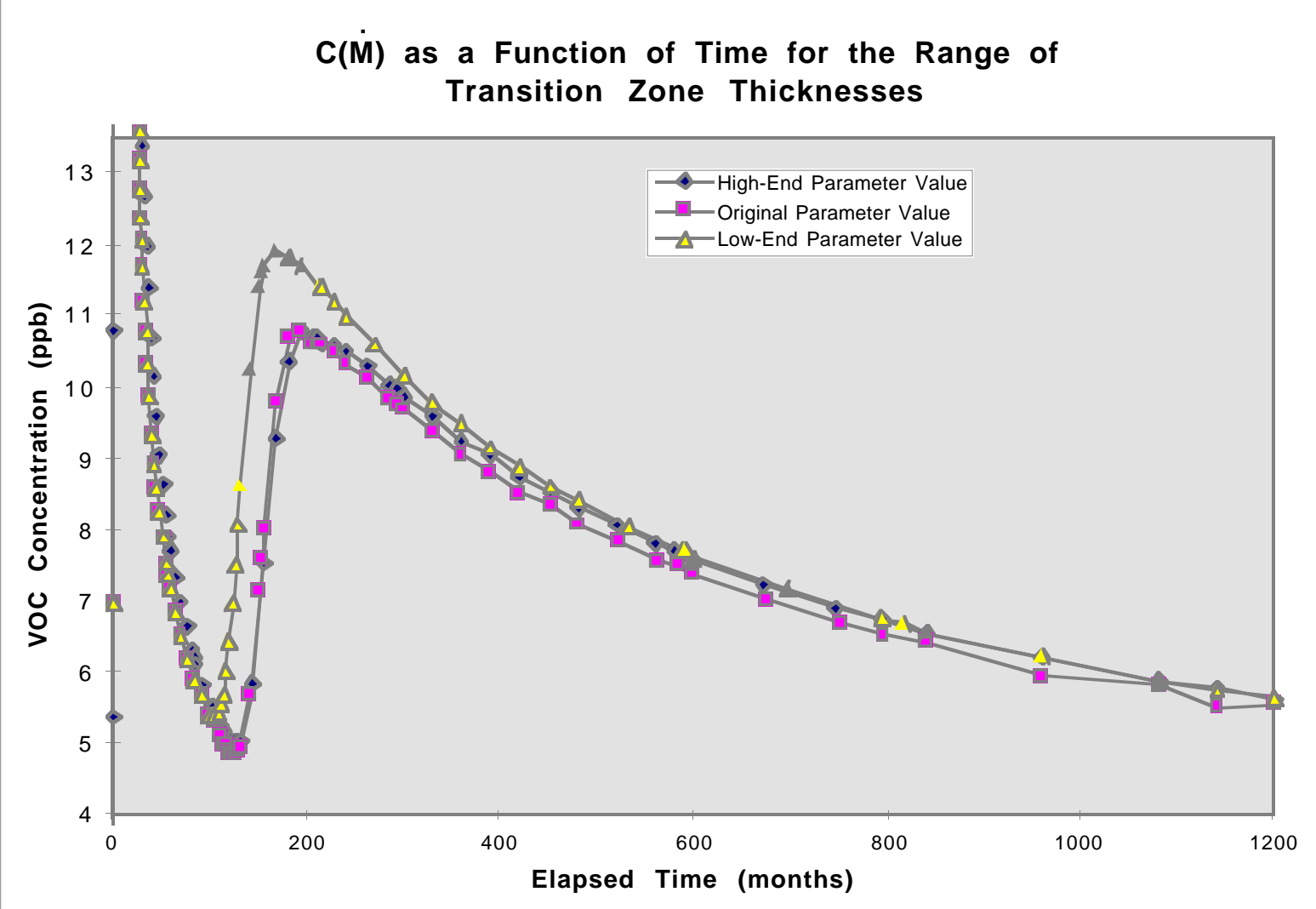

Figure 21. $\mathrm{C}(\dot{\mathrm{M}})$ for various values of transition zone thickness, plotted as a function of time over a 100 year simulation of VOC transport.

The goal of pump and treat remediation (to effect long-term cleanup of the source area) requires continuation of cleanup until this concentration rebound will not cause $C(\dot{M})$ values to exceed the MCL. Through adjustment of the time we leave pumps in our simulation running, we attempt to determine the $\mathrm{C}(\dot{\mathrm{M}})$ level (necessarily below the MCL) at which pumps can be turned off and these cleanup objectives still met. As expected, our sensitivity analysis shows that longer periods of simulated remediation result in lower peaks of concentration rebound lower values of $\mathrm{C}(\dot{\mathrm{M}})$ over the time course of the simulation. The sensitivity of $\mathrm{C}(\dot{\mathrm{M}})$ to changes in pumping time is shown in figure 22. 


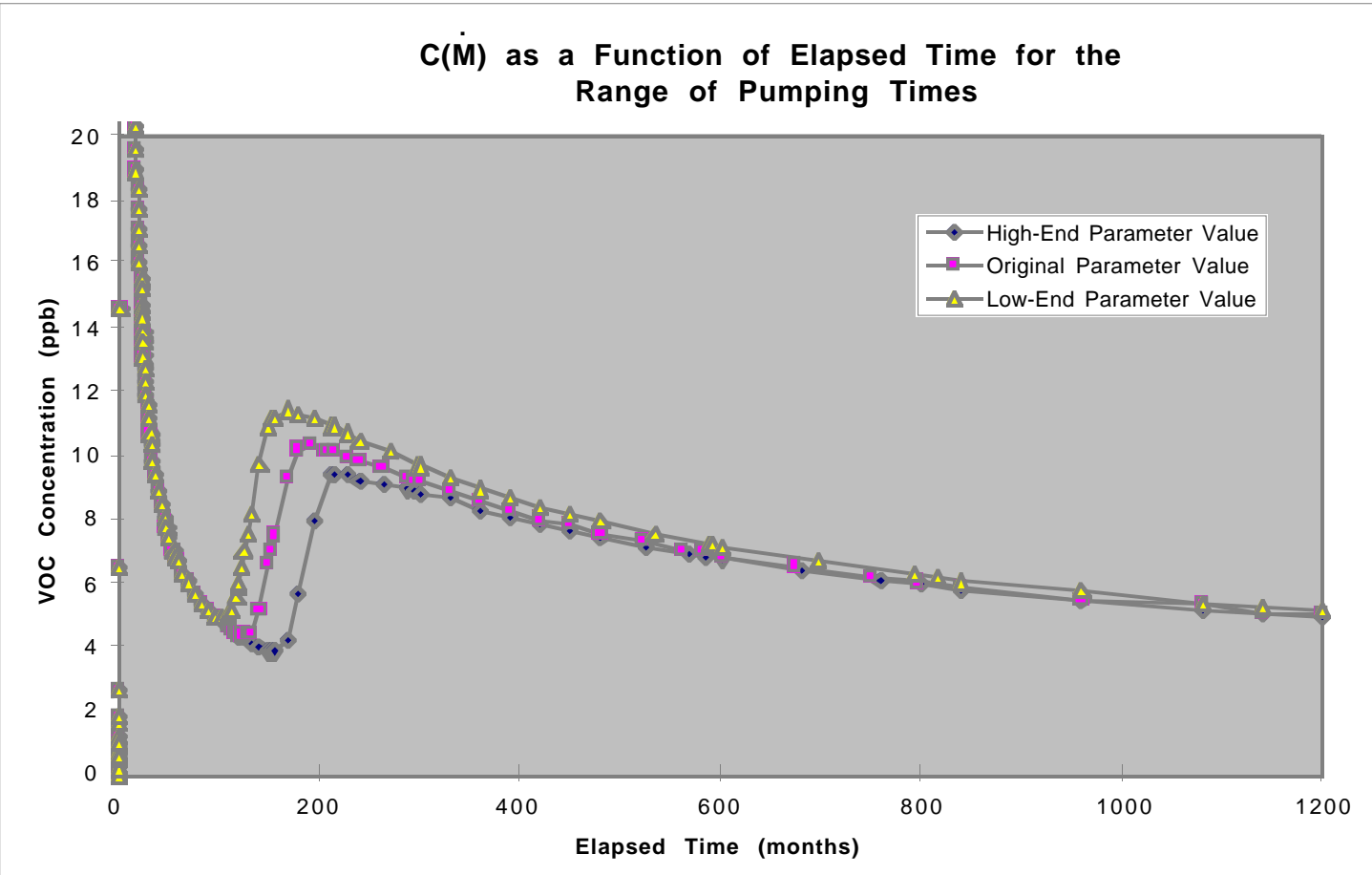

Figure 22. $\mathrm{C}(\dot{\mathrm{M}})$ for various values of pumping times, plotted as a function of time over a 100 year simulation of VOC transport.

\subsection{CONCLUSIONS}

- Adaptive-grid Finite Element Analysis is capable of accurately resolving the transport of VOCs in ground water across fine and coarse grained geological contacts.

- We verified that our algorithm solves the 1-D diffusion equation in precise accordance with the analytic 1-D diffusion solution.

- Representation of the facies change between LK and HK zones using an analytic smoothing function allows us to model transition zones of variable gradient.

- An analytical examination of the effects of interfacial smoothing suggested that diffusion may occur at a greater rate across smoother geological contacts.

- Consideration of the scale of transport processes and of the order of dominant terms of the ADE in the HK and LK zones allowed us to define effective domain geometry and boundary conditions.

- The preliminary results of our model of VOC transport at the TFA source area demonstrate the rapid remediation of $\mathrm{HK}$ zones and the slow process of diffusion of contaminants out of LK zones and into neighboring HK zones. 
- Preliminary results of the TFA model match conceptual expectations and roughly approximate field data.

- An analytic sensitivity analysis of diffusion allowed us to reduce the effective parameter space of our model.

- Sensitivity analysis of some of the parameters in the reduced parameter space indicated that the $\mathrm{C}(\dot{\mathrm{M}})$ is the most-sensitive to variation in the hydraulic conductivity of the HK zone and least-sensitive to changes in the hydraulic conductivity of the LK zone.

- The response of $\mathrm{C}(\dot{\mathrm{M}})$ to the distribution of parameters across the transition zone is difficult to predict and is hence best studied numerically.

- At the modeled time of cessation of simulated pump and treat remediation processes, downgradient VOC concentrations that have reached below the MCL rebound to above the MCL.

\subsection{Areas of Continuing Research}

- Incorporation of further geometric and geological complexity into our domain, including:

1. localized, small-scale heterogeneity within HSUs

2. lenses and channels within HSUs, connected in the third dimension (normal to the vertical cross-section)

3. leakage and communication between aquifers

- Examination of the effect of various scales and classes of interfacial geometrical complexity on VOC transport across geological contacts

- Incorporation of additional parameters (i.e. bulk density and the quantification of immobile pockets of ground water) into our analysis of VOC retardation

- Consideration of additional contaminant sources, including:

1. grain-sized LK lenses

2. grain-sized pools of VOC in the dense non aqueous phase liquid (DNAPL) state

3. leaching of contaminants into the saturated zone from the vadose zone

- Estimation of time to remediate source areas under various cleanup strategies 


\subsection{ACKNOWLEDGMENTS}

UC-Berkeley Professor T.N. Narasimhan added important insights to the development of this research. Professor E. F. Brown of Virginia Polytechnic Institute and State University helped guide the production of this paper. The work benefited from frequent discussions with $\mathrm{Z}$. Demir and P.F. McKereghan. 


\subsection{REFERENCES}

Bear, Jacob. (1972) Dynamics of Fluids in Porous Media. Dover Publications, Inc., New York, 15-22.

Cherry, John A., and Freeze, R. Allan. (1979) Groundwater. Prentice-Hall, Inc., New York, 549-552.

Dickenson, R. and Gelinas, R. (1975) "Sensitivity Analysis of Ordinary Differential Equation Systems--A Direct Method." Journal of Computational Physics., Vol. 21, No. 2, June 1976. Academic Press, Inc., New York.

Diersch, H. G. (1996) Feflow User's Manual V. 4.5, WASY Institute Ltd., Berlin.

Macsyma, Inc. (1995) PDEase Manual and Installation Guide. SPDE, Inc., Bass Lake, CA.

Fetter, C. W. (1993) Contaminant Hydrology. Prentice-Hall, Inc., New York, 70-73.

Fetter, C. W. (1994) Applied Hydrogeology. Prentice-Hall, Inc., New York, 143.

Gupta, S.K, et al . (1987) "Coupled Fluid, Energy, and Solute Transport (CFEST) Model: Formulation and User's Manual." Report BMI/ONWI-660. Office of Nuclear Waste Isolation, Battelle Memorial Institute, Columbus, $\mathrm{OH}$.

Hoffman, Fredric, et al. (1997) "A Conceptual Model and Remediation Strategy for VOCs in Low Organic Carbon Unconsolidated Sediments." Submitted to Ground Water Monitoring and Remediation, June 1997. Preprint UCRL-JC- 125199 Rev 1., Lawrence Livermore National Laboratory, Livermore, CA.

National Resource Council. (1994) Alternatives for Ground Water Cleanup. National Academy Press, Washington, D. C. 


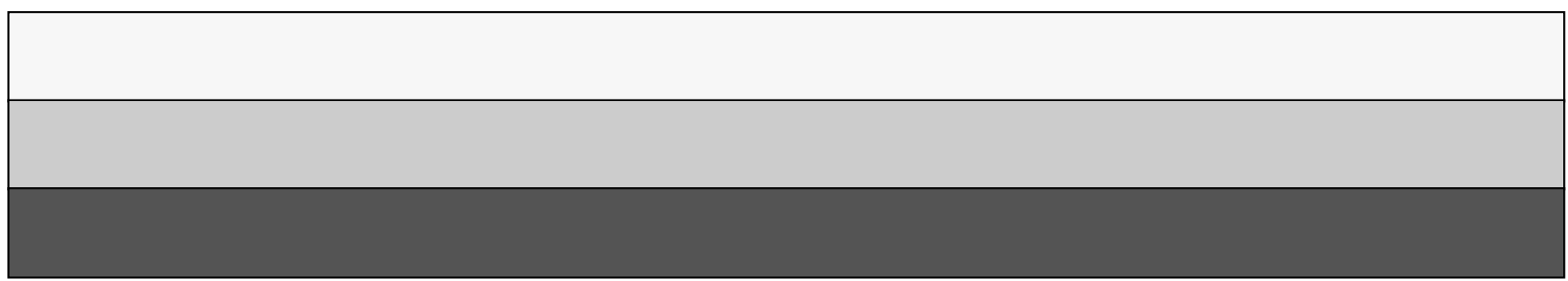

